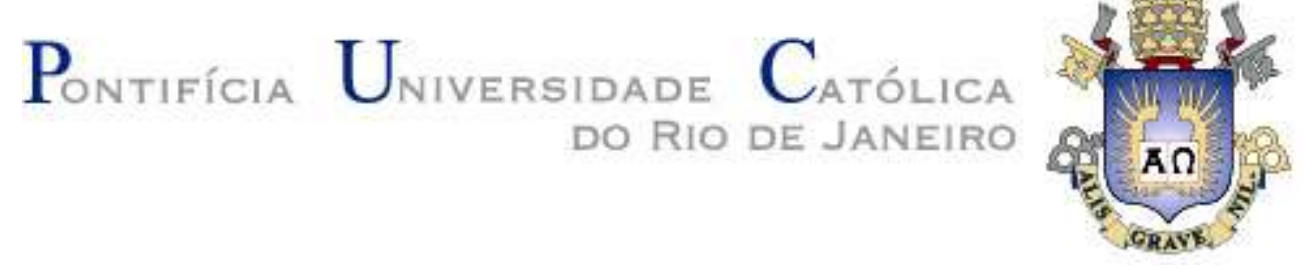

Julia Figueiredo Genovesi

\title{
Aspectos da Modelagem de Estruturas sob Ação de Forças Seguidoras
}

\author{
Dissertação de Mestrado
}

Dissertação apresentada como requisito parcial para a obtenção do grau de Mestre pelo Programa de Pós-Graduação em Engenharia Civil da PUC-Rio.

Orientador: Prof. Raul Rosas e Silva 


\section{Julia Figueiredo Genovesi}

\section{Aspectos da Modelagem de Estruturas sob Ação de Forças Seguidoras}

Dissertação apresentada como requisito parcial para a obtenção do grau de Mestre pelo Programa de Pós-Graduação em Engenharia Civil da PUC-Rio. Aprovada pela Comissão Examinadora abaixo assinada.

Prof. Raul Rosas e Silva Orientador

Departamento de Engenharia Civil e Ambiental - PUC-Rio

Prof. Paulo Batista Gonçalves Departamento de Engenharia Civil e Ambiental - PUC-Rio

Prof. Rodolfo Luiz Martins Suanno Universidade do Estado do Rio de Janeiro - UERJ

Prof. Márcio da Silveira Carvalho Coordenador Setorial do Centro Técnico Científico - PUC-Rio 
Todos os direitos preservados. É proibida a reprodução total ou parcial do trabalho sem autorização da universidade, do autor ou do orientador.

\section{Julia Figueiredo Genovesi}

Graduou-se em engenharia civil pela PUC-Rio em dezembro de 2015. Trabalhou em projetos de estruturas de concreto armado e metálicas. Sua área de interesse abrange instabilidade de estruturas, dinâmica e modelagem computacional. .

Ficha Catalográfica

Genovesi, Julia Figueiredo

Aspectos da modelagem de estruturas sob ação de forças seguidoras / Julia Figueiredo Genovesi ; orientador: Raul Rosas e Silva - 2018.

106 f. : il. color. ; $30 \mathrm{~cm}$

Dissertação (Mestrado) - Pontifícia Universidade Católica do Rio de Janeiro, Departamento de Engenharia Civil, 2018.

Inclui bibliografia

1. Engenharia civil - Teses. 2. Flambagem dinâmica. 3. Forças seguidoras. 4. Apoios e base elásticos. 5. Métodos numéricos. I. Silva, Raul Rosas e. II. Pontifícia Universidade Católica do Rio de Janeiro. Departamento de Engenharia Civil. III. Título. 


\section{Agradecimentos}

Ao professor Raul Rosas e Silva que tive o prazer de conhecer desde a graduação. Agradeço sua amizade durante toda minha trajetória acadêmica, sua dedicação, paciência e ensinamentos fizeram a diferença.

Aos professores do departamento pela atenção e dedicação disponibilizada para todos os alunos. Em especial agradeço ao professor Giuseppe Guimarães que acreditou no meu potencial desde o início, seus ensinamentos e conselhos foram muito valiosos.

Aos professores integrantes da banca examinadora, Rodolfo Suanno e Paulo Batista.

A CAPES e FAPERJ pelo apoio financeiro.

Aos queridos amigos que dividiram essa experiência do mestrado comigo, me sinto honrada de ter estudado ao lado de pessoas tão extraordinárias como vocês. A amizade e parceria que vivenciei esses dois anos foram marcantes e fizeram tudo ser mais fácil e divertido. Sou muito grata por tudo e vou levar com muito carinho vocês sempre em meu coração.

As minhas amigas Ana Beatriz, Juliana, Maisa e Maria Isabel que me apoiam e me motivam a ser uma pessoa melhor. A amizade que dividimos ultrapassa diferenças e se perpetuará por muitos anos mais.

Finalmente, agradeço minha família. Meus pais dedicaram todo tempo e amor em permitir que eu e meus irmãos pudéssemos conquistar nossos sonhos e sermos a nossa melhor versão. Minha gratidão é enorme e meu amor por todos é imensurável. 


\section{Resumo}

Genovesi, Julia Figueiredo; Silva, Raul Rosas e. Aspectos da Modelagem de Estruturas sob Ação de Forças Seguidoras. Rio de Janeiro, 2018. 106 p. Dissertação de Mestrado - Departamento de Engenharia Civil e Ambiental. Pontifícia Universidade Católica do Rio de Janeiro.

Nesta dissertação estuda-se em detalhe o modelo de coluna submetido a carregamentos não conservativos dependentes do deslocamento. Analisa-se a influência da base elástica de Winkler e de apoios elásticos nos dois problemas clássicos de Beck e Leipholz. Apresenta-se uma metodologia para o método dinâmico de determinação da condição e carga crítica através de uma formulação matricial. A modelagem é desenvolvida para um elemento de viga esbelta através do método de Rayleigh-Ritz com o campo de deslocamentos descrito pela combinação de polinômios cúbicos e funções trigonométricas. Desenvolveu-se um programa em MATLAB ${ }^{\circledR}$ de acordo com a metodologia apresentada. Os problemas clássicos foram utilizados para avaliar numericamente a eficácia desta abordagem. Apresentam-se as análises de influência de base elástica e apoios elásticos avaliados tanto separadamente como em conjunto. Isto permite mostrar que as cargas críticas e respectivos modos são afetados de forma distinta para cada tipo de apoio elástico e forma de carregamento. Finalmente, as análises são comparadas com resultados presentes na bibliografia, de modelos mais completos, considerando movimento de fluido ao longo do elemento, com o objetivo de avaliar a faixa de aplicabilidade do modelo de Beck para o caso de tubulações.

\section{Palavras-chave}

Flambagem dinâmica; Forças seguidoras; Apoios e base elásticos; Métodos numéricos 


\section{Abstract}

Genovesi, Julia Figueiredo Cardoso; Silva, Raul Rosas e (Advisor). On the Modelling of Structures Subjected to Follower Forces. Rio de Janeiro, 2018. 106 p. Dissertação de Mestrado - Departamento de Engenharia Civil e Ambiental. Pontifícia Universidade Católica do Rio de Janeiro.

In this dissertation, the model of column subjected to displacementdependent non-conservative loads is studied in detail. The influence of Winkler's elastic foundation and elastic supports is carried out for some classical problems such as Beck's and Leipholz's. A methodology based on a matrix formulation is presented for determining the critical condition and load in a dynamic approach. The model developed is based on Rayleigh-Ritz method, using a combination of cubic polynomials and trigonometric functions to describe the displacement field of slender beam elements. This methodology was implemented in a computer program developed in MATLAB ${ }^{\circledR}$. The classical problems were used as numerical tests to evaluate the accuracy of this approach. Later, the analysis of elastic foundation and elastic supports influence are presented separately and together. It was possible to show that both critical load and its respective modes are affected differently for each type of elastic support and load distribution. Finally, the influence analysis of Beck's problem is compared to results presented in in bibliography of a model which includes fluid movement within the element. This comparison has the purpose to estimate a range of applicability of the classical Beck's model to a pipe conveying fluid.

\section{Keywords}

Dynamic buckling; Follower forces; Elastic supports and foundation; Numerical methods. 


\section{Sumário}

1 . Introdução

1.1. Considerações Iniciais _........................................................................... 18

1.2. Motivação

1.3. Objetivo

1.4. Organização da dissertação

2 . Estabilidade de Sistemas Não Conservativos ……………….................2

2.1. Introdução

2.2. Classificação das forças ..........................................................................2

2.3. Conceito de Estabilidade

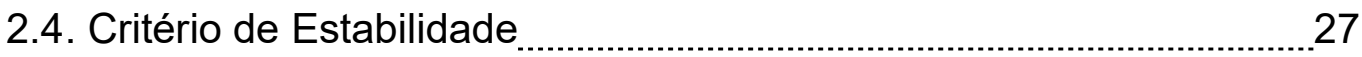

2.5. Métodos Aproximados

2.6. Formas de Instabilidade

2.7. Colunas Submetidas a Carregamentos Circulatórios _..........................34

3 . Formulação das Equações Matriciais para Determinação da Carga

Crítica e Implementação do Programa Computacional _................................. 41

3.1. Introdução

3.2. Obtenção das Equações Matriciais ………………................................... 41

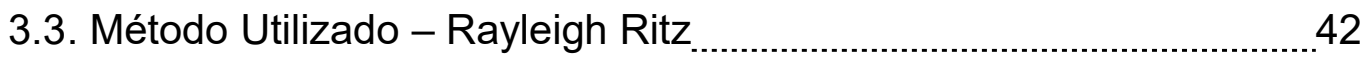

3.4. Matriz de Massa e de Rigidez Tangente .................................................. 45

3.5. Matriz de Rigidez Associada ao Comportamento da Carga 
3.6. Base Elástica 49

3.7. Condições de Contorno

3.8. Obtenção da Carga Crítica: Problema de Autovalor .......................... 51

3.9. Implementação

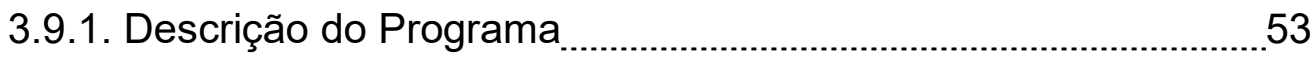

3.9.2. Descrição das Sub-rotinas/ Algoritmo do Programa _................... 54

4 . Resultados e Análise

4.1. Introdução

4.2. Estudo dos Modelos Clássicos de Colunas (Beck e Leipholz)...........56

4.2.1. Estudo de Convergência _............................................................ 59

4.2.2. Análise da influência da base elástica de Winkler ...................... 61

4.2.3. Análise da Influência dos Apoios Elásticos ……....................... 64

4.2.4. Análise Conjunta da Influência da Base Elástica e dos Apoios Elásticos 83

4.3. Comparação Entre os Modelos Clássicos de Colunas e o Modelo com Análise da Influência dos Apoios Elásticos

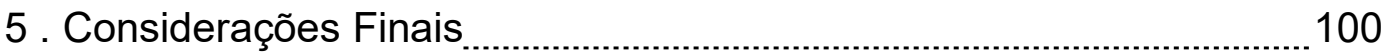

5.1. Conclusões

5.2. Sugestões para trabalhos futuros

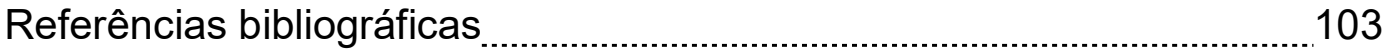




\section{Lista de figuras}

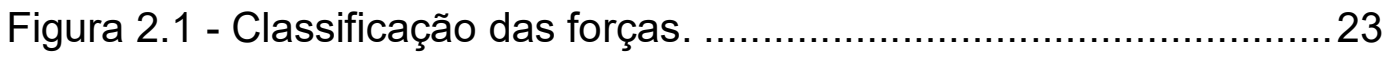

Figura 2.2 - Três situações de equilíbrio: (a) instável; (b) estável; (c) neutro.

Figura 2.3 - Deslocamento $x$ tempo para a situação de equilíbrio estável: (a) sem amortecimento; (b) com amortecimento.

Figura 2.4 - Deslocamento $x$ tempo para a perda de estabilidade por "flutter".

Figura 2.5 - Variação das duas primeiras frequências de um sistema conservativo.

Figura 2.6 - Variação das primeiras frequências em um sistema não conservativo ("couple-mode flutter").

Figura 2.7 - Coluna engastada-apoiada submetida à força seguidora na extremidade do apoio: (a) indeformada; (b) deformada.

Figura 2.8 - Coluna submetida à força concentrada na extremidade:

(a) seguidora (Coluna de Beck); (b) de direção constante.

Figura 2.9 - Colunas submetidas à carregamentos seguidores:

(a) Coluna de Pflüger; (b) Coluna de Ziegler; (c) Coluna de Leipholz......35

Figura 2.10 - Ensaio de Sugiyama et al:: (a) Foto do sistema utilizado

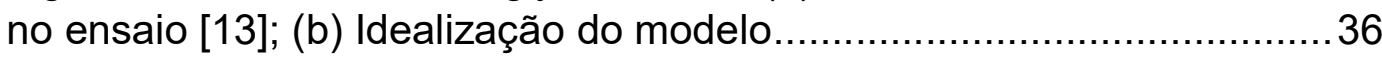

Figura 2.11 - Ensaio Bigoni \& Noselli (adaptado [14])............................. 36

Figura 2.12 - Modelo de tubulação engastada-livre com movimento de fluido.

Figura 2.13 - Modelo de coluna com apoio elástico translacional com:

(a) Carga concentrada na extremidade; (b) Carregamento distribuído. ...39

Figura 2.14 - Modelo de tubulação com apoio elástico translacional e rotacional

Figura 3.1 - Representação do elemento de viga com os quatro primeiros graus de liberdade. 43

Figura 3.2 - Funções adicionais: (a) $n=1$; (b) $n=2$; (c) $n=3$. 44 
Figura 3.3 - Matriz de comportamento da carga nodal dirigida a um ponto: (a) coluna indeformada e graus de liberdade; (b) variação no deslocamento $d_{1}$; (c) variação no deslocamento $d_{2}$.

Figura 3.4 - Matriz de comportamento da carga nodal seguidora $C f$. [40]: (a) coluna indeformada e graus de liberdade; (b) variação no deslocamento $d_{1}$; (c) variação no deslocamento $d_{2}$.

Figura 3.5 - Coluna de Leipholz: (a) Um único elemento com carregamento contínuo; (b) Três elementos com carregamento nodal. ...48

Figura 3.6 - Elemento de viga sob base elástica com apoios elásticos....50

Figura 3.7 - Idealização do sistema estrutural para análise da influência de apoios elásticos: (a) Sistema composto por viga e coluna;

(b) Idealização com apoios elásticos na extremidade da coluna.

Figura 4.1 - Variação das duas primeiras frequências ao incremento de carga (caso I)

Figura 4.2 - Variação das duas primeiras frequências ao incremento de carga (caso II).

Figura 4.3 - Estudo de convergência (caso I)

Figura 4.4 - Estudo de convergência (caso II).

Figura 4.5 - Variação das duas primeiras frequências ao incremento de carga para diferentes valores do parâmetro de base elástica (Caso I)

Figura 4.6 - Variação das duas primeiras frequências ao incremento de carga para diferentes valores do parâmetro de base elástica (Caso II)

Figura 4.7 - Comportamento das frequências de coalescências dos casos I e II ao incremento de rigidez da base elástica.

Figura 4.8 - Apoio elástico - mola translacional: (a) Coluna engastada e com deslocamento transversal parcialmente restrito; (b) Coluna engastada-apoiada.

Figura 4.9 - Apoia elástico - mola rotacional: (a) Coluna engastada e com rotação parcialmente restrita; (b) Coluna engastada e com restrição à rotação.

Figura 4.10 - Carga crítica vs. Rigidez translacional da mola $\left(k_{t}\right)-$ Caso I.

Figura 4.11 - Carga crítica vs. Rigidez rotacional da mola $\left(k_{r}\right)$ - Caso I. . 67

Figura 4.12 - Carga crítica vs. Rigidez translacional da mola $\left(k_{t}\right)-$ Caso II. 
Figura 4.13 - Carga crítica vs. Rigidez rotacional da mola $\left(k_{r}\right)$ - Caso II. . 69

Figura 4.14 - Representação da componente restauradora - coluna de Beck: (a) Coluna deformada; (b) Detalhe das parcelas da carga $P$ quando deformada.

Figura 4.15 - Representação da componente restauradora - coluna de Leipholz: (a) Coluna deformada; (b) Detalhe das parcelas do carregamento $q$ quando deformada.

Figura 4.16 - Distribuição do carregamento $q$ na coluna deformada para diferentes condições no apoio superior: (a) translação impedida, rotação livre; (b) translação livre, rotação impedida.

Figura 4.17 - Primeira e segunda frequência de vibração vs. parâmetro de carga, para diferentes parâmetros de rigidez rotacional $\left(k_{r}\right)$ - Caso I. 72

Figura 4.18 - Primeira e segunda frequência de vibração vs. parâmetro de carga, para diferentes parâmetros rigidez rotacional $\left(k_{r}\right)$ - Caso II. ....73

Figura 4.19 - Variação das frequências de coalescência com o incremento do parâmetro dos apoios elásticos $\left(k_{t} e k_{r}\right)$. 75

Figura 4.20 - Coluna engastada e com deslocamento transversal e rotação parcialmente restritos 76

Figura 4.21 - Variação das duas primeiras frequências ao incremento de carga para a combinação de $k_{t}=10$ e $k_{r}=[0 ; 5 ; 10 ; 15]$ (Caso I).

Figura 4.22 - Variação das duas primeiras frequências ao incremento de carga para a combinação de $k_{t}=20$ e $k_{r}=[0 ; 5 ; 10 ; 15]$ (Caso I).

Figura 4.23 - Variação das duas primeiras frequências ao incremento de carga para a combinação de $k_{t}=36$ e $k_{r}=[0 ; 5 ; 10 ; 15]$ (Caso I).

Figura 4.24 - Variação das duas primeiras frequências ao incremento de carga para a combinação de $k_{t}=40$ e $k_{r}=[0 ; 5 ; 10 ; 15]$ (Caso I).

Figura 4.25 - Variação das duas primeiras frequências ao incremento de carga para a combinação de $k_{t}=70$ e $k_{r}=[0 ; 15 ; 30 ; 90]$ (Caso II). ....81

Figura 4.26 - Variação das duas primeiras frequências ao incremento de carga para a combinação de $k_{t}=100$ e $k_{r}=[0 ; 15 ; 30 ; 90]$ (Caso II). ..81

Figura 4.27 - Variação das duas primeiras frequências ao incremento de carga para a combinação de $k_{t}=150$ e $k_{r}=[0 ; 15 ; 30 ; 90]$ (Caso II). ..82

Figura 4.28 - Variação das duas primeiras frequências ao incremento de carga para a combinação de $k_{t}=180$ e $k_{r}=[0 ; 15 ; 30 ; 90]$ (Caso II). ..83

Figura 4.29 - Carga crítica vs. rigidez translacional transversal da mola $\left(k_{t}\right)$ para $\mathrm{k}=0, \mathrm{k}=50$ e $\mathrm{k}=100-$ Caso $\mathrm{I}$. 
Figura 4.30 - Carga crítica vs. rigidez rotacional da mola $\left(k_{r}\right)$ para $\mathrm{k}=0$, $\mathrm{K}=50$ e $\mathrm{K}=100$ - Caso I.

Figura 4.31 - Carga crítica vs. rigidez translacional da mola $\left(k_{t}\right)$ para $\mathrm{k}=0, \mathrm{k}=50$ e $\mathrm{k}=100$ - Caso II.

Figura 4.32 - Carga crítica vs. rigidez translacional da mola $\left(k_{t}\right)$ para $\mathrm{k}=102, \mathrm{k}=104, \mathrm{k}=106$ e $\mathrm{k}=108$ - Caso II.

Figura 4.33 - Carga crítica vs. rigidez translacional da mola $\left(k_{t}\right)$ para $\mathrm{K}=111$ - Caso II.

Figura 4.34 - Primeira e segunda frequência de vibração vs. parâmetro de carga na condição engastada-apoiada da coluna do caso II para $\mathrm{k}=108, \mathrm{k}=110$ e $\mathrm{k}=111$.

Figura 4.35 - Carga crítica vs. rigidez translacional da mola $\left(k_{r}\right)$ para $\mathrm{K}=0, \mathrm{~K}=100-$ Caso II.

Figura 4.36 - Variação das frequências de coalescência ao incremento do parâmetro do apoio elástico translacional $\left(k_{t}\right)$ para $\mathrm{k}=0, \mathrm{k}=50 \mathrm{e}$ $\mathrm{K}=100-$ Caso $\mathrm{I}$.

Figura 4.37 - Variação das frequências de coalescência ao incremento do parâmetro de apoio elástico rotacional $\left(k_{r}\right)$ para $\mathrm{K}=0, \mathrm{k}=50 \mathrm{e}$ $\mathrm{K}=100-$ Caso $\mathrm{I}$.

Figura 4.38 - Variação das frequências de coalescência ao incremento do parâmetro do apoio elástico translacional $\left(k_{t}\right)$ para $\mathrm{k}=0, \mathrm{~K}=50 \mathrm{e}$ $\mathrm{K}=100-$ Caso II.

Figura 4.39 - Variação das frequências de coalescência ao incremento do parâmetro de apoio elástico rotacional $\left(k_{r}\right)$ para $\mathrm{k}=0, \mathrm{k}=50$ e $\mathrm{k}=100-$ Caso II.

Figura 4.40 - Relação entre a velocidade crítica $\left(u_{c r}\right)$ e o parâmetro $\beta$ (adaptado [9]): (a) Efeito desestabilizador $0<\beta \leq 10^{-4}$; (b) Efeito estabilizador $10^{-4}<\beta \leq 1$.

Figura 4.41 - Influência da base elástica de Winkler $\left(\kappa=k L^{4} / E I\right)$ no modelo de tubulação engastada-livre (adaptada [9]).

Figura 4.42 - Influência do apoio elástico translacional $\left(k t=K L^{3} / E I\right)$ no modelo de tubulação engastada-elasticamente apoiada com duas curvas teóricas (sólida para $y=0,02$ e tracejada para $y=0,001$ ) (adaptada [42]). 


\section{Lista de tabelas}

Tabela 4.1- Carga crítica estática e dinâmica das colunas de Beck e Leipholz.

Tabela 4.2 - Número de graus adicionais associados às funções de refinamento $\left(n_{g a}\right)$ utilizado nas análises realizadas.

Tabela 4.3 - Valores de parâmetro elástico dos apoios a serem combinados nas análises dos casos I e II

Tabela 4.4 - Comparação entre os valores de rigidez dos pontos de transição

para $\mathrm{K}=0, \mathrm{~K}=50$ e $\mathrm{K}=100$

Tabela 4.5 - Comparação entre os valores de parâmetro crítico de convergência $\left(k_{t \rightarrow \infty}\right.$ ou $\left.k_{r} \rightarrow \infty\right)$ para $\mathrm{K}=0, \mathrm{~K}=50$ e $\mathrm{K}=100$.

Tabela 4.6 - Efeito estabilizador na presença de base elástica para o caso I com influência do apoio elástico translacional $\left(k_{t}\right)$.

Tabela 4.7 - Comparação da variação das frequências de coalescência associadas ao ponto de transição para $\mathrm{k}=0, \mathrm{k}=50$ e $\mathrm{k}=100$ - Caso I

Tabela 4.8 - Valores de ponto de transição para a constante de apoio elástico transversal $\left(k_{t}^{*}\right)$ observado no ensaio reportado por Sugiyama et.al [42] para diferentes valores de $\beta$ 


\section{Lista de símbolos}

\section{Romanos:}

A Área da seção transversal do elemento

$d(t) \quad$ Vetor de deslocamentos generalizados

$d_{A} \quad$ Vetor de deslocamentos nodais associados às funções $N_{A}$

$d_{B} \quad$ Vetor de deslocamentos associados às funções $N_{B}$

D Operador diferencial

$\bar{D} \quad$ Vetor de deslocamentos generalizados do elemento

E Módulo de elasticidade longitudinal do material

$E^{*} \quad$ Coeficiente de amortecimento do material da tubulação

$f \quad$ Vetor de forças conservativas atuantes

$f^{n c} \quad$ Vetor de forças não conservativas atuantes

$i \quad$ Unidade imaginária

I Momento de inércia

$k \quad$ Rigidez elástica da base elástica de Winkler

$k_{1} \quad$ Rigidez elástica do primeiro grau de liberdade do elemento de viga Euler-Bernoulli

$k_{2} \quad$ Rigidez elástica do segundo grau de liberdade do elemento de viga Euler-Bernoulli

$k_{3} \quad$ Rigidez elástica do terceiro grau de liberdade do elemento de viga Euler-Bernoulli

$k_{4} \quad$ Rigidez elástica do quarto grau de liberdade do elemento de viga EulerBernoulli

$K \quad$ Rigidez do apoio elástico translacional no modelo de tubulação

$K^{c c} \quad$ Matriz que incorpora as condições de contorno do elemento

$K^{E} \quad$ Matriz de rigidez elástica do elemento

$K^{G} \quad$ Matriz de rigidez geométrica do elemento associada ao comportamento da carga 
$\bar{K}^{G} \quad$ Matriz de rigidez geométrica do elemento associada ao comportamento da carga parametrizada através de um fator de carga

$K^{L} \quad$ Matriz que relaciona o vetor de forças ao deslocamento

$\bar{K}^{L} \quad$ Matriz que relaciona o vetor de forças ao deslocamento parametrizada através de um fator de carga

$K^{n c} \quad$ Matriz de rigidez geométrica associada ao carregamento não conservativo

$\bar{K}^{n c} \quad$ Matriz de rigidez geométrica associada ao carregamento não conservativo parametrizada através de um fator de carga

$K^{n c I I} \quad$ Matriz de rigidez geométrica associada ao carregamento distribuído não conservativo

$k_{r} \quad$ Parâmetro adimensional de apoio elástico rotacional

$k_{r}$ * Parâmetro adimensional de apoio elástico rotacional que marca a mudança na condição crítica

$K^{t} \quad$ Matriz de rigidez tangente do elemento

$k_{t} \quad$ Parâmetro adimensional de apoio elástico translacional

$k_{t}{ }^{*} \quad$ Parâmetro adimensional de apoio elástico translacional que marca a mudança na condição crítica

$K^{w} \quad$ Matriz que incorpora a contribuição da base elástica ao sistema

L Lagrangeano

$m \quad$ Massa linear do elemento de viga

$m_{f} \quad$ Massa linear do fluido no modelo de tubulação

$m_{s} \quad$ Massa linear da tubulação no modelo de tubulação

M Matriz de massa do elemento

$N \quad$ Função que descreve o comportamento espacial do sistema

$N_{A} \quad$ Funções de forma adicionais

$N_{B} \quad$ Funções de forma do elemento de viga Euler-Bernoulli

$n_{g a} \quad$ Número de graus adicionais incorporados ao modelo

$P \quad$ Força concentrada aplicada

$\bar{p} \quad$ Parâmetro de carga adimensional para a carga concentrada aplicada

Parâmetro de carga adimensional crítico para a carga concentrada

$\bar{p}_{c r} \quad$ aplicado 
$\bar{p}_{c r}{ }^{(1)} \quad$ Parâmetro de carga adimensional crítico para a carga concentrada aplicado de tendência para a condição de contorno engastada e apoiada Parâmetro de carga adimensional crítico para a carga concentrada $\bar{p}_{c r}{ }^{(2)}$ aplicado de tendência para a condição de contorno engastada e com rotação impedida

$q \quad$ Carregamento constante distribuído ao longo do elemento de coluna

$\bar{q} \quad$ Parâmetro de carga adimensional para o carregamento distribuído aplicado

$\bar{q}_{c r} \quad$ Parâmetro de carga adimensional crítico para o carregamento distribuído aplicado

Parâmetro de carga adimensional crítico para o carregamento

$\bar{q}_{c r}{ }^{(1)}$ distribuído aplicado de tendência para a condição de contorno engastada e apoiada

Parâmetro de carga adimensional crítico para o carregamento

$\bar{q}_{c r}{ }^{(2)}$ distribuído aplicado de tendência para a condição de contorno engastada e com rotação impedida

$R \quad$ Resíduo de uma solução (Método de Galerkin)

ro Posição inicial de equilíbrio

$T \quad$ Energia cinética total do sistema

$t \quad$ Tempo

$U \quad$ Energia interna de deformação elástica do sistema

$u \quad$ Velocidade constante do fluido ao longo da tubulação

$V \quad$ Potencial das forças externas

w Função do deslocamento transversal

$\hat{w} \quad$ Função aproximada do deslocamento transversal

W Funções de ponderação (Método de Galerkin)

$W_{\text {linear }}$ Trabalho realizado pelas forças não dependentes dos deslocamentos, linear

$\delta W^{n c} \quad$ Variação do trabalho realizado pelas forças não conservativas

$W_{\text {quad }}$ Trabalho realizado pelas forças dependentes dos deslocamentos,
quadrático

$x \quad$ Coordenada espacial no eixo longitudinal

$y \quad$ Coordenada espacial no eixo transversal

$z \quad$ Coordenada espacial fora do plano 


\section{Gregos:}

$\pi \quad$ Energia potencial total do sistema

$\beta \quad$ Parâmetro adimensional que relaciona a massa linear do fluido com a massa linear total no modelo de tubulação

$\delta \quad$ Variação

$\kappa \quad$ Constante adimensional da base elástica

$\lambda \quad$ Parâmetro de carga

$\xi \quad$ Parâmetro adimensional para o comprimento do elemento

$\xi_{1} \quad$ Parâmetro adimensional para a posição em $\mathrm{x}=\mathrm{L}$

$\sigma \quad$ Tensão ao longo da seção transversal

$\tau \quad$ Parâmetro adimensional para o tempo no modelo de tubulação

$\Omega \quad$ Frequência de vibração

$\omega \quad$ Constante adimensional da frequência

$\omega_{1} \quad$ Primeira frequência de vibração do sistema

$\omega_{2}$ Segunda frequência de vibração do sistema

$\omega_{c}$

Frequência de coalescência entre as frequências de vibrações do modelo 


\section{Introdução}

\subsection{Considerações Iniciais}

O estudo de instabilidade em sistemas não conservativos teve grande avanço no século $\mathrm{XX}$ devido ao crescimento da indústria aeroespacial e aeronáutica, principalmente nos anos 60 e 70. Estes sistemas são caracterizados por uma variação de energia total, verificado em sistemas que apresentam interação entre fluído e estrutura e presença de forças de atrito ou eletromagnéticas.

O primeiro estudo em estruturas submetidas a cargas não conservativas foi desenvolvido em 1929-1930 por Nikolai [1] ao investigar instabilidade elástica em barras submetidas à torsão. Bolotin [1] e Ziegler [2] deram continuidade a esta linha de pesquisa através de publicações de extrema relevância, apresentando definições de conceitos básicos e soluções de diversos problemas de instabilidade dinâmica.

Dentre os tipos de carregamentos não conservativos estudados, o carregamento seguidor ou circulatório se destaca entre um dos mais conhecidos. Este carregamento tem como principal característica a mudança de direção na deformada da estrutura em que está aplicado de forma a permanecer sempre tangente a mesma. Um dos primeiros problemas a serem solucionados com este tipo de carregamento foi uma coluna engastada e livre submetida a uma carga seguidora na extremidade livre. Beck publicou o primeiro trabalho com a determinação da carga crítica deste problema [1,3], tendo então atualmente seu nome associado ao problema como homenagem.

Muitos trabalhos foram inspirados pelo problema da coluna de Beck ao longo dos anos, analisando diferentes parâmetros como condições de contorno, leis constitutivas e variações no carregamento. As diferenças nos carregamentos marcaram os primeiros trabalhos a determinarem cargas críticas para colunas, também nomeadas em homenagem aos primeiros autores a pesquisarem os problemas, Leipholz [4] e Pfüger [5]. Ambos problemas apresentam mesmas restrições de deslocamento nas extremidades da viga, engastada e livre. O primeiro apresenta um carregamento seguidor distribuído ao longo do elemento, já o segundo tem um carregamento concentrado misto na extremidade livre, composto por uma força seguidora e outra de direção constante.

Os métodos estático e dinâmico, são utilizados na teoria da estabilidade elástica para determinação do parâmetro crítico de um sistema. O método estático define o parâmetro crítico como o menor valor capaz de gerar configurações de 
equilíbrio próximas a fundamental. Já método dinâmico avalia as vibrações do sistema em torno de uma configuração de equilíbrio. Sendo então o parâmetro de carga crítico determinado como o menor valor capaz de tornar as vibrações do sistema instáveis.

O desenvolvimento da solução dos problemas não conservativos é feito através da formulação de equações diferenciais de movimento. A solução analítica de alguns casos, principalmente com a inclusão de novos parâmetros e utilizando modelos mais complexos, é árdua e em alguns casos inviável. Recorre-se então a métodos aproximados para a resolução destes problemas. Independentemente do método adotado, a determinação do parâmetro crítico de carga requer o cálculo de valores característicos de problema de valores de contorno.

Um sistema não conservativo submetido a um carregamento seguidor, diferentemente de um sistema conservativo usual, pode perder a estabilidade de duas formas: estática (divergência) ou dinâmica ("flutter"). O fenômeno da divergência é comum a sistemas conservativos e é caracterizado, em colunas, pela perda de rigidez efetiva ao atingir a carga crítica assim adotando uma configuração de equilíbrio próxima à inicial. Esse tipo de condição crítica pode ser investigado através dos métodos estático e dinâmico sem nenhum prejuízo ao resultado.

O fenômeno de "flutter", entretanto, se distingue pelo movimento oscilatório com amplitudes crescentes ao redor da configuração inicial, observado no atingimento da carga crítica. A possibilidade desta condição crítica faz necessária a utilização do método dinâmico. Assim, a utilização do método dinâmico é recomendável para análise de estabilidade de sistemas não conservativos.

\subsection{Motivação}

A dificuldade de validação experimental de diversos trabalhos submetidos a forças circulatórias, principalmente dos modelos clássicos de coluna como a de Beck, despertou grande questionamento sobre a aplicabilidade do modelo utilizado [6, 7]. Além da falta da validação experimental, Elishakoff [7] usa também como argumentação o resultado, considerado paradoxal, da indiferença do modelo na presença de base elástica [8]. Este ponto será esclarecido nesta dissertação.

Koiter [6] e Elishakoff [7] sugerem então o abandono da idealização de forças seguidoras em modelos, considerando os estudos puramente teóricos e com pouca representatividade. Para Elishakoff o modelo de colunas submetidas a apenas cargas seguidoras não gera um modelo útil para caracterizar o principal foco de análise, em sua opinião, da tubulação com movimento de fluido. Os resultados divergentes da análise de influência da base elástica $[8,9]$ e a pequena 
complexidade a mais envolvida num modelo mais realista, sustentam sua opinião. Elishakoff sugere a utilização apenas do modelo de tubulação com movimento de fluido em que são considerados os efeitos da força centrífuga e de Coriolis para trabalhos futuros.

Houve algumas respostas aos questionamentos e críticas feitos às forças seguidoras, como a de Sugiyama et al. [10]. Alegando a forte importância na indústria aeroespacial e descrevendo exemplos de aplicação que incluem tubulação com movimento de fluido, atrito entre discos de freio automobilísticos e foguetes, Sugiyama et al. defende a relevância deste tipo de carregamento. Experimentos realizados em foguetes são considerados por Sugiyama et al. como bem sucedidos em demonstrar a instabilidade dinâmica em foguetes [11], a verificação qualitativa da carga crítica de "flutter" no sistema [12] e seu efeito estabilizador [13]. A carga seguidora na extremidade da coluna representa o impulso do foguete, podendo ser mais realista ao considerar uma força peso concentrada na extremidade, se aproximando então mais do modelo de coluna de Pflüger. Recentemente também foi reportado por Bigoni \& Noselli [14] um experimento relativamente simples validando o modelo de coluna de Ziegler, coluna engastada livre com dois graus de liberdade submetida a uma carga concentrada seguidora na extremidade livre. A força de atrito entre a ponta da coluna e uma chapa em movimento com velocidade constante representou a força seguidora na extremidade.

Essa certa polêmica envolvendo a aplicabilidade de modelos clássicos de colunas sob efeito de forças seguidoras e da própria idealização desta força motivou a realização deste trabalho. A falta de um consenso a respeito desse tema gera incerteza quanto aos resultados obtidos dos modelos simplificados e dúvidas quanto ao seu emprego, em diversas referências. Na verdade, a discussão moderna sobre aplicação de forças seguidoras deve lembrar a existência de sensores e atuadores com os mais diversos comportamentos, possibilitando o controle dinâmico de estruturas. Os atuadores, portanto, se constituem em ações não conservativas.

\subsection{Objetivo}

A principal finalidade deste trabalho é a realização de um estudo detalhado do modelo de coluna submetido a dois tipos de carregamento seguidor, concentrado na extremidade e distribuído ao longo do elemento. Neste estudo analisa-se a influência da base elástica de Winkler e dos apoios elásticos na condição crítica da estrutura. A avaliação da aplicabilidade dos modelos faz-se possível com os resultados destas análises e a comparação com o modelo de tubulação com movimento de fluido, por ser considerado mais representativo.

O desenvolvimento deste estudo é feito através de uma rotina implementada no programa MATLAB, desenvolvida através do método 
aproximado de Rayleigh-Ritz com adição de efeitos não conservativos. Utiliza-se um elemento de viga reta com hipótese de Euler-Bernoulli com o campo de deslocamentos descrito por uma combinação de funções cúbicas com trigonométricas. O programa permite, considerando pequenos deslocamentos, a determinação da condição e parâmetro crítico de colunas sob ação de forças seguidoras, de direção constante ou dirigidas a um ponto.

Um objetivo secundário está então associado à avaliação da eficácia do método e da implementação computacional através de comparações com soluções analíticas e numéricas que já estão bem definidas na literatura.

\subsection{Organização da dissertação}

Além da introdução, esta dissertação contém outros quatro capítulos. No capítulo 2 faz-se uma apresentação de conceitos relacionados ao estudo de estabilidade de sistemas não conservativos além de uma breve revisão bibliográfica de trabalhos contendo estudos de estabilidade de colunas submetidas a cargas seguidoras. O capítulo 3 apresenta o desenvolvimento da formulação matricial para o desenvolvimento do problema de estabilidade analisado neste trabalho, bem como a descrição da implementação computacional adotada no MATLAB ${ }^{\circledR}$ para desenvolvimento da solução. A apresentação da validação da metodologia implementada no programa e dos resultados das diferentes análises de influência realizadas nos problemas clássicos de coluna de Beck e Leipholz estão no capítulo 4. Neste capítulo também é realizada uma apreciação e análise dos resultados obtidos em cada um dos casos e uma breve comparação do modelo de coluna com o modelo de tubulação com movimento de fluido. Por último, no capítulo 5 as conclusões e sugestões para trabalhos futuros são apresentadas. 


\section{Estabilidade de Sistemas Não Conservativos}

\subsection{Introdução}

Este capítulo apresenta os principais conceitos para uma análise de estabilidade de sistemas elásticos submetidos a carregamentos não conservativos. A classificação das forças atuantes na estrutura é feita com o objetivo de esclarecer a natureza dos carregamentos assim como a exposição dos critérios de estabilidade e métodos para desenvolvimento da solução.

Após a exposição desses conceitos, é feita uma breve revisão de trabalhos relacionados ao estudo de estabilidade de sistemas não conservativos clássicos.

\subsection{Classificação das forças}

Uma classificação precisa das forças é necessária tanto para o estudo de instabilidade quanto para qualquer investigação do comportamento mecânico de um sistema. Além disso, um estudo quanto a natureza destas forças é fundamental para idealização de modelos, de modo que representem a sua real complexidade.

Neste contexto, as forças podem ser divididas em dois grupos quanto a conservação de energia. As forças conservativas podem ser descritas através de uma função potencial dependente apenas da configuração final e inicial do sistema. As forças não conservativas, entretanto, não possuem um potencial associado. O trabalho relacionado a este tipo de carregamento é dependente da trajetória de deformação do sistema ao estágio final. A Figura 2.1 apresenta de forma esquemática a classificação de forças. 


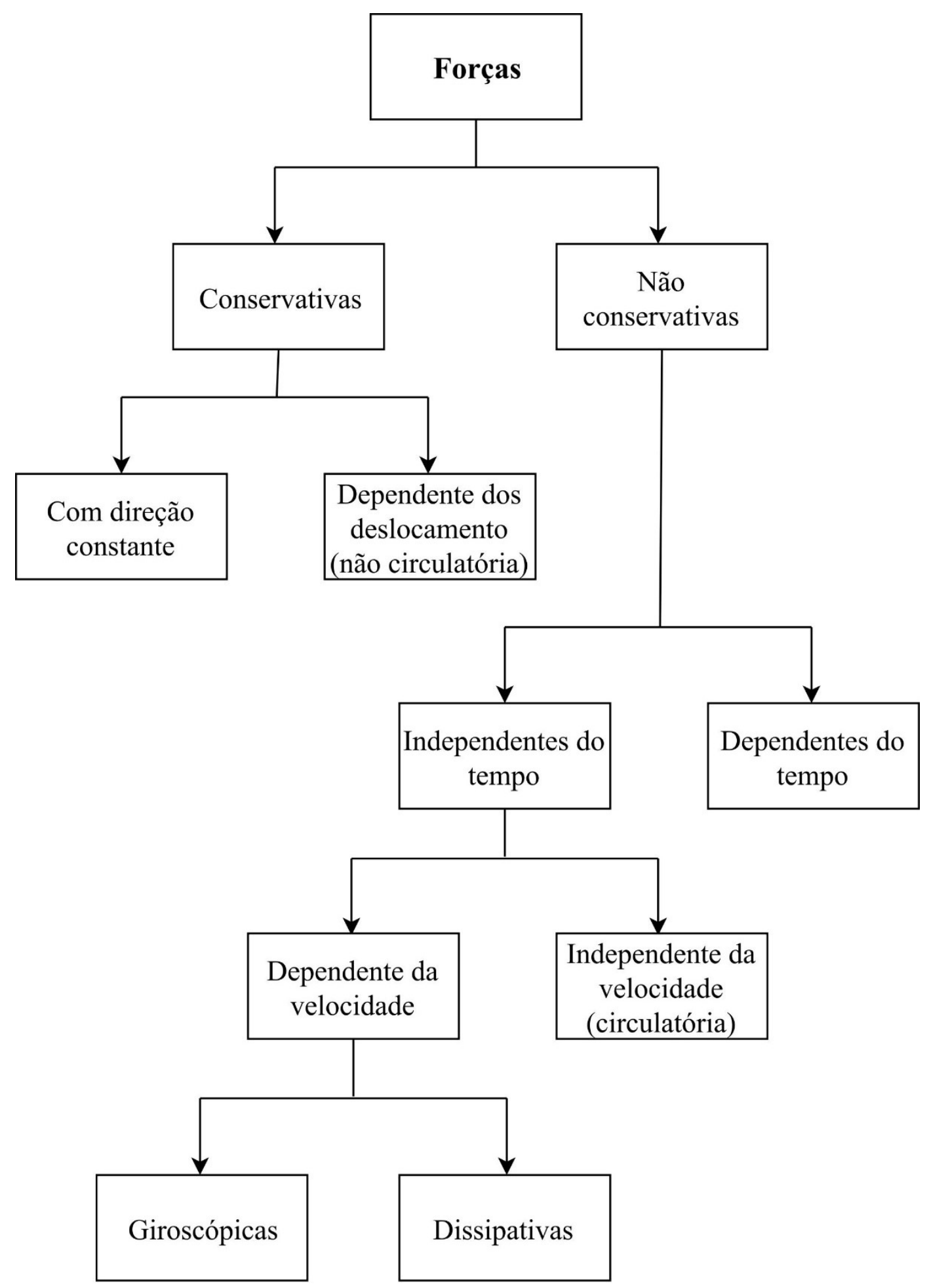

Figura 2.1 - Classificação das forças.

As forças conservativas compõem os carregamentos mais usuais na análise estrutural e podem ser classificadas quanto à dependência do deslocamento. As forças dirigidas a um ponto fixo ou força centrifuga exemplificam as forças dependentes do deslocamento, já a força peso que tem direção constante exemplifica as forças independentes. 
As forças não conservativas, objeto de estudo deste trabalho, são classificadas quanto à dependência do tempo. As forças não conservativas independentes do tempo, ditas como estacionárias, são divididas em dois grupos distintos: dependentes e independentes da velocidade. As forças dependentes da velocidade podem ser dissipativas ou giroscópicas. As forças dissipativas têm como característica a produção de um trabalho negativo, dissipando energia do sistema, já as forças giroscópicas apresentam um trabalho nulo.

As forças giroscópicas correspondem a uma exceção da definição feita acima, pois, devido ao trabalho nulo, são consideradas conservativas apesar de não serem derivadas de uma função potencial. Forças como a de Coriolis, associada ao giro ou deformação do eixo de referência, ou de Lorentz, associada a campos eletromagnéticos, apresentam uma dependência da velocidade tal que o trabalho sobre um movimento real do sistema é sempre nulo [2, 15].

As forças não conservativas independentes da velocidade são ditas como circulatórias ou seguidoras devido a dependência do deslocamento. Estas forças são mais comuns do que costuma ser suposto e estão normalmente associadas a forças aerodinâmicas, hidrodinâmicas e de atrito. Vale ressaltar exemplos de sistemas lineares sob efeito deste carregamento uma vez que correspondem aos sistemas avaliados neste trabalho, sendo eles:

- tubulações com movimento de fluido [15];

- foguetes e aeronaves submetidos à força de propulsão [11, 13];

- coluna humana submetida ao esforço compressivo do ato de levantar [16].

\subsection{Conceito de Estabilidade}

A avaliação de estabilidade de um determinado sistema deve ser feita a partir da introdução de uma perturbação em sua configuração indeformada [17]. A estabilidade do sistema está então associada ao nível de perturbação necessário para que o sistema atinja o limite entre uma situação estável e instável. A Figura 2.2 representa um exemplo ilustrativo em que é avaliado o equilíbrio de uma esfera rígida inserida num campo gravitacional com os três possíveis estados, instável (a), estável (b) e indiferente (c). 


\section{g.}

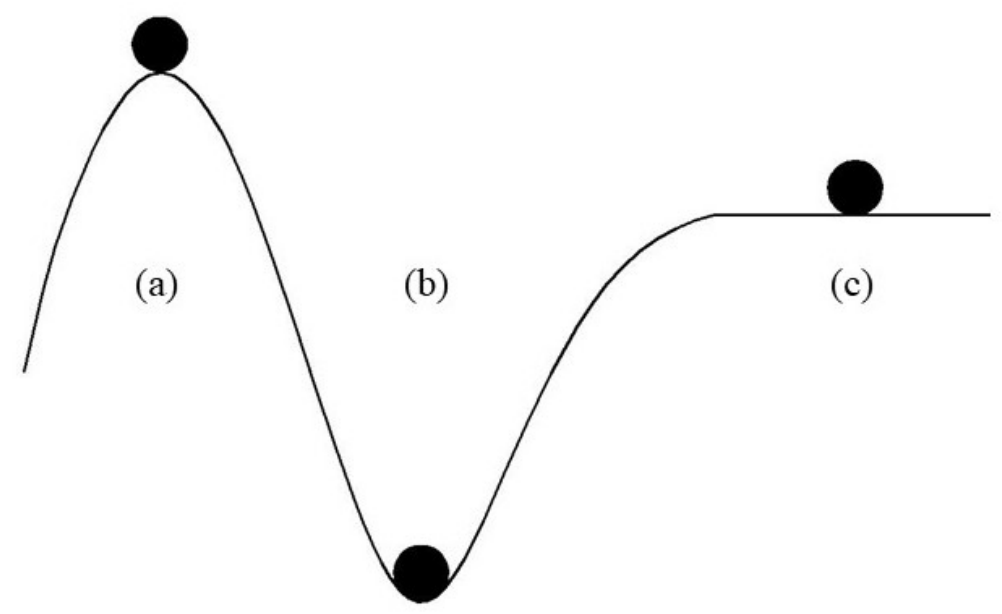

Figura 2.2 - Três situações de equilíbrio: (a) instável; (b) estável; (c) neutro.

$\mathrm{Na}$ situação (a) a esfera se encontra em uma posição instável, pois existe uma tendência de grandes deslocamentos para qualquer intensidade de impulso a ser aplicado. Já no caso (b), equilíbrio estável, os deslocamentos da esfera são limitados e a esfera tende a oscilar em torno da posição de equilíbrio indefinidamente, desprezando o efeito do amortecimento, ou tende a retornar à posição inicial. As curvas (a) e (b) presentes na Figura 2.3 representam respectivamente estes dois movimentos de equilíbrio estável, mostrando a variação do deslocamento generalizado ao longo do tempo t. 


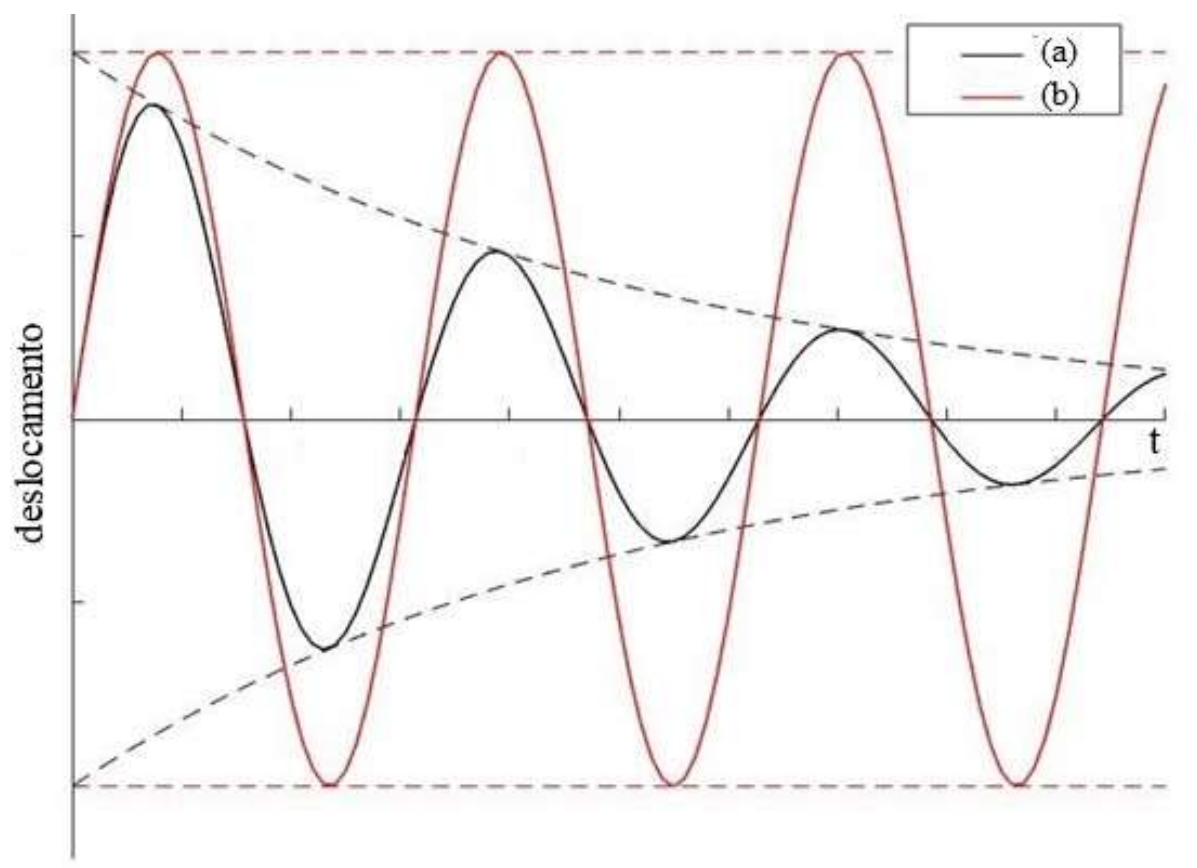

Figura 2.3 - Deslocamento x tempo para a situação de equilíbrio estável: (a) sem amortecimento; (b) com amortecimento.

A situação descrita na Figura 2.2c representa uma situação neutra, para uma dada perturbação a esfera irá se deslocar em movimento uniforme. Mesmo em uma nova posição a esfera permanecerá em equilíbrio.

O comportamento de um sistema estrutural pode depender de diversos parâmetros, como: parâmetros mecânicos, de carga e possivelmente o tempo. A estabilidade do mesmo depende dos valores destes parâmetros e no exemplo das esferas ilustrado na Figura 2.2 o parâmetro de controle para a avaliação da estabilidade poderia ser a altura do impulso aplicado. A magnitude do impulso aplicado na esfera é determinante para identificar a sua estabilidade e ele é dito como crítico quando corresponde ao valor limite entre a condição estável e instável. Assim, a fronteira de estabilidade é determinada pela investigação de valores críticos do sistema, podendo ser definida através de considerações dinâmicas ou estáticas.

Os sistemas não conservativos têm possibilidade de perder estabilidade de duas formas: através de um movimento oscilatório com amplitudes crescentes chamado de "flutter" ou divergência. A Figura 2.4 representa no gráfico de deslocamento x tempo o fenômeno de "flutter". 


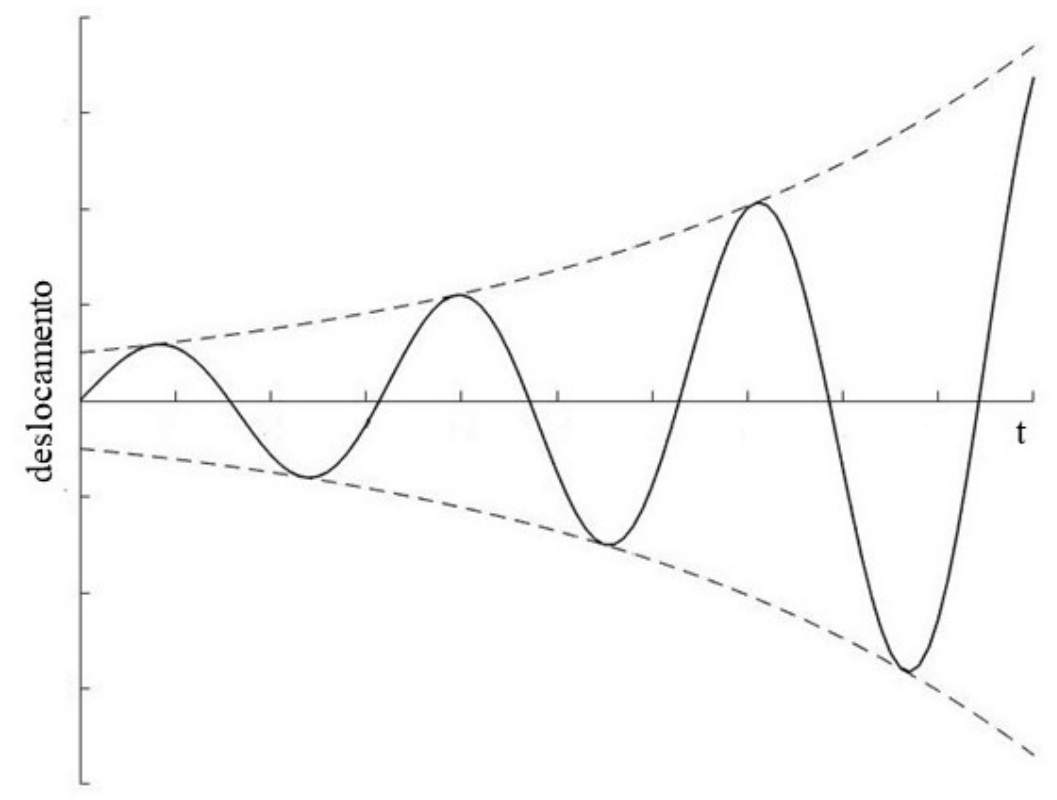

Figura 2.4 - Deslocamento x tempo para a perda de estabilidade por "flutter".

A utilização de considerações estáticas em sistemas que podem perder estabilidade por "flutter" leva a conclusões errôneas, como indicado por Nikolai em 1930 [1]. A investigação da instabilidade elástica de barras submetidas a um momento de torção tinha como objetivo comprovar a previsão de que não há formas de equilíbrio próximas da configuração indeformada. Nikolai, entretanto, obteve utilizando considerações estáticas o resultado de que para qualquer intensidade de momento a barra permaneceria na posição original. O momento de torção de direção constante aplicado na extremidade livre é definido como um esforço não conservativo [2] e os resultados paradoxais obtidos indicaram a necessidade de considerações dinâmicas para a avalição destes sistemas. $O$ trabalho de Nikolai marca o início do estudo de instabilidade em sistemas não conservativos.

Devido ao papel fundamental da resposta dinâmica no estudo de estabilidade de sistemas não conservativos, o critério de Liapunov é aplicável para verificação da estabilidade do sistema [18]. Logo, o sistema é dito como estável caso uma perturbação suficientemente pequena gere um movimento com pequenos deslocamentos e velocidades ou caso estas quantidades tenderem a se anular com o tempo.

\subsection{Critério de Estabilidade}

O limite entre o equilíbrio estável e o instável, chamado de fronteira de estabilidade, pode ser determinado através do critério estático, de energia ou dinâmico. 
O critério estático corresponde à simples observação das forças resultantes do sistema na configuração perturbada. A tendência restauradora ou não destas forças caracterizará a estabilidade do sistema. Este critério pode ser aplicável ao exemplo das esferas na Figura 2.2, através da resultante das forças peso (na direção da aceleração da gravidade) e normal (perpendicular à superfície). A tendência da esfera se afastar ou retornar à posição original, Figura 2.2a e Figura $2.2 \mathrm{~b}$, configuram respectivamente posições de equilíbrio instável e estável. No caso da esfera na Figura 2.2c as forças estão em equilíbrio sempre, assim sendo classificada como uma posição de equilíbrio neutro.

O critério de energia apresenta uma certa equivalência ao critério estático, porém com uma maior aplicabilidade devido à dependência de quantidades escalares em vez de vetoriais. O teorema de Lagrange-Dirichlet é a base deste critério, relacionando a estabilidade do sistema ao mínimo de energia potencial total. A energia potencial total é definida como:

$$
\pi=U+V
$$

onde $U$ é a energia interna de deformação elástica e $V$ é o potencial das forças externas. A relação

$$
\delta \pi=0
$$

é válida para o equilíbrio do sistema uma vez que há conservação de energia.

A análise de estabilidade em torno de uma posição de equilíbrio $r_{0}$ pode ser feito através da expansão em séries de Taylor,

$$
\pi\left(r_{0}+\delta r\right)=\pi\left(r_{0}\right)+\delta \pi\left(r_{0}\right)+\frac{1}{n !} \delta^{2} \pi\left(r_{0}\right)+\frac{1}{\imath 1} \delta^{3} \pi\left(r_{0}\right)+\ldots .
$$

Havendo equilíbrio na posição $r_{0}$ a equação (2.2) é satisfeita, $\delta \pi\left(r_{0}\right)=0$, indicando um extremo (máximo ou mínimo). Ao avaliar se está posição trata-se de um máximo ou um mínimo, verifica-se então se a estrutura está estável ou não. O primeiro termo seguinte não nulo da equação (2.3) fornece as indicações sobre o comportamento do sistema, caso ele seja positivo a configuração é dita como estável, caso contrário a configuração é instável.

Uma vez que o critério de energia só deve ser empregado em sistemas conservativos e o uso do critério estático não garante a validade dos resultados em sistemas não conservativos, a determinação das fronteiras de estabilidade nestes sistemas deve ser feita pelo critério dinâmico. A estabilidade de sistemas não conservativos é então analisada através da observação do movimento do sistema em torno da posição de equilíbrio após a introdução de pequenas perturbações. A obtenção da equação que governa o problema é feita através do princípio de Hamilton.

O princípio de Hamilton, estendido para casos não conservativos [19], estabelece que a variação da soma das parcelas do Lagrangeano $(L)$ e a variação do trabalho associado ao carregamento não conservativo $\left(W^{n c}\right)$ deve ser nula num intervalo de tempo arbitrado. Ele pode ser escrito como 


$$
\delta \int_{t_{1}}^{t_{2}} L d t+\int_{t_{1}}^{t_{2}} \delta W^{n c} d t=0
$$

onde o Lagrangeano é dado por:

$$
L=T-\pi
$$

sendo

$T=$ energia cinética total do sistema;

$\pi=$ energia potencial total do sistema.

A equação (2.4) pode ser interpretada como uma abordagem mais geral, sendo comum aos sistemas não conservativos e conservativos. Assim os sistemas conservativos configuram apenas um caso especial em que a expressão depende apenas da primeira variação do Lagrangeano $(L)$. Por analisar diferentes formas de instabilidade, o critério dinâmico atinge o mesmo resultado obtido nos outros critérios ao avaliar a estabilidade de sistemas conservativos.

Cabe ressaltar que o princípio de Hamilton está normalmente associado a sistemas fechados, em que há conservação de massa. Porém, a partir de algumas hipóteses simplificadoras como a desconsideração do atrito entre o fluido e a parede do tubo e da possibilidade de movimento turbulento do fluido ele pode ser aplicado em tubulações [20, 21]. Benjamin [22] e Païdoussis \& Gregory [23] afirmam que estas hipóteses são válidas para a análise de instabilidade de tubulações por avaliarem que seus efeitos não têm muita relevância no resultado. Há entretanto uma vasta quantidade de trabalhos em que esses efeitos são considerados, como Lee [24], Curling \& Païdoussis [25] e Hellum et al. [26].

\subsection{Métodos Aproximados}

As equações de movimento, obtidas através da aplicação do princípio de Hamilton, são particulares para cada problema e dependem das características do material e carregamentos da estrutura. A equação de movimento é tida como um problema de valor de contorno e a sua solução, função que descreve o comportamento do sistema, depende tanto das coordenadas espaciais $(x, y, z)$ como do tempo $(t)$. Esta função pode ser descrita pelo produto de duas funções,

$$
w(x, y, z, t)=N(x, y, z) d(t) .
$$

A função que dependente apenas das coordenas espaciais descreve o modo de flambagem, enquanto a outra descreve o comportamento do sistema no tempo, respectivamente $N(x, y, z)$ e $d(t)$.

Devido à grande dificuldade em obter soluções analíticas para as equações de movimento, principalmente considerando modelos estruturais complexos, o uso de métodos aproximados se torna cada vez mais necessário. Os métodos de Rayleigh-Ritz e Galerkin se destacam na aproximação dos deslocamentos 
espaciais da estrutura devido à fácil implementação e alta confiabilidade dos resultados.

A solução aproximada utilizando o método de Rayleigh depende do uso de uma função arbitrária que satisfaça as condições de contorno e de continuidade. Por se tratar de uma aproximação com o uso de apenas uma função arbitrária, a qualidade dos resultados é proporcional a quão próxima a função escolhida está da configuração fundamental exata.

Uma expansão deste método, chamada de Rayleigh-Ritz, descreve o deslocamento do sistema através de uma série de funções aproximadas multiplicadas por fatores amplificadores, chamados de graus de liberdade. O número de funções necessárias para descrever a forma do deslocamento do sistema é determinado de acordo com a precisão necessária. Assim a solução aproximada é desenvolvida pela combinação linear

$$
\hat{w}=\sum_{i=1}^{n} a_{i} N_{i}
$$

de uma quantidade $n$ de funções admissíveis $N_{i}$.

O método de Galerkin corresponde a um dos métodos de resíduos ponderados mais utilizados. A solução aproximada, nesse caso, está associada à minimização dos resíduos obtidos com o emprego de uma combinação de funções arbitrárias. A solução aproximada deve então satisfazer além das condições de contorno e de continuidade, a condição de mínimo resíduo.

A condição de mínimo resíduo é obtida através de

$$
\begin{gathered}
R=D \hat{w} \\
\int W_{i} R d V=0 \\
\int W_{i} R d V=0 \quad \text { para } i=1,2, \ldots, n
\end{gathered}
$$

onde:

$R=$ Função de resíduo;

$D=$ Operador diferencial;

$\hat{w}=$ Solução aproximada;

$W_{i}=$ Funções de ponderação.

As funções de ponderação também são arbitrárias, porém é comum o uso de funções de ponderação relacionadas a primeira derivada da solução aproximada. Existe, porém, recomendações na literatura de funções de ponderação que geram resultados com melhor convergência para determinados problemas. 
Ambos métodos descritos acima podem ser combinados com a subdivisão do domínio. O método dos elementos finitos, por exemplo, corresponde a divisão do domínio em diversos subdomínios a serem desenvolvidos separadamente pelo método de Rayleigh-Ritz.

\subsection{Formas de Instabilidade}

Ao atingir o parâmetro de carga crítica, a configuração de equilíbrio do sistema tem suas características modificadas e seu comportamento está relacionado tanto ao tipo de carregamento quanto às condições de contorno geométricas. Os sistemas conservativos perdem estabilidade apenas por divergência. Já os sistemas não conservativos podem perder estabilidade por duas formas, divergência e "flutter". A conceituação então, das duas possíveis formas de instabilidade se faz necessária.

\section{i. Divergência.}

Processo de perda de estabilidade estática em que após um parâmetro crítico a estrutura tem sua rigidez efetiva reduzida e assim grandes deslocamentos são observados para pequenas variações de carga.

\section{ii. Flutter.}

A perda de estabilidade ocorre de maneira dinâmica, a partir de um parâmetro crítico a estrutura inicia um processo vibratório com amplitudes crescentes (Figura 2.4). A vibração do sistema é um produto da variação observada nas frequências da estrutura em decorrência da transferência de energia verificada em sistemas não conservativos.

Ao analisar a estabilidade de um sistema através do critério dinâmico, a forma de instabilidade é determinada pelo comportamento das frequências naturais de vibração ao incremento de carga. A divergência se dá quando pelo menos uma das frequências se anula, configurando a condição crítica (Figura 2.5). Quando em equilíbrio estável a estrutura apresenta frequências reais e ao ultrapassar o ponto crítico, pelo menos alguma frequência se torna imaginária caracterizando o equilíbrio instável. 


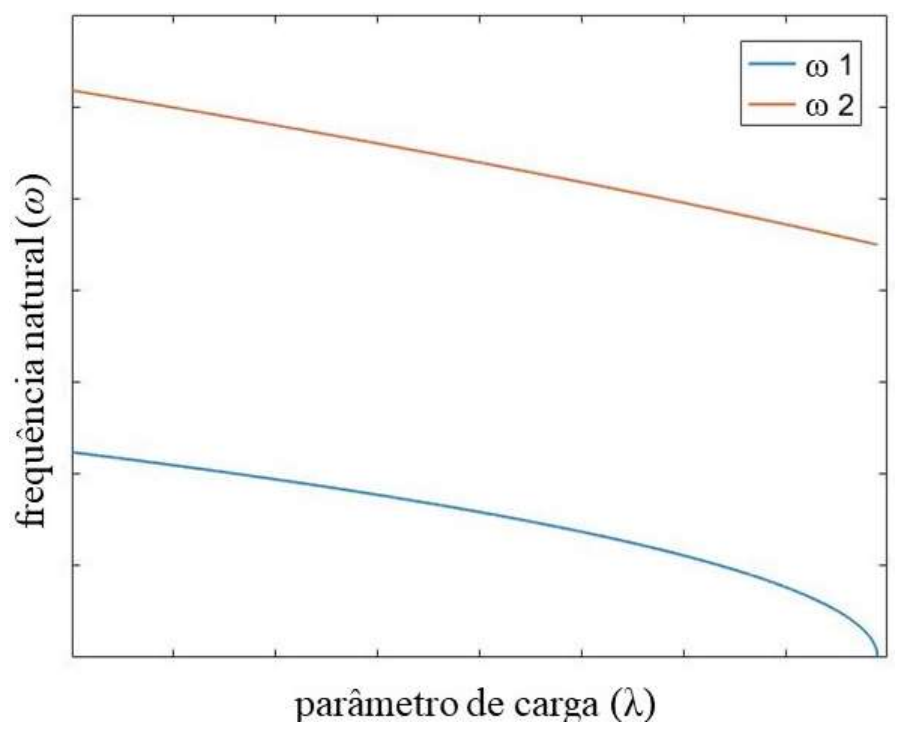

Figura 2.5 - Variação das duas primeiras frequências de um sistema conservativo.

O "flutter", todavia, pode ocorrer de duas formas: através da coalescência de duas frequências vizinhas ("couple-mode flutter") ou apenas quando uma das frequências se torna instável ("single-mode flutter"). Os modelos clássicos: a coluna de Beck [1] e a tubulação engastada-livre $[9,15]$ com movimento de fluido exemplificam as duas formas respectivamente. A Figura 2.6 representa a variação das primeiras frequências da coluna de Beck e o fenômeno de coalescência das frequências marca o parâmetro crítico da estrutura e o início do movimento oscilatório.

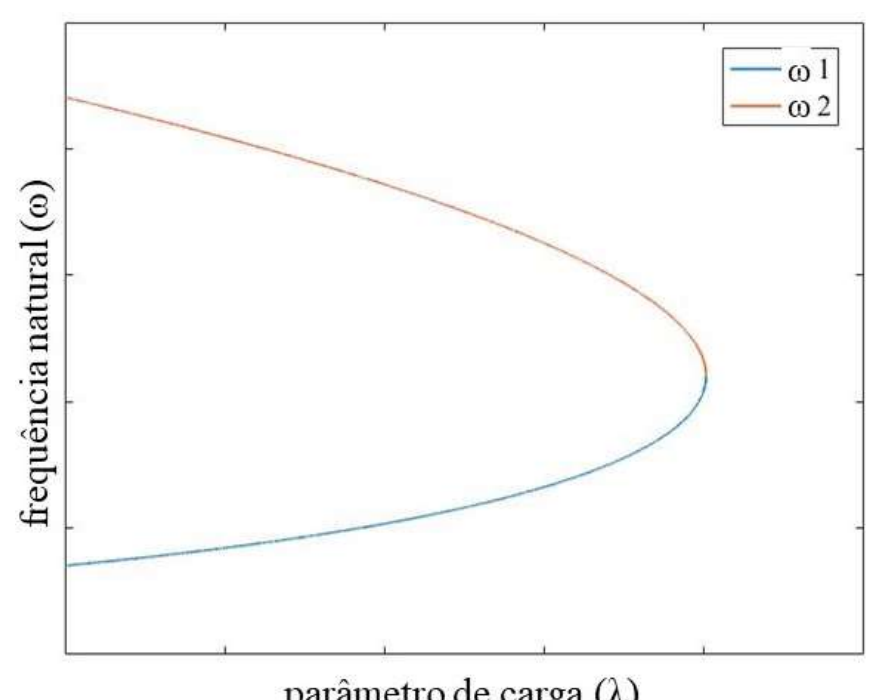

Figura 2.6 - Variação das primeiras frequências em um sistema não-conservativo ("couple-mode flutter"). 
O modelo da tubulação engastada-livre com movimento de fluido se diferencia da coluna de Beck principalmente pela presença da força de Coriolis além da força seguidora na extremidade comum aos dois. A força de Coriolis, devido a dependência de velocidade, funciona como um pseudo-amortecimento e a coalescência das frequências não é mais observada mesmo sofrendo perda de instabilidade dinâmica. Neste caso as frequências são representadas por um complexo conjugado e a perda de estabilidade ocorre quando a parte real se torna positiva.

Os sistemas podem ser classificados também com respeito à forma de instabilidade. Os sistemas conservativos apresentam instabilidade apenas por divergência, mas podem ser divididos em dois grupos. O primeiro grupo é constituído de sistemas submetidos a carregamentos conservativos e pela definição clássica tem sua energia potencial conservada. Já o segundo grupo, apesar de estar submetido a carregamentos não conservativos, apresenta conservação da energia potencial. O sistema representado nas Figuras 2.7 (a) e (b) exemplifica este segundo grupo. A condição de apoio geométrico nesse caso é o fator determinante para que o funcional de energia seja conservado.

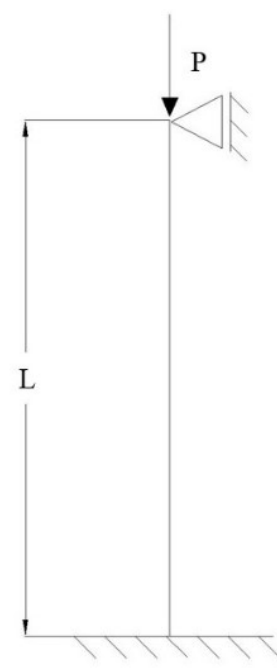

(a)

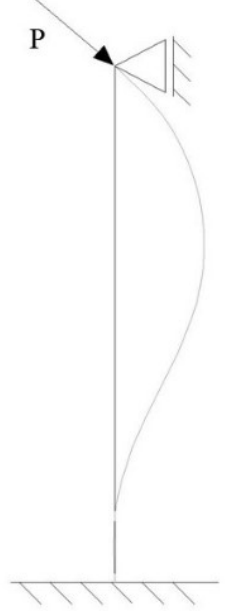

(b)

Figura 2.7 - Coluna engastada-apoiada submetida à força seguidora na extremidade do apoio: (a) indeformada; (b) deformada.

No caso de tubulações bi-apoiadas ou bi-engastadas, essa regra não se aplica. Objeto de muitos estudos ao longo dos anos, estes sistemas apresentam, em uma análise linear, a possibilidade de perda de estabilidade dinâmica na condição pós crítica, apesar de serem caracterizados como conservativos [15, 27]. Não há, entretanto, nenhum experimento comprobatório deste fenômeno observado por Holmes [28], ao analisar esse problema incluindo os efeitos não- 
lineares verifica-se que não há mais a possibilidade de perda de instabilidade por "flutter" nesses sistemas.

Os sistemas não conservativos podem ser também divididos em dois grupos. Os sistemas que perdem estabilidade apenas por "flutter" compõem o primeiro grupo, enquanto que sistemas híbridos, que podem perder estabilidade tanto por "flutter" como por divergência compõem o segundo grupo.

\subsection{Colunas Submetidas a Carregamentos Circulatórios}

O primeiro estudo em colunas sujeitas a carregamentos circulatórios foi desenvolvido por Beck em 1952 [1], sendo ele o primeiro a determinar parâmetro de carga crítica do modelo. O sistema é composto por uma coluna engastada-livre submetida a uma força seguidora em sua extremidade livre (Figura 2.8 (a)). A componente restauradora da força $\mathrm{P}$ desse sistema faz com que o sistema só perca estabilidade dinamicamente com um parâmetro crítico superior a oito vezes a da mesma coluna quando submetida a uma força com direção constante (Figura 2.8 (b)).

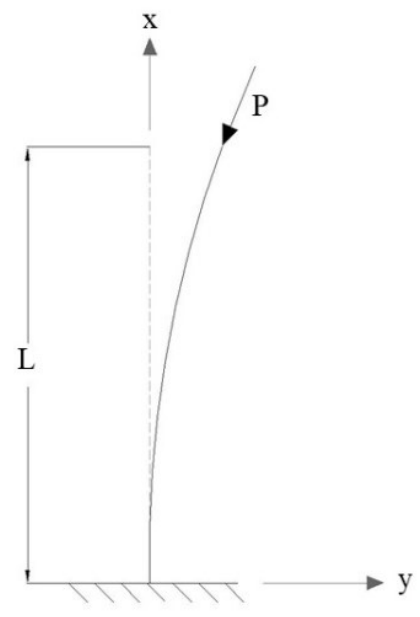

(a)

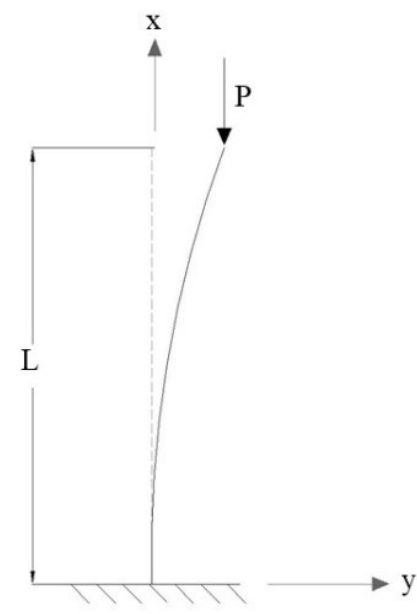

(b)

Figura 2.8 - Coluna submetida à força concentrada na extremidade: (a) seguidora (Coluna de Beck); (b) de direção constante.

Diversos outros sistemas não conservativos foram analisados ao longo dos anos seguintes, com destaque às colunas de Pflüger, Ziegler e Leipholz [1, 5, 29, 4]. A coluna de Pflüger (Figura 2.9 (a)) é engastada-livre e se diferencia da coluna de Beck pela combinação de dois tipos de carregamento na extremidade livre, força seguidora e de direção constante (representada na Figura 2.9 (a) pela força peso proporcional à massa na extremidade). A coluna de Ziegler (Figura 2.9 (b)) se distingue por se tratar de um sistema com duas barras rígidas e apenas dois 
graus de liberdade. Já a coluna de Leipholz (Figura 2.9 (c)) apresenta um carregamento seguidor distribuído $q$ ao logo do comprimento, tornando o sistema consideravelmente mais estável do que a coluna de Beck, sendo a carga crítica $q L$ aproximadamente duas vezes maior.

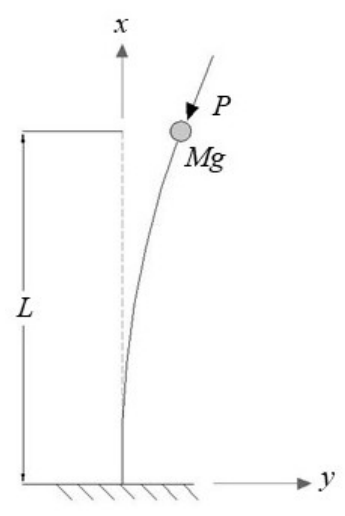

(a)

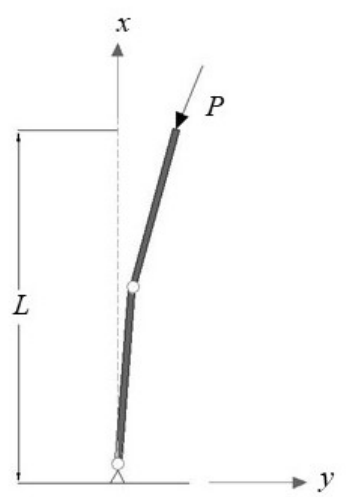

(b)

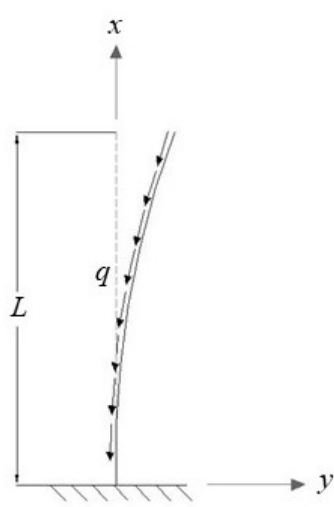

(c)

Figura 2.9 - Colunas submetidas à carregamentos seguidores: (a) Coluna de Pflüger; (b) Coluna de Ziegler; (c) Coluna de Leipholz.

Apesar dos grandes avanços no estudo desses modelos, principalmente nos anos 60, alguns questionamentos começaram a surgir quanto a sua validade prática principalmente devido à dificuldade de realização de experimentos. Koiter [6] foi o precursor deste movimento em 1996 defendendo a eliminação de estudos deste tema da literatura. A sua proposta teve grande repercussão e obteve respostas tanto de acordo quanto discordante. A defesa destes modelos feita por Sugiyama et al. [10] em 1999 discute a realidade do esforço não conservativo em exemplos como discos de freio, mangueiras e foguetes. Argumenta ainda que os modelos simplificados, como a coluna de Beck, mantêm as características fundamentais de estabilidade. Deve ser lembrada aqui a existência, modernamente, de sensores e atuadores generalizados que certamente exercem ações não conservativas, podendo induzir respostas dinâmicas instáveis.

Alguns experimentos foram realizados visando a validação de alguns modelos simplificados clássicos. Entre eles vale destacar os realizados por Sugiyama et al. [11,13] e por Bigoni \& Noselli [14]. O ensaio reportado por Sugiyama et al. corresponde a um modelo simplificado de um foguete, estrutura livre-livre, por uma coluna de Pflüger [11] e um modelo mais refinado considerando também a massa distribuída ao logo do comprimento [13] (Figura 2.10). A perda de estabilidade dinâmica foi verificada, porém devido ao curto tempo de ensaio, inferior a 10 segundos, não foi possível uma comparação com as cargas críticas teóricas dos modelos clássicos. O ensaio realizado por Bigoni \& Noselli, notavelmente mais simples, foi capaz de validar experimentalmente a carga crítica da coluna de Ziegler. A carga seguidora foi idealizada no ensaio 
através do atrito entre uma roda acoplada na extremidade da coluna e uma placa de alumínio em movimento uniforme (Figura 2.11).

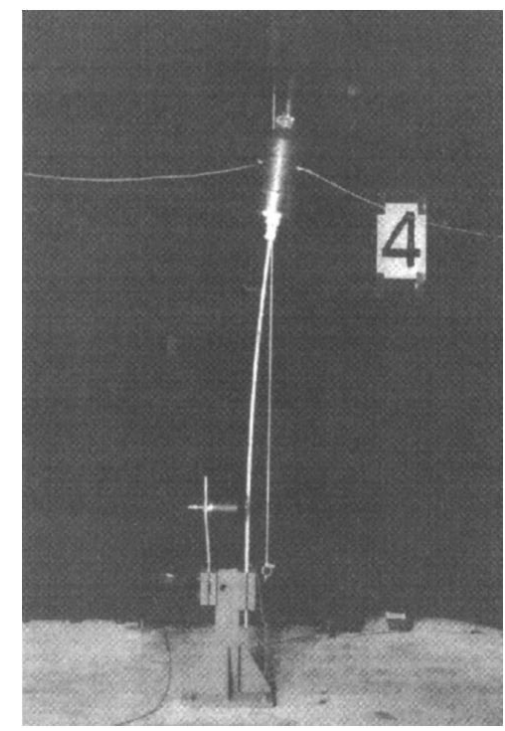

(a)

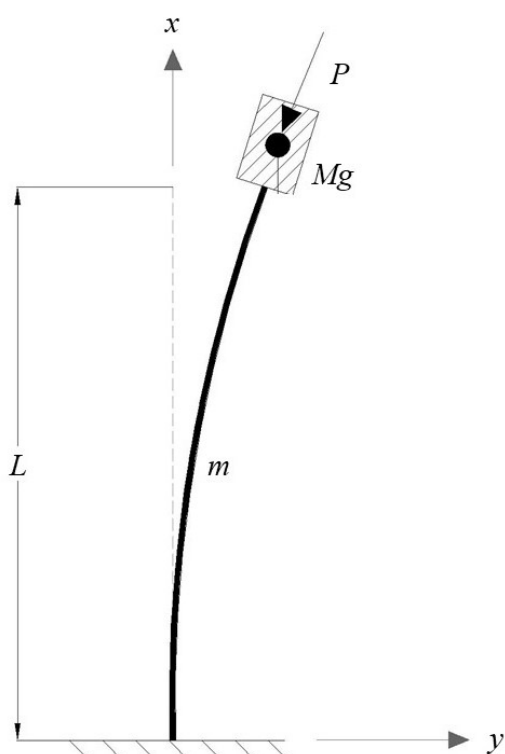

(b)

Figura 2.10 - Ensaio de Sugiyama et al.: (a) Foto do sistema utilizado no ensaio [13]; (b) Idealização do modelo

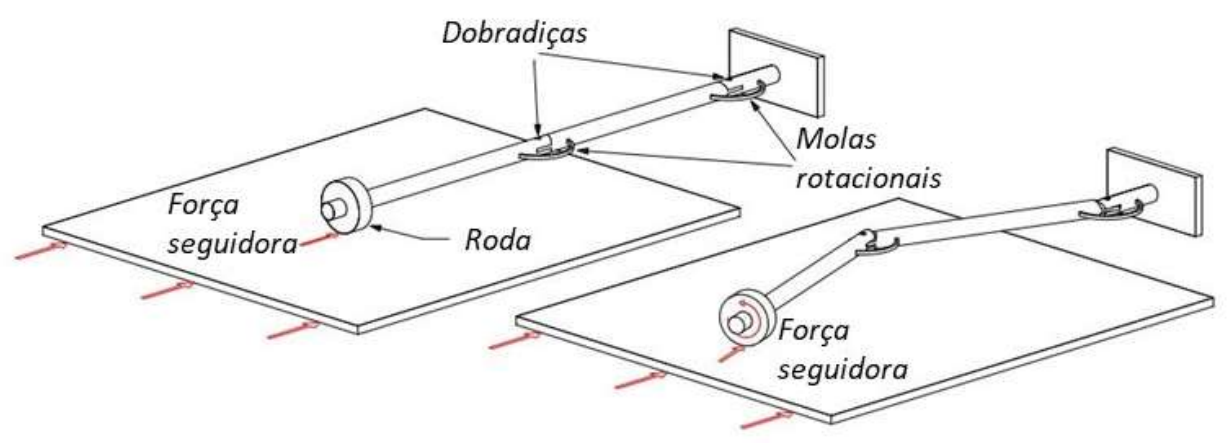

Figura 2.11 - Ensaio Bigoni \& Noselli (adaptado [14])

Com o objetivo de esclarecer certa polêmica que envolvia este tema, Elishakoff [7] publicou em 2005 uma vasta revisão bibliográfica e apresentou uma opinião similar à de Koiter [6]. A justificativa usada, porém, não é feita apenas com base na falta de experimentos, mas também em resultados paradoxais de alguns trabalhos sobre a influência do parâmetro crítico dos modelos clássicos de coluna na presença de base elástica. Assim, por acreditar que o modelo de tubulações com movimento de fluidos (Figura 2.12) tem uma representação do carregamento mais próxima à realidade e apresenta vastos experimentos 
comprobatórios, Elishakoff recomenda a utilização deste modelo em trabalhos futuros. Entretanto, como aqui já mencionado, esquece da questão de sensores e atuadores que podem ser fontes importantes de cargas não conservativas.

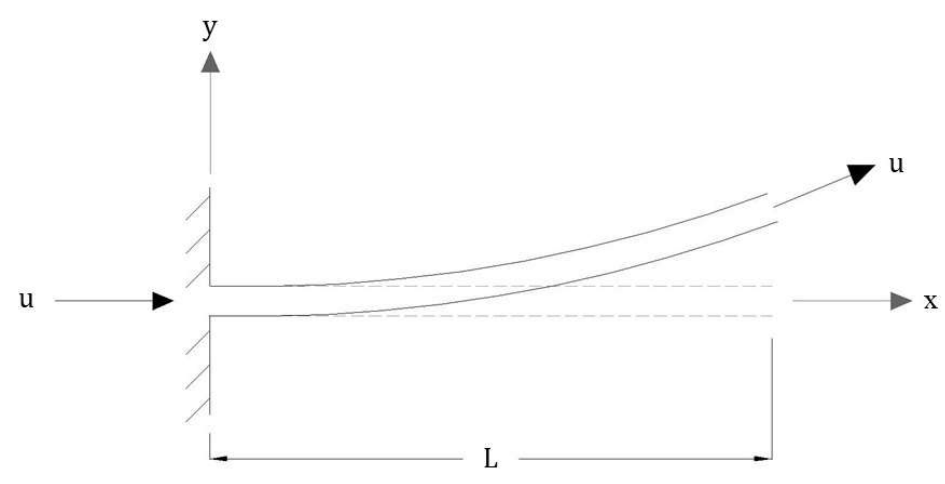

Figura 2.12 - Modelo de tubulação engastada-livre com movimento de fluido

Mesmo antes desses questionamentos, diversos problemas já haviam sido desenvolvidos para análise de instabilidade de tubulações com o modelo sugerido por Elishakoff. O primeiro estudo foi realizado por Bourrières em 1939 ([30] apud [15]) porém devido à segunda grande guerra este foi esquecido. Novos avanços neste tema foram só obtidos cerca de 20 anos depois por pesquisas como a de Benjamin [22] em 1961, Païdoussis \& Gregory [23] em 1966.

A facilidade de realização de experimentos deste modelo é comprovada pela vasta quantidade de trabalhos que obtém grande convergência de resultados com a teoria. Os primeiros ensaios em tubulações com condição de apoio engastada-livre foram realizados por Païdoussis \& Gregory [31] para diferentes tipos de fluido e materiais do tubo e Benjamin [32] para tubos articulados. Outros trabalhos se destacam por uma boa compatibilidade com os resultados teóricos, como Greenwald \& Dungundji ([33] apud [15]), com diferença inferior a 2\%, e Becker et al. ([34] apud [15]), que mesmo ao utilizar um simples ensaio com canudos obtiveram diferença inferior a $6 \%$.

O modelo da coluna de Beck, com carga seguidora concentrada na extremidade, e o modelo de tubulação com movimento de fluido na condição engastada-livre se diferenciam apenas pela contribuição do termo associado à força de Coriolis. A contribuição da Força de Coriolis pode ser comparada ao efeito de um amortecimento interno no modelo de coluna [9], para pequenas magnitudes o efeito é desestabilizador, já para maiores tem-se um efeito estabilizador $[9,15]$.

Sendo um dos argumentos utilizados por Elishakoff [7], a presença da força de Coriolis traz como consequência a diferença da resposta do sistema quanto a presença de base elástica no estudo de estabilidade. Primeiro estudado por Smith \& Hermann [8] e depois generalizado por Elishakoff \& Wang [35], o modelo da coluna de Beck apresenta indiferença no parâmetro crítico ao 
incorporar a base elástica ao longo de todo o comprimento da coluna. $\mathrm{O}$ mesmo resultado também foi obtido por Kim et al. [36] para o modelo de coluna de Leipholz. A presença da base elástica, para esses sistemas, resulta apenas em um aumento das frequências de vibração. $\mathrm{O}$ esperado, dentro de um conceito quase estático, porém, seria que o aumento de rigidez do sistema obtida pela introdução da base elástica resultasse em um efeito estabilizador. Portanto, o aparente paradoxo decorre de um erro de interpretação do fenômeno, ao se utilizar de um conceito estático de carga de flambagem em um problema regido pela troca de energias entre dois modos de vibração. $\mathrm{Na}$ carga crítica, haverá vibrações em "flutter" apresentando frequências crescentes cujas amplitudes se reduzem com o aumento da rigidez da base elástica, por limitação da energia externa introduzida no sistema. Portanto, não há contradição nem paradoxo no resultado preconizado por Hermann e Smith. Isto é confirmado no modelo desenvolvido nesta dissertação, cujos resultados são apresentados no Cap. 4.

Já para o modelo de tubulações a presença de base elástica resulta sim em um aumento do parâmetro crítico. O efeito estabilizador no sistema foi comprovado em estudos feitos por Lottati [9] para base elástica de Winkler. Djondjorov et al. [37] e Marzani et al. [38] deram continuidade a este estudo analisando a influência de bases elásticas não simétricas e não uniformes, também observando o seu efeito estabilizador.

Apesar das diferenças entre as respostas dos modelos de coluna e do modelo de tubulação para a influência da base elástica, o estudo de influência de apoios elásticos na extremidade livre dos sistemas demonstra consistência entre eles. Para ambos os modelos a adição de um apoio elástico na extremidade pode resultar em uma súbita perda de estabilidade por divergência. Esse fenômeno foi investigado para a coluna de Beck por Sundararajan [39] e Suanno [40] e para a coluna de Leipholz por Venuraju \& Ramu [41] através de um processo incremental de rigidez de um apoio elástico translacional (Figura 2.13 (a) e (b)). O incremento de rigidez do apoio para um valor inferior ao definido como limite tem efeito estabilizador e a perda de estabilidade ocorre por "flutter". Já para valores de rigidez superiores a esse limite o processo de perda de estabilidade se altera para divergência, e o incremento de rigidez apresenta efeito desestabilizador. 


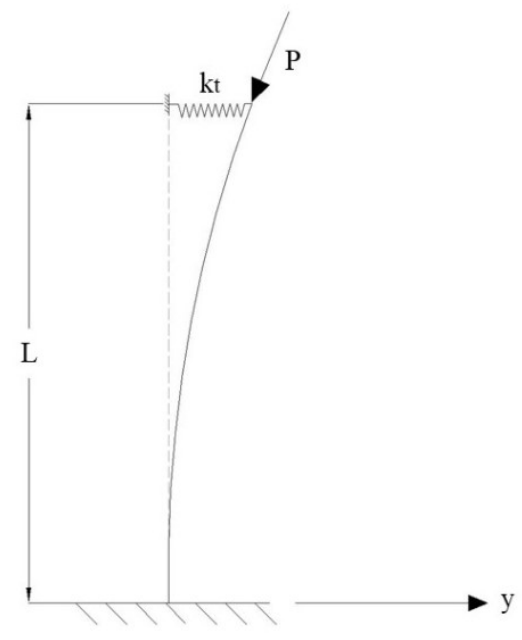

(a)

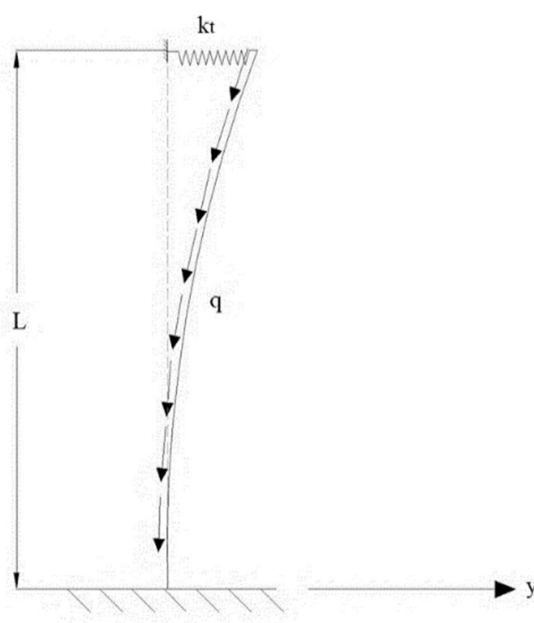

(b)

Figura 2.13 - Modelo de coluna com apoio elástico translacional com: (a) Carga concentrada na extremidade; (b) Carregamento distribuído.

Um fenômeno similar a esse foi observado experimentalmente por Benjamin [32] ao adicionar um apoio exercido pelo contato de seu dedo com a extremidade do tubo e depois comprovado por Sugiyama et al. [42]. No experimento realizado por Benjamin uma tubulação engastada livre de dois graus de liberdade foi submetida a uma certa velocidade em que o sistema se encontrava estável. Porém, ao adicionar um apoio mesmo que leve exercido pelo dedo na extremidade o sistema subitamente perdia estabilidade estaticamente.

Sugiyama et al. [42] compararam as previsões teóricas com experimentos ao analisar o efeito da rigidez do apoio elástico e da posição deste ao longo de uma tubulação contínua na estabilidade do sistema. As mesmas conclusões obtidas no modelo analítico de coluna foram observadas no experimento: após uma determinada rigidez elástica da mola, havia uma mudança do comportamento crítico para divergência, sendo observado então um efeito desestabilizador do incremento de rigidez. Observou-se que a posição do apoio elástico na extremidade $\mathrm{x}=\mathrm{L}$ teve maior efeito desestabilizador que as demais analisadas $(x$ $=0,25 L, x=0,5 L$ e $x=0,75 L)$.

Em uma análise numérica feita por Noah \& Hopkins [43] para o modelo de tubulação, este fenômeno também foi observado tanto para o apoio elástico translacional como para o rotacional (Figura 2.14). Foi analisada também a influência conjunta dos dois apoios na extremidade, uma condição de engaste parcial, sendo observado que combinações com rigidez de mola superiores aos limites individuais ainda permitiriam a instabilidade dinâmica. Assinalou-se então que nesse caso o comportamento do sistema não dependeria apenas do valor 
individual de rigidez elástica de cada apoio, mas também da relação entre suas magnitudes.

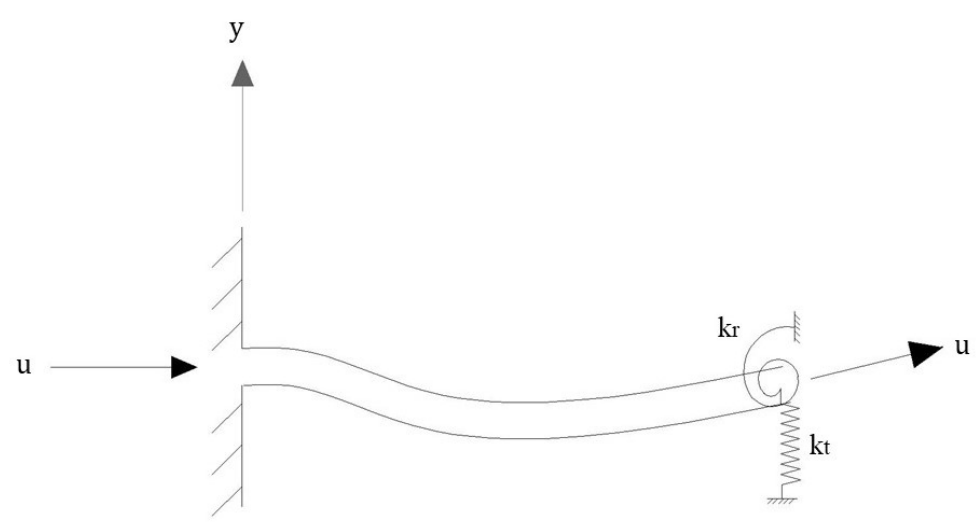

Figura 2.14 - Modelo de tubulação com apoio elástico translacional e rotacional 


\section{Formulação das Equações Matriciais para Determinação da Carga Crítica e Implementação do Programa Computacional}

\subsection{Introdução}

Neste capítulo desenvolve-se a formulação utilizada para descrever o problema de estabilidade do modelo de coluna sujeita a um carregamento não conservativo do tipo circulatório. Esta formulação foi desenvolvida de modo a permitir e facilitar a análise de influência de base elástica e diferentes condições de contorno.

Além disso, faz-se a descrição do programa desenvolvido no MATLAB com a finalidade de determinar o parâmetro e condição crítica de uma coluna submetida a diferentes condições de contorno e tipo de carregamento.

\subsection{Obtenção das Equações Matriciais}

Foi admitido um material de comportamento elástico, com pequenos deslocamentos e deformações e rotações moderadas. Não foram considerados na análise os efeitos de cisalhamento e inércia rotacional. As deformações axiais são consideradas pequenas, não sendo incluídas na descrição do campo de deslocamento, baseando-se a formulação na configuração inicial do elemento de viga [44].

$\mathrm{O}$ vetor generalizado de deslocamentos $w$ é descrito como o produto entre duas funções $N(x)$ e $d(t)$, dependentes da coordenada espacial $x$ e do tempo $t$ respectivamente.

$$
w(x, t)=N(x) d(t)
$$

onde a função $N(x)$ é descrita através do método apresentado no item seguinte e $d(t)$, vetor de deslocamentos nodais generalizados, é descrito por

$$
d(t)=\sum_{j=i}^{n} \bar{D}_{j} e^{i \Omega_{j} t}
$$

sendo $\bar{D}_{j}$ a amplitude de uma das funções de aproximação $j$ em um certo modo de vibração, cuja frequência corresponde à $\Omega_{j}$ e a letra $i$ corresponde à unidade imaginária.

Cabe ressaltar que diversos trabalhos se destacam por avaliarem com maior profundidade algumas das simplificações adotadas neste trabalho, como os 
realizados por Suanno [40] e Inch [45].Ambos avaliaram a influência do efeito de cisalhamento em colunas sujeitas a cargas seguidoras. Além deste efeito, Suanno avaliou também a influência da inércia rotacional e Inch a influência de um modelo constitutivo viscoelástico tanto em elementos de viga quanto em elementos sólidos.

\subsection{Método Utilizado - Rayleigh Ritz}

O elemento adotado é o elemento de viga, cujo campo de deslocamentos é descrito através do método de Rayleigh-Ritz. A formulação do elemento é desenvolvida de acordo com a teoria de vigas de Euler-Bernoulli, sendo necessário o uso de apenas uma função aproximada para descrever os deslocamentos transversais e rotações uma vez que um se relaciona ao outro através da derivação.

A importância do efeito de flexão no processo de flambagem faz com que seja necessário o uso de funções de maior grau na descrição dos deslocamentos do que as utilizadas em uma análise estática de tensões. Assim, os deslocamentos transversais do elemento de viga foram descritos através do enriquecimento das funções do elemento de viga esbelta convencional. Há então a combinação de dois conjuntos de funções para descrever o campo dos deslocamentos, um responsável pela descrição dos deslocamentos da viga a partir dos deslocamentos nodais e outro pelo refino interno da aproximação.

$$
\begin{gathered}
w(x)=\sum_{j=0}^{n} N(x)_{j} d_{j} \\
w(x)=\sum_{i=0}^{4} N_{B}(x)_{i} d_{B i}+\sum_{j=5}^{n} N_{A}(x)_{j} d_{A j}
\end{gathered}
$$

onde:

$$
\begin{aligned}
& N_{B}=\text { funções de forma do elemento de viga Euler-Bernoilli } \\
& N_{A}=\text { funções adicionais } \\
& d_{B}=\text { graus de liberdade associados as funções } N_{B} \\
& d_{A}=\text { graus de liberdade associados as funções } N_{A}
\end{aligned}
$$

$\mathrm{O}$ conjunto de funções $N_{B}$ correspondem às funções convencionais de um elemento de viga do tipo Euler-Bernoulli. Este elemento é composto por quatro graus de liberdade, $d_{B}$, sendo dois em cada extremidade representando o deslocamento e rotação nodal, Figura 3.1. 


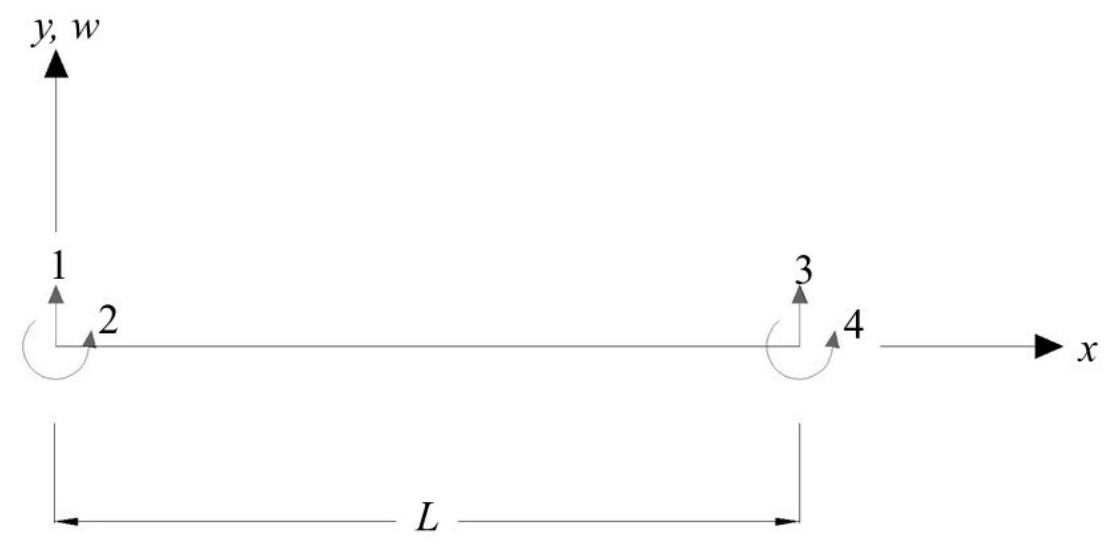

Figura 3.1 - Representação do elemento de viga com os quatro primeiros graus de liberdade.

As funções de forma convencionais $N_{B}$ são dadas por:

$$
\begin{gathered}
N_{B}(x)_{1}=1-\frac{3 x^{2}}{L^{2}}+\frac{2 x^{3}}{L^{3}} \\
N_{B}(x)_{2}=x-\frac{2 x^{2}}{L}+\frac{x^{3}}{L^{2}} \\
N_{B}(x)_{3}=\frac{3 x^{2}}{L^{2}}+\frac{2 x^{3}}{L^{3}} \\
N_{B}(x)_{4}=-\frac{x^{2}}{L}+\frac{x^{3}}{L^{2}}
\end{gathered}
$$

em que cada se relaciona ao seu respectivo grau de liberdade representado na Figura 3.1.

As funções adicionais, $N_{A}$ são desenvolvidas de forma a gerarem deslocamentos e rotações nulos nas extremidades do elemento, contribuindo apenas para melhorar a interpolação dos deslocamentos e rotações ao longo do elemento. De acordo com a teoria de vigas esbeltas, em que a primeira derivada da função que descreve o deslocamento representa a rotação. Com isto as condições de contorno das funções adicionais devem ser

$$
N_{A}(0)_{n}=0 ; N_{A}(L)_{n}=0 ; N_{A}^{\prime}(0)_{n}=0 ; N_{A}^{\prime}(L)_{n}=0
$$

onde ( )' representa a derivação na coordenada espacial $x$. Tais condições são atendidas para as $n$ funções a serem incorporadas no modelo.

Essa característica é aqui garantida pela combinação de um polinômio de terceiro grau e uma função seno. Este conjunto de funções adicionais pode ser interpretado como uma função generalizada da série de Fourier. 


$$
N_{A}(x)_{n}=-\frac{n \pi}{L} x+\frac{n \pi}{L^{2}}\left[2+(-1)^{n}\right] x^{2}-\frac{n \pi}{L^{3}}\left[1+(-1)^{n}\right] x^{3}+\sin \left(\frac{n \pi x}{L}\right)
$$

As Figuras 3.2 (a), (b) e (c) apresentam as três primeiras funções adicionais, parcelas que contribuem para o refino do deslocamento. Estas figuras exemplificam os comentários feitos acima a respeito da imposição de deslocamentos e rotações nulos na extremidade do elemento.

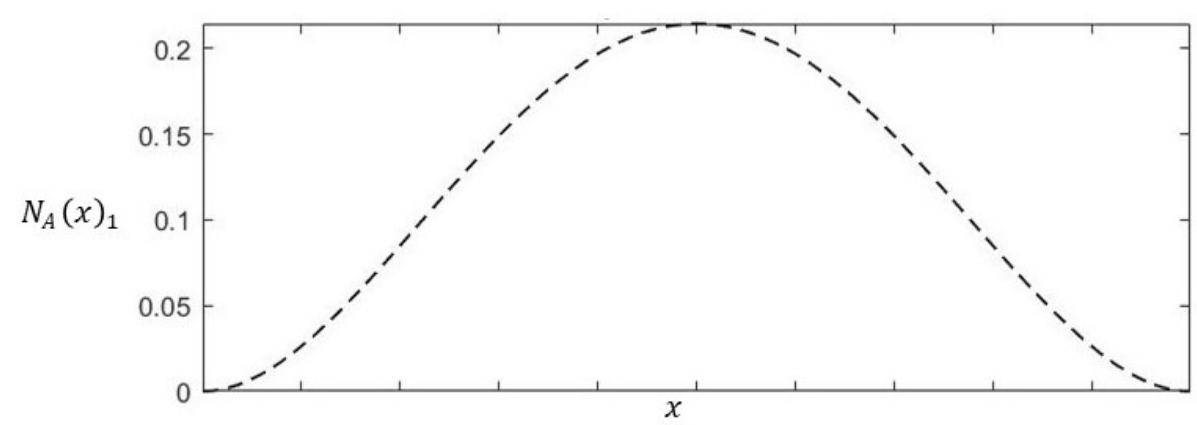

(a)

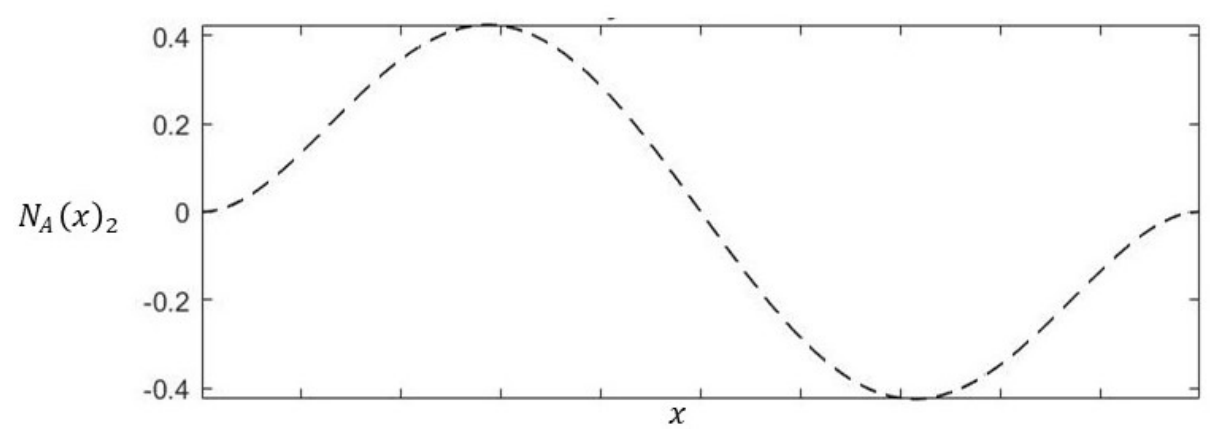

(b)

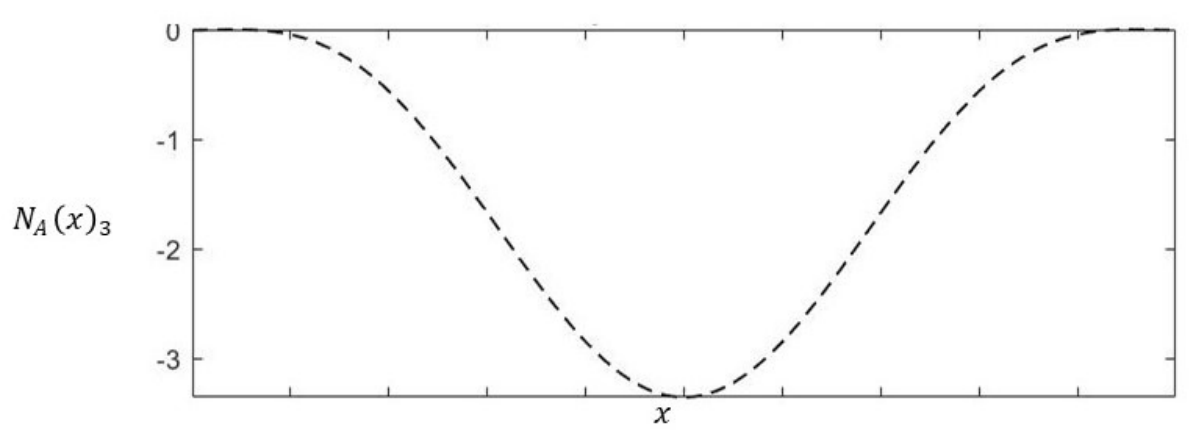

(c)

Figura 3.2 - Funções adicionais: (a) $n=1$; (b) $n=2$; (c) $n=3$.

O desenvolvimento da solução da deflexão do elemento está em função do número de funções adicionais à serem inseridos na discretização. Quanto maior o 
número de funções, maior será a precisão do método. O número ótimo a ser incorporado no modelo deve ser determinado através de processo de convergência do resultado.

Alguns benefícios do uso deste método de aproximação foram determinantes para a sua escolha como o baixo número de graus de liberdade e um refinamento da solução com maior significado físico, não sendo necessárias informações sobre nós adicionais. O principal benefício, porém, foi que através da escolha das funções de aproximação, uma variedade de condições de contorno pode ser facilmente imposta através de um método análogo ao método da penalidade. Este tópico vai ser abordado no item $3.7 \mathrm{em}$ detalhe.

\subsection{Matriz de Massa e de Rigidez Tangente}

O desenvolvimento da formulação matricial é feito através de considerações dinâmicas, a partir da equação do princípio de Hamilton estendido,

$$
\delta \int_{t_{1}}^{t_{2}} L d t+\int_{t_{1}}^{t_{2}} \delta W^{n c} d t=0 .
$$

O Lagrangeano descrito na equação (3.8) pode ter a parcela relacionada a energia cinética escrita como:

$$
T=\frac{1}{2} \dot{w}_{i} M_{i, j} \dot{w}_{j}
$$

onde o ponto simboliza a derivação no tempo $t$ e $M_{i, j}$ corresponde à matriz de massa do elemento, descrita por

$$
M_{i, j}=\int_{L} m N_{i} N_{j} d L
$$

sendo $m$ é a massa linear do material.

Dessa forma, o elemento é descrito através de uma matriz consistente de massa, opção mais adequada para avaliar a estabilidade dinâmica de estruturas sujeitas a cargas seguidoras pois, de acordo com Suanno \& Silva [46], o uso de distribuição concentrada de massas ("lumped masses") pode levar a erros acentuados ao se estimar a carga de coalescência das frequências, como por eles exemplificado para as colunas de Beck e Leipholz (a coluna de Leipohlz mostrando-se mais sensível).

A energia de deformação interna é descrita como:

$$
U=\frac{1}{2} w_{i} K_{i, j}^{t} w_{j}
$$


onde $K_{i, j}^{t}$ representa a rigidez tangente. A matriz tangente é descrita pela a soma de duas parcelas [47],

$$
K_{i, j}^{t}=K_{i, j}^{E}+K_{i, j}^{G} .
$$

Enquanto a matriz de rigidez elástica está associada à configuração indeformada da estrutura, a matriz de rigidez tangente considera as deformações da estrutura durante a aplicação da carga. A matriz $K^{G}{ }_{i, j}$ representa então a não linearidade do sistema e, para sistemas com baixa não-linearidade, pode ser relacionada a um parâmetro de carga. Sendo elas descritas como:

$$
\begin{gathered}
K_{i, j}^{E}=\int_{L} E I w_{i}^{\prime \prime} w_{j}^{\prime \prime} d L \\
K_{i, j}^{G}=\int_{L}\left(\int_{A} \sigma w_{i}^{\prime} w_{j}^{\prime} d A\right) d L
\end{gathered}
$$

onde $E$ é o módulo de elasticidade do material, $I$ o momento de inércia e $\sigma$ a tensão ao longo da seção transversal de área $A$ e ( )" representa a segunda derivada em relação à coordenada espacial.

\subsection{Matriz de Rigidez Associada ao Comportamento da Carga}

As estruturas submetidas a carregamentos dependentes de deslocamentos devem ter seus vetores de carregamento reescritos em função dos graus de liberdade [48, 49]. São incorporados a estes vetores, matrizes capazes de descrever o comportamento da carga a medida que a intensidade da carga aumente e a estrutura se deforme.

As cargas dirigidas à um ponto, classificadas como conservativas, tem seu vetor de força descrito por:

$$
f_{i}^{\prime}=K_{i, j}^{L} d_{j}
$$

sendo esta matriz que relaciona o vetor de força $f_{i}$ ao vetor de deslocamento $d_{j}$.

Vale ressaltar que por ser conservativa, esta carga é derivada de um potencial, porém a dependência do deslocamento faz com que o potencial associado à esta carga seja quadrático, diferentemente das cargas de direção constante.

$$
\begin{gathered}
W_{\text {linear }}=f_{i} d_{i} \\
W_{\text {quad }}=W_{\text {linear }}+\frac{1}{2} d_{i} K_{i, j}^{L} d_{j}
\end{gathered}
$$

onde $f_{i}$ corresponde ao vetor de cargas com direção constante. 
Para o carregamento do tipo circulatório, dependente do deslocamento e não conservativo, i. e., não há um potencial associado a ele, é necessário incorporar o efeito em forma incremental através de

$$
\begin{aligned}
\delta W^{n c} & =\sum f_{i} \delta d_{i} \\
f_{i}^{n c} & =K_{i, j}^{n c} d_{j}
\end{aligned}
$$

onde $f^{n c}{ }_{i}$ corresponde ao vetor de cargas seguidoras e $K^{n c}{ }_{i, j}$ a matriz que relaciona o carregamento ao vetor de deslocamento $d_{j}$.

O processo de obtenção das matrizes $K_{i, j}^{L}$ e $K^{n c}{ }_{i, j}$ é bastante similar, porém elas se diferenciam quanto à simetria. Os sistemas não conservativos apresentam um caráter não autoadjunto, associado a uma matriz de rigidez tangente não simétrica, representada pela matriz $K_{i, j}^{n c}$. Já os problemas conservativos, em geral de caráter autoadjunto, apresentam a matriz de rigidez tangente simétrica.

Como já descrito anteriormente no ítem 2.6, para determinadas condições de contorno, mesmo que o sistema seja submetido a um carregamento circulatório, ele pode ser classificado como conservativo. Nesse caso ele ainda é caracterizado como de caráter não autodjunto, mas as restrições do sistema alteram a natureza do problema.

As Figura 3.3 e Figura 3.4 apresentam de forma simplificada o processo de obtenção das matrizes associadas ao comportamento da carga para uma carga pontual dirigida a um ponto e outra seguidora, respectivamente.

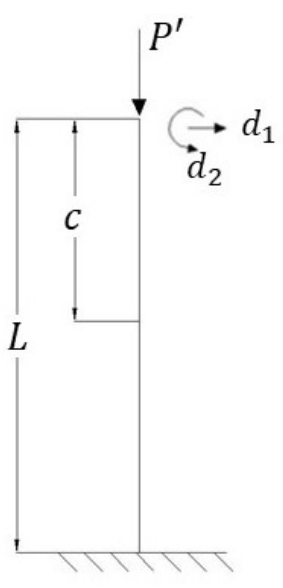

(a)

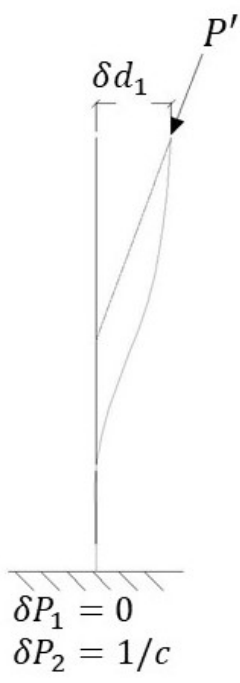

(b)

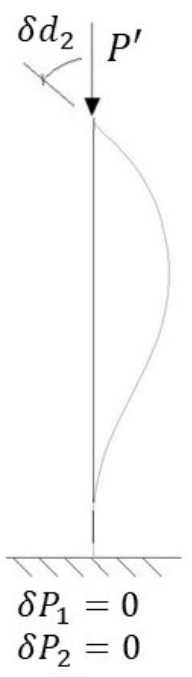

(c)

Figura 3.3 - Matriz de comportamento da carga nodal dirigida a um ponto: (a) coluna indeformada e graus de liberdade; (b) variação no deslocamento $d_{l}$; (c) variação no deslocamento $d_{2}$. 


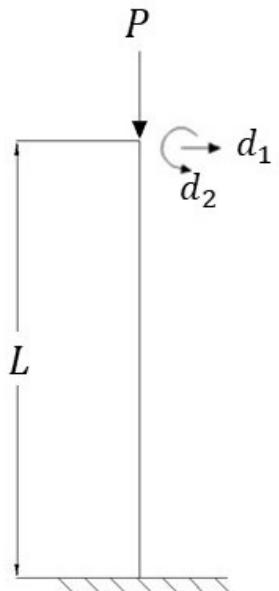

(a)

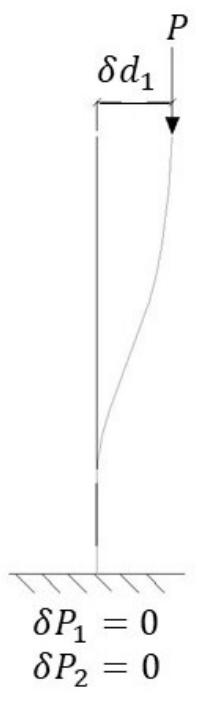

(b)

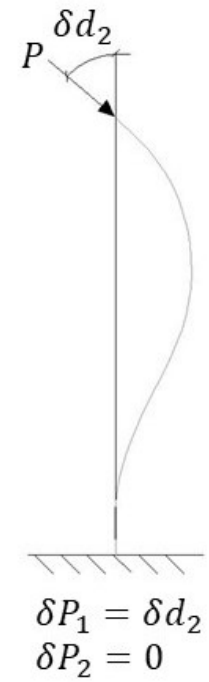

(c)

Figura 3.4 - Matriz de comportamento da carga nodal seguidora $C f$. [40]: (a) coluna indeformada e graus de liberdade; (b) variação no deslocamento $d_{l}$; (c) variação no deslocamento $d_{2}$.

Para o carregamento circulatório contínuo, descrito na coluna de Leipholz, duas abordagens podem ser usadas para descrevê-lo no modelo: aplicação de um carregamento circulatório contínuo ao longo de todo o domínio (Figura 3.5 (a)) ou a subdivisão do domínio em $n$ elementos com forças seguidoras nodais (Figura 3.5 (b) para $n=3$ ). Importa ressaltar que para a segunda opção é necessário um estudo de convergência para que o carregamento seja descrito corretamente.

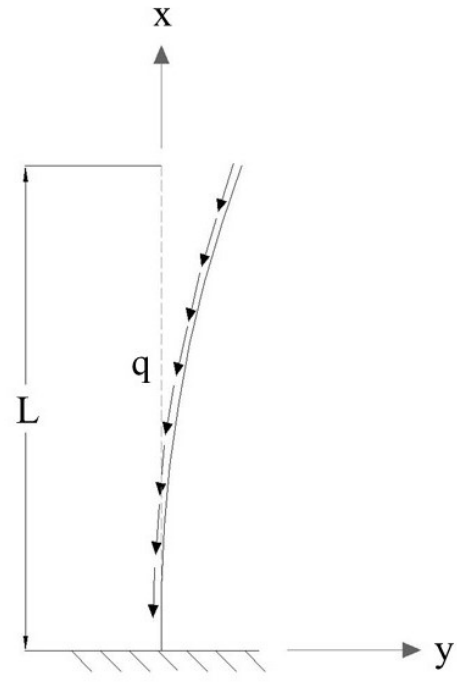

(a)

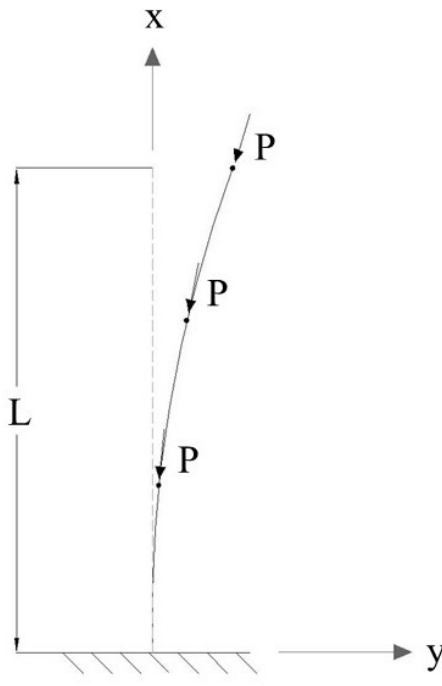

(b)

Figura 3.5 - Coluna de Leipholz: (a) Um único elemento com carregamento contínuo; (b) Três elementos com carregamento nodal. 
Como neste trabalho foi utilizado o método de Rayleigh-Ritz sem subdivisão do domínio, apenas um elemento de viga enriquecido, a primeira opção descrita se mostra mais conveniente e foi adotada. Sendo então a contribuição deste carregamento descrita por

$$
K_{i, j}^{n c I I}=\int_{L} q w_{i}^{\prime} w_{j} d L
$$

\subsection{Base Elástica}

Ao avaliar a estabilidade de um sistema submetido à presença de base elástica a rigidez correspondente a esta ação também deve ser incorporada a análise. Neste trabalho foi avaliada a influência da base elástica de Winkler, cuja a força de reação da base é proporcional à deflexão do elemento em cada ponto. Esta base elástica pode então ser idealizada com molas translacionais, infinitamente próximas, sem resistência ao cisalhamento (Figura 3.6). Assim, a contribuição da rigidez deste elemento é dada por

$$
K_{i, j}^{w}=\int_{L} k w_{i} w_{j} d L
$$

sendo $k$ o módulo elástico da fundação de Winkler.

Caso fosse analisada a influência de uma base elástica não uniforme seria apenas necessário alterar o parâmetro $k$, constante para a base elástica de Winkler, por uma função $k(x)$. A possibilidade de uma base elástica distribuída parcialmente ao longo do elemento também poderia ser facilmente implementada, apenas alterando o domínio da integração para o trecho correspondente.

\subsection{Condições de Contorno}

A escolha das funções de interpolação do método Rayleigh-Ritz para descrever a deformada do elemento de viga permitiu que as características das condições de contorno ficassem restritas apenas nos quatro primeiros graus de liberdade. Assim, de forma similar à consideração da influência da base elástica no modelo, as condições de apoio podem ser idealizadas como molas, nesse caso discretas, translacionais e rotacionais nas extremidades (Figura 3.6). 


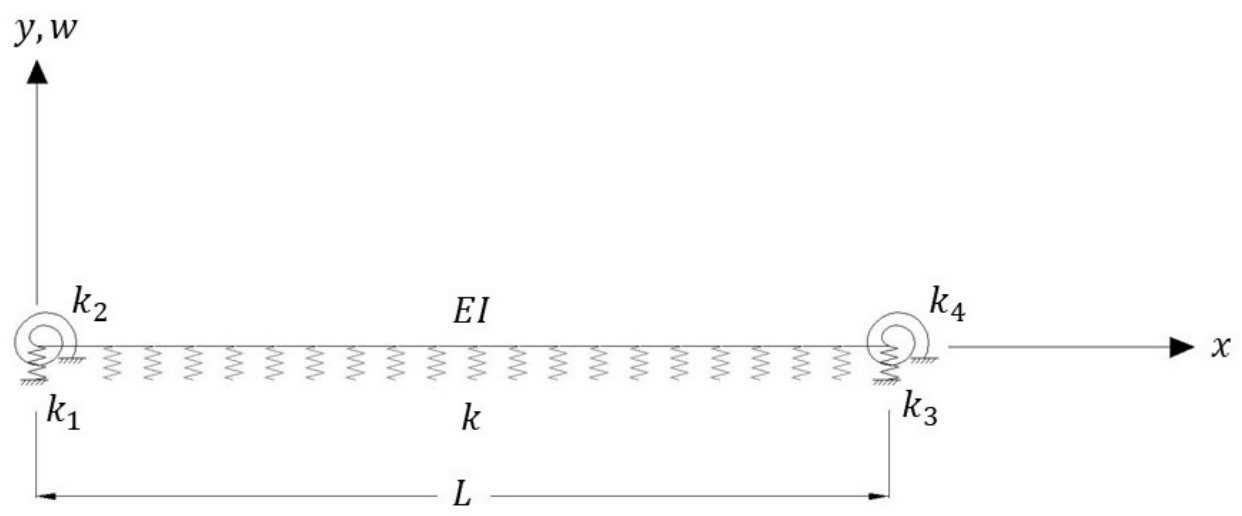

Figura 3.6 - Elemento de viga sob base elástica com apoios elásticos.

A imposição das condições de contorno é feita através de constantes de rigidezes elásticas nas extremidades para deslocamento transversal e rotação. Esse procedimento é análogo ao método da penalidade e o peso incorporado na matriz de rigidez corresponde à constante de rigidez das molas, equação (3.22). Assim, caso o deslocamento seja restrito no nó, é atribuído um valor de rigidez suficientemente grande e quanto maior for seu valor mais restrito o vínculo estará.

$$
K^{c c}=\left[\begin{array}{ccccccc}
k_{1} & 0 & 0 & 0 & \cdots & & 0 \\
0 & k_{2} & 0 & 0 & & & \\
0 & 0 & k_{3} & 0 & & & \\
0 & 0 & 0 & k_{4} & & & \vdots \\
\vdots & & & & 0 & & \\
& & & & & \ddots & \\
0 & & & \ldots & & & 0
\end{array}\right]
$$

No método da penalidade a escolha do parâmetro de penalidade a ser aplicado ao nó com restrição de deslocamento é importante para o condicionamento da matriz. O valor não pode ser superior a um limite, considerado como ótimo, uma vez que a tendência é produzir uma matriz singular ao tender o parâmetro a infinito [47]. Como é sabido, este efeito é muito mais pronunciado quando a restrição imposta via penalidade ocorre envolvendo interação entre dois ou mais deslocamentos (no caso em apreço, cada restrição incide em apenas um deslocamento.)

Para a condição de vínculo restrito foi incorporada uma constante de rigidez suficientemente alta, sendo este valor definido a partir de alguns testes. Já para a condição de deslocamento livre foi adotada uma constante nula. Então, os valores intermediários estão relacionados a restrições parciais, apoios elásticos. 
O estudo da influência dos apoios elásticos foi considerado neste trabalho como a idealização de um sistema estrutural composto por um pilar e uma viga, (Figura 3.7). A constante de mola das restrições elásticas na extremidade $x=L$ está associada aos parâmetros da coluna,

$$
\begin{aligned}
& k_{t}=k_{3} \frac{L^{3}}{E I} ; \\
& k_{r}=k_{4} \frac{L}{E I} .
\end{aligned}
$$

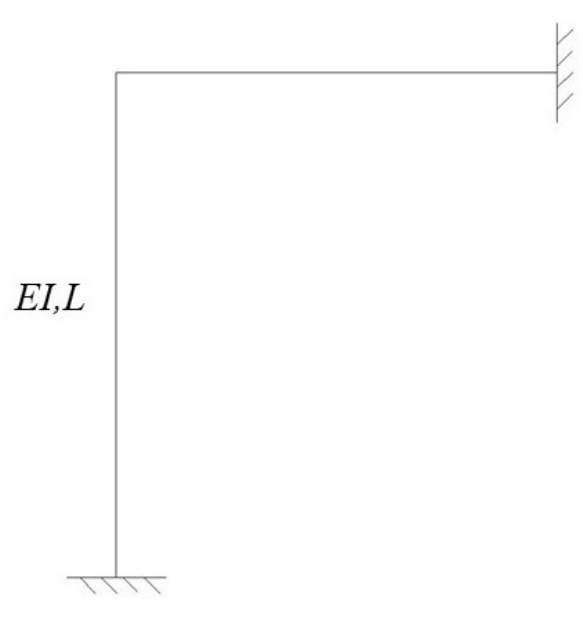

(a)

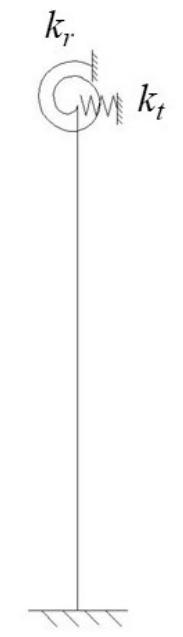

(b)

Figura 3.7 - Idealização do sistema estrutural para análise da influência de apoios elásticos: (a) Sistema composto por viga e coluna; (b) Idealização com apoios elásticos na extremidade da coluna.

\subsection{Obtenção da Carga Crítica: Problema de Autovalor}

A equação de movimento, com as parcelas de energia na forma matricial, pode então ser descrita como:

$$
\int_{t_{1}}^{t_{2}}\left(-\Omega^{2} M+K^{E}+K^{G}+K^{L}+K^{n c}+K^{w}+K^{c c}\right) \bar{D} e^{i \Omega t} d t=0
$$

A independência do tempo $t$ dos termos é possível escrever

$$
\left(K^{E}+K^{G}+K^{L}+K^{n c}+K^{w}+K^{c c}\right) \bar{D}=\Omega^{2} M \bar{D} .
$$


onde:

$K^{E}=$ Matriz de rigidez elástica da estrutura

$K^{G}=$ Matriz de rigidez geométrica

$K^{L}=$ Matriz de correção de carga associada ao carregamento conservativo

$K^{n c}=$ Matriz de correção de carga associada ao carregamento

não-conservativo

$K^{w}=$ Matriz associada a rigidez da base elástica

$K^{c c}=$ Matriz que incorpora as condições de contorno da estrutura

$M=$ Matriz de massa

$\bar{D}=$ Vetor de deslocamentos generalizados

A equação (3.25) caracteriza um problema de autovalor generalizado em que o quadrado das frequências naturais corresponde ao autovalor. Uma vez que os esforços e deformações foram considerados proporcionais ao carregamento que a estrutura é submetida, pode-se reescrevê-la com a inclusão de um parâmetro associado ao nível de carga. Assim, a equação é dada por

$$
\left[K^{E}+K^{w}+K^{c c}+\lambda\left(\bar{K}^{G}+\bar{K}^{L}+\bar{K}^{n c}\right)\right] \bar{D}=\Omega^{2} M \bar{D} .
$$

A análise de estabilidade então, através de um processo incremental de carga e, para cada passo, as frequências naturais são avaliadas. A variação de comportamento das frequências ao incremento de carga é investigada para a determinação do parâmetro crítico de carga e caracterização do tipo de instabilidade.

As frequências do sistema apresentam os seguintes comportamentos, classificados em duas etapas:

\section{Etapa I}

O carregamento aplicado no sistema é baixo, as frequências do sistema são reais e distintas. Assim, quando nessa região o comportamento é classificado como estável e seu movimento permanece limitado.

\section{Etapa II}

Com o aumento do carregamento o sistema pode apresentar duas formas perda de estabilidade: divergência e "flutter". A condição crítica é observada quando pelo menos uma das frequências se torna imaginária, assim o parâmetro crítico é determinado pelo limite desta condição. Caso uma das frequências se 
anule, a instabilidade é por divergência. Este processo, entretanto, não ocorre se o sistema perde estabilidade por "flutter", pois após o parâmetro de carga crítico a frequência se torna complexa sem antes se anular.

Cabe ressaltar que para sistemas conservativos com baixa não linearidade a obtenção do parâmetro crítico pode ser feita de forma bastante simplificada, sem a necessidade de um processo incremental de carga. A análise de estabilidade pode ser feita através de considerações estáticas através da seguinte equação

$$
\left[\left(K^{E}+K^{w}+K^{c c}\right)+\lambda\left(\bar{K}^{G}+\bar{K}^{L}+\bar{K}^{n c}\right)\right] \bar{D}=0 .
$$

\subsection{Implementação}

A formulação desenvolvida nos capítulos anteriores foi avaliada numericamente através de um programa desenvolvido no MATLAB R2016b® [50]. A estabilidade de elementos de coluna foi avaliada através de carregamentos concentrados na extremidade e distribuídos ao longo do elemento, conservativos ou não conservativos do tipo circulatório.

O objetivo do programa é, através de uma análise de estabilidade global, determinar o parâmetro de carga crítico da estrutura bem como o tipo de condição crítica.

\subsubsection{Descrição do Programa}

$\mathrm{Na}$ etapa de introdução dos dados de entrada, primeira etapa do programa, são definidos o tipo de carregamento, constante da base elástica de Winkler, o número inicial de graus de liberdade associados às funções de enriquecimento $\left(n_{g a}\right)$ e as condições de contorno. Esses parâmetros são fundamentais para a determinação da metodologia da solução e em consequência dos resultados a serem obtidos.

Os carregamentos podem ser concentrados na extremidade $x=L$ ou distribuídos através de uma função ao longo do comprimento da coluna. Estes carregamentos podem ser conservativos (de direção constante ou dirigidos a um ponto) ou a não conservativos (com direção variável de acordo com a deformada). O programa também permite diferentes condições de apoio, incluindo apoios elásticos tanto transversais como rotacionais.

Em seguida é feita a montagem das matrizes de rigidez elástica, geométrica e de massa. Caso o sistema esteja submetido à um carregamento dependente do deslocamento, a matriz de rigidez associada a ele é incorporada ao modelo. Assim as matrizes globais do sistema são definidas $K^{E}, K^{G}, M$ (problema de autovalor). 
A análise de estabilidade do sistema é feita através da resolução do problema de autovalor, desenvolvido com o auxílio da função eig do MATLAB. Esta função avalia as características das matrizes do problema, e caso sejam simétricas, positivas e definidas faz-se o uso da fatoração de Choleski (cho algorithm), caso contrário, a decomposição de Shur é utilizada (QZ algorithm). Logo, para os problemas conservativos a análise foi feita através da fatoração de Choleski, já para os não conservativos o algoritmo "QZ" foi utilizado.

A definição do tipo de critério a ser utilizado depende do tipo de carregamento, caso o sistema fosse submetido a apenas cargas conservativas o critério adotado seria o estático. Mesmo gerando mesmos resultados dos obtidos no critério dinâmico essa diferenciação de métodos de cálculo é feita visando agilizar o processo, quando possível. No caso, ao utilizar o critério estático em sistemas conservativos o resultado do problema de instabilidade é obtido em apenas uma etapa.

O critério dinâmico, utilizado nos sistemas não conservativos, é desenvolvido através de um processo incremental de carga. O incremento de carga é variável e à medida que o sistema se aproxima ou ultrapassa de pontos críticos o passo de carga é corrigido de forma que o carregamento crítico do sistema tenha menos de $1 \%$ de variabilidade. As duas opções de perda de estabilidade, dinâmica e estática, são avaliadas e a função retorna tanto o parâmetro crítico como o comportamento das frequências frente ao incremento de carga.

Há então uma análise do número de graus de liberdade associados às funções de enriquecimento $\left(n_{g a}\right)$, sendo feito um estudo de convergência. Nesta análise todas as etapas são refeitas aumentando o número de graus adicionais do modelo. Assim o resultado é gerado apenas quando a variabilidade do parâmetro crítico é pequena ao incremento de graus de liberdade.

\subsubsection{Descrição das Sub-rotinas/ Algoritmo do Programa}

1. Leitura dos dados

1.1. Carregamento

1.2. Condições de contorno

1.3. Graus de liberdade adicionais

2. Monta matrizes globais

2.1. Matriz de rigidez elástica

2.1.1. Impõe as condições de contorno

2.2. Matriz de massa

2.3. Matriz de rigidez geométrica

2.4. Se existir carregamento não conservativo

2.4.1. Matriz associada ao comportamento da carga não conservativa 
3. Determinação da carga crítica

3.1. Se o sistema for conservativo

3.1.1. Utilização do critério estático (energia)

3.2. Se o sistema for não conservativo

3.2.1. Utilização do critério dinâmico

4. Convergência dos resultados

4.1. Aumento do número de graus de liberdade adicionais, repete etapas 2 e 3

4.2. Se a diferença entre o parâmetro crítico anterior e o atual for aceitável

4.2.1. Terminar

Senão

4.2.2. Voltar ao passo 4.1 


\section{Resultados e Análise}

\subsection{Introdução}

Neste capítulo são apresentados os resultados da análise de influência de alguns parâmetros em dois problemas clássicos: coluna de Beck e de Leipholz. Para ambos os problemas, designados como caso I e II respectivamente, são analisadas a influência de base elástica e apoios elásticos, translacionais e rotacionais. As análises são feitas separadamente e depois em conjunto de modo a avaliar melhor a relevância destes parâmetros na estabilidade dos sistemas.

Os resultados são expostos neste capítulo em itens separados de forma a possibilitar uma melhor comparação do comportamento dos sistemas do caso I e II ao avaliar a influência de cada parâmetro. Em sequência faz-se uma breve comparação dos resultados obtidos no modelo de coluna de Beck com o modelo de tubulação engastada livre.

\subsection{Estudo dos Modelos Clássicos de Colunas (Beck e Leipholz)}

Os modelos das colunas de Beck e Leipholz são exemplos clássicos na literatura e se distinguem quanto a distribuição do carregamento do tipo circulatório. Enquanto a coluna de Beck, caso I, apresenta um carregamento concentrado aplicado na extremidade livre da coluna, a coluna de Leipholz, caso II, apresenta um carregamento distribuído ao longo da coluna.

As equações diferenciais parciais que governam os dois modelos são dadas por

$$
\begin{gathered}
E I \frac{\partial^{4} w}{\partial x^{4}}+m \frac{\partial^{2} w}{\partial t^{2}}+k w+P \frac{\partial^{2} w}{\partial x^{2}}=0 \\
E I \frac{\partial^{4} w}{\partial x^{4}}+m \frac{\partial^{2} w}{\partial t^{2}}+k w+q(L-x) \frac{\partial^{2} w}{\partial x^{2}}=0
\end{gathered}
$$

Ambos os problemas foram desenvolvidos através do método descrito no item 3.3, com apenas um elemento de viga esbelto enriquecido com funções adicionais. A exposição dos resultados então, é em forma adimensional através dos parâmetros: 


$$
\begin{gathered}
\omega=\Omega L^{2} \sqrt{\frac{m}{E I}} ; \bar{p}=P \frac{L^{2}}{E I} ; \bar{q}=q \frac{L^{3}}{E I} ; \kappa=\frac{k L^{4}}{E I} \\
k_{t}=k_{3} \frac{L^{3}}{E I} ; k_{r}=k_{4} \frac{L}{E I} .
\end{gathered}
$$

A metodologia implementada neste trabalho foi validada pelo comparativo de valores de referência da literatura do parâmetro crítico e frequência de coalescência para a coluna de Beck $[1,51]$ e de Leipholz $[4,52]$ (Tabela 4.1).

Tabela 4.1- Carga crítica estática e dinâmica das colunas de Beck e Leipholz

\begin{tabular}{cc}
\hline Coluna de Beck & Coluna de Leipholz \\
\hline $\bar{p}_{c r}=20,05$ & $\bar{q}_{c r}=40,06$ \\
\hline$\omega_{c}=11,0$ & $\omega_{c}=11,0$
\end{tabular}

Os gráficos representados nas Figuras 4.1 e 4.2 apresentam a variação das duas primeiras frequências com o incremento de carga, respectivamente associados ao caso I e II. O ponto em que há a coalescência das frequências marca a condição crítica do sistema e o carregamento correspondente é denominado como crítico. Estão representadas, em cada um dos gráficos, duas linhas pretas tracejadas que correspondem ao parâmetro de carga crítico e de frequência de coalescência de referência expostos na Tabela 4.1. Para ambos os casos os resultados apresentam uma ótima correlação com os valores usados como referência. 


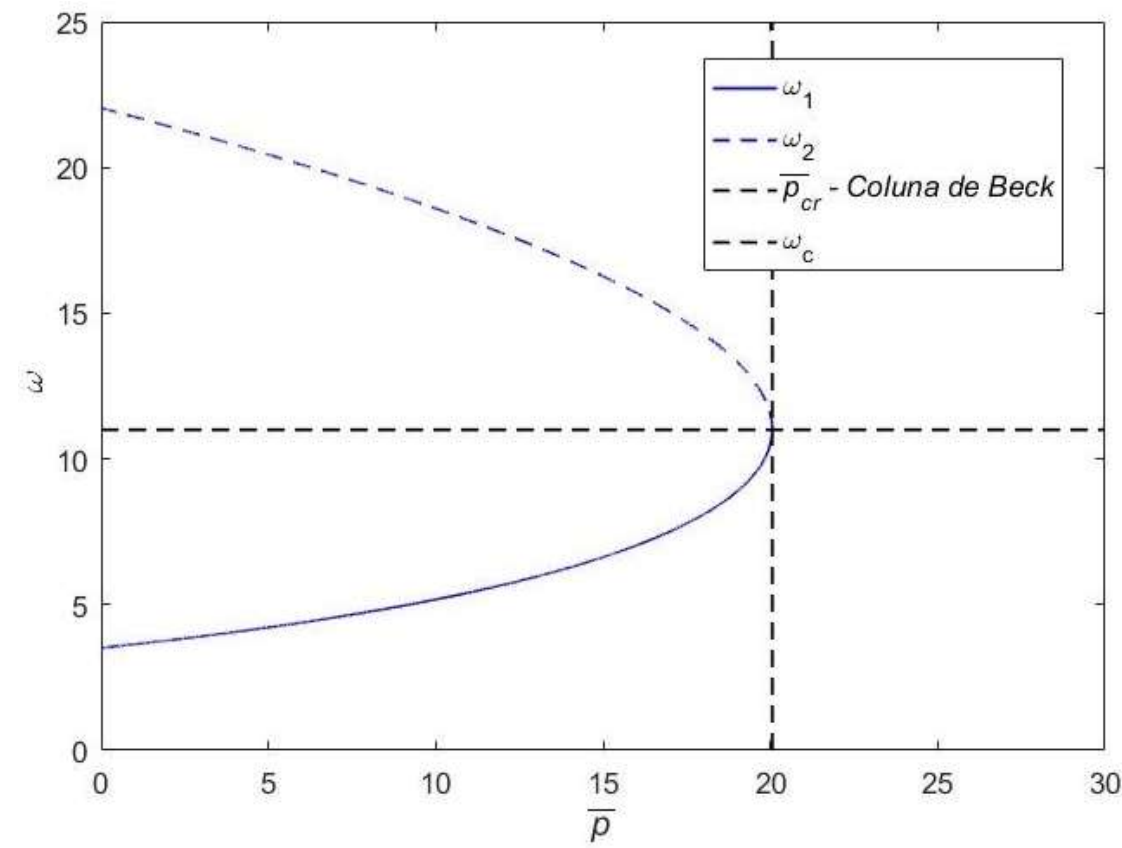

Figura 4.1 - Variação das duas primeiras frequências ao incremento de carga (caso I).

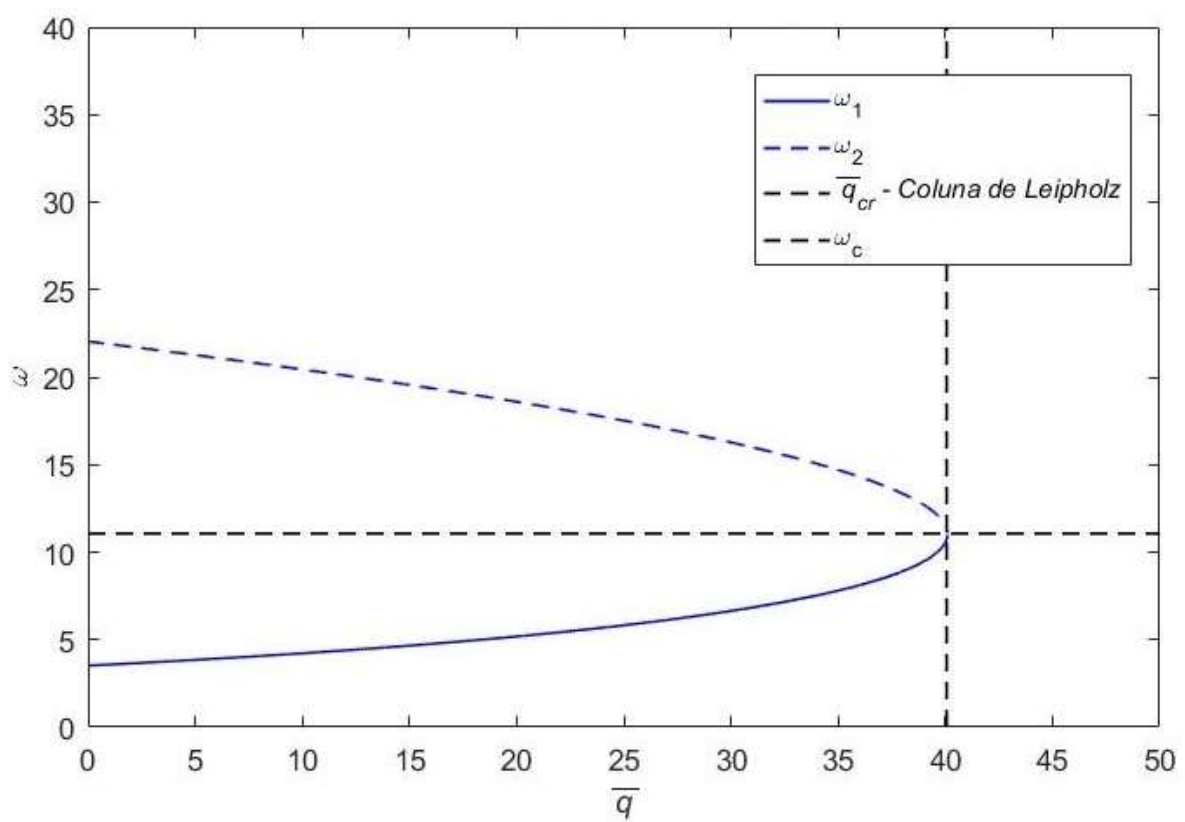

Figura 4.2 - Variação das duas primeiras frequências ao incremento de carga (caso II). 


\subsubsection{Estudo de Convergência}

O estudo de convergência acompanhou todo o processo, desde a análise das versões clássicas até as análises de influência tanto da base elástica quanto dos apoios elásticos, nos dois casos. $\mathrm{O}$ aumento no número de funções adicionais incorporadas na descrição da forma do elemento corresponde a uma melhor aproximação do modelo. Para determinar o número necessário de funções adicionais, considerou-se aceitável uma variação relativa de cerca de $10^{-4}$ entre duas aproximações sucessivas. Assim, nas Figuras 4.3 e 4.4 há a representação da variação das primeiras frequências ao incremento de carga, já apresentada nas Figuras 4.1 e 4.2, porém para diferentes números de graus adicionais $\left(n_{g a}\right)$ incorporados aos respectivos casos I e II.

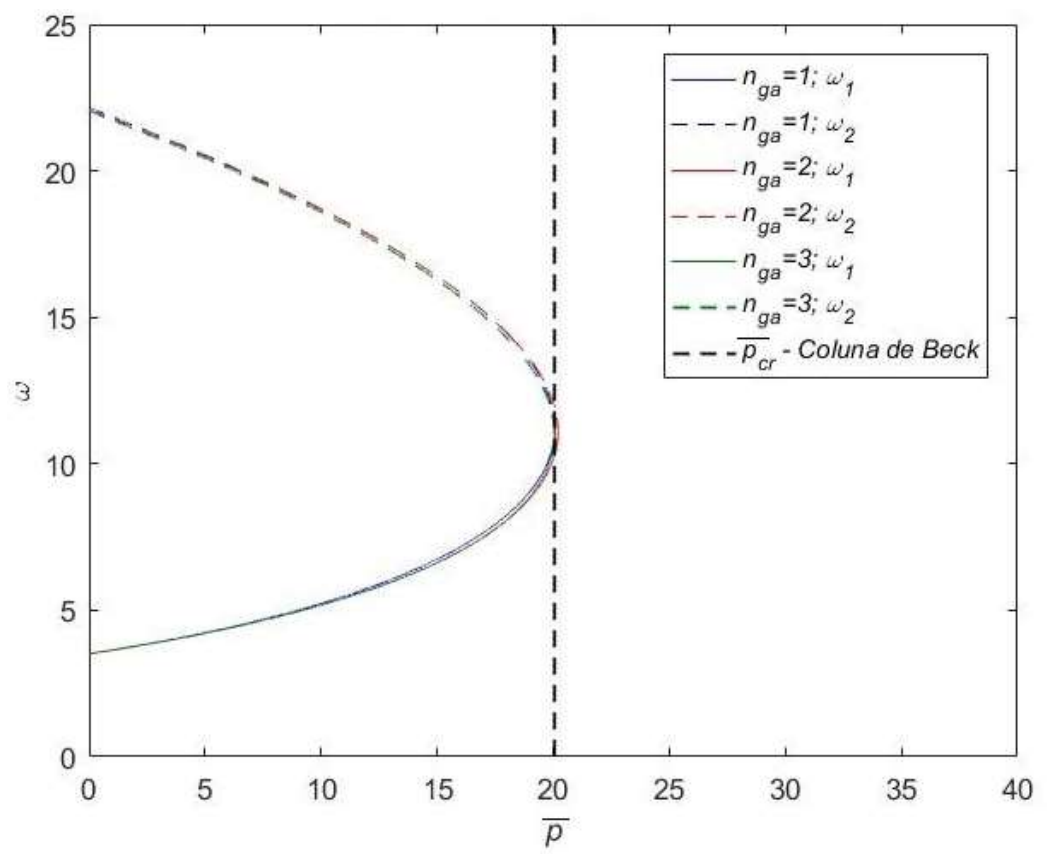

Figura 4.3 - Estudo de convergência (caso I). 


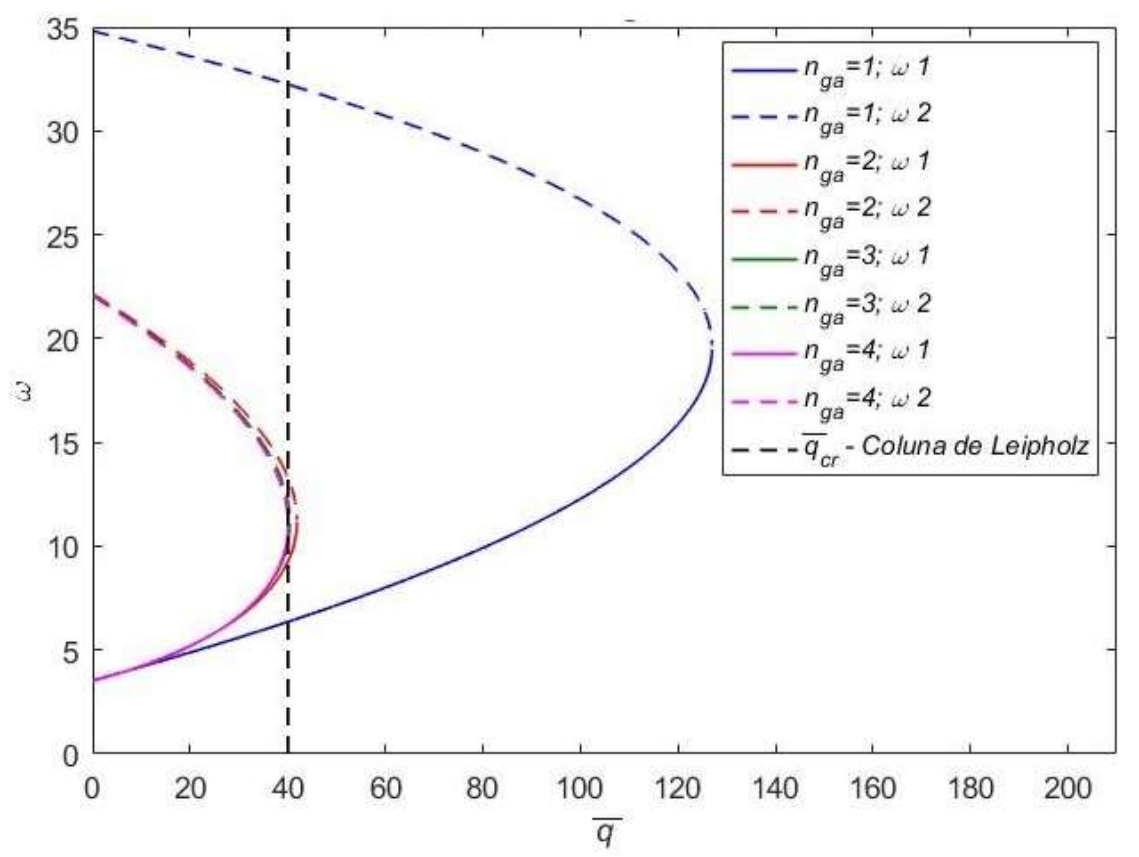

Figura 4.4 - Estudo de convergência (caso II).

O carregamento distribuído ao longo do elemento no caso II faz com que a discretização tenha mais relevância do que no caso I em que o carregamento é nodal e concentrado na extremidade. Assim, nota-se que a convergência das respostas do caso I (Figura 4.3) é perceptível com um número menor de graus adicionais $\left(n_{g a}\right)$ do que no caso II (Figura 4.4).

Durante o processo de análise de influência tanto da base elástica quanto dos apoios elásticos, foi utilizado um número de graus adicionais $\left(n_{g a}\right)$ determinado pela combinação extrema em questão (Tabela 4.2). Esta opção agilizou as análises, uma vez que para o estudo de cada parâmetro era necessário investigar o comportamento do sistema em diversas combinações de valores de constantes de base elástica e de mola associada ao apoio elástico. 
Tabela 4.2 - Número de graus adicionais associados às funções de refinamento $\left(n_{g a}\right)$ utilizado nas análises realizadas.

\begin{tabular}{c|cc}
\hline & Caso I & Caso II \\
\hline $\begin{array}{c}\text { Influência base elástica }(\kappa) \\
\begin{array}{c}\text { Influência do apoio elástico } \\
\text { translacional }\left(k_{t}\right)\end{array}\end{array}$ & $n_{g a}=4$ & $n_{g a}=8$ \\
\hline $\begin{array}{c}\text { Influência do apoio elástico } \\
\text { rotacional }\left(k_{r}\right)\end{array}$ & $n_{g a}=4$ & $n_{g a}=17$ \\
\hline $\begin{array}{c}\text { Influência da combinação dos } \\
\text { apoios elásticos }\left(k_{t} \mathrm{e} k_{r}\right)\end{array}$ & $n_{g a}=11$ & $n_{g a}=8$ \\
\hline $\begin{array}{c}\text { Influência da combinação } \\
\text { apoio elástico com base } \\
\text { elástica }\left(k_{t} \mathrm{e} \kappa ; k_{r} \text { e } \kappa\right)\end{array}$ & $n_{g a}=6$ & $n_{g a}=17$ \\
\hline
\end{tabular}

\subsubsection{Análise da influência da base elástica de Winkler}

A análise de influência da base elástica de Winkler foi feita através da

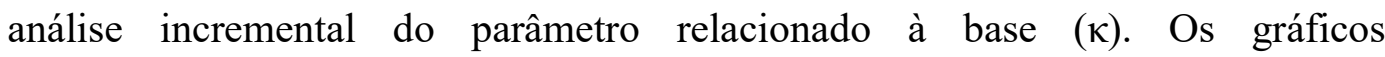
representados nas Figuras 4.5 e 4.6, caso I e II respectivamente, mostram a variação das duas primeiras frequências ao incremento de carga para diferentes valores do parâmetro de base elástica $(\kappa)$. 


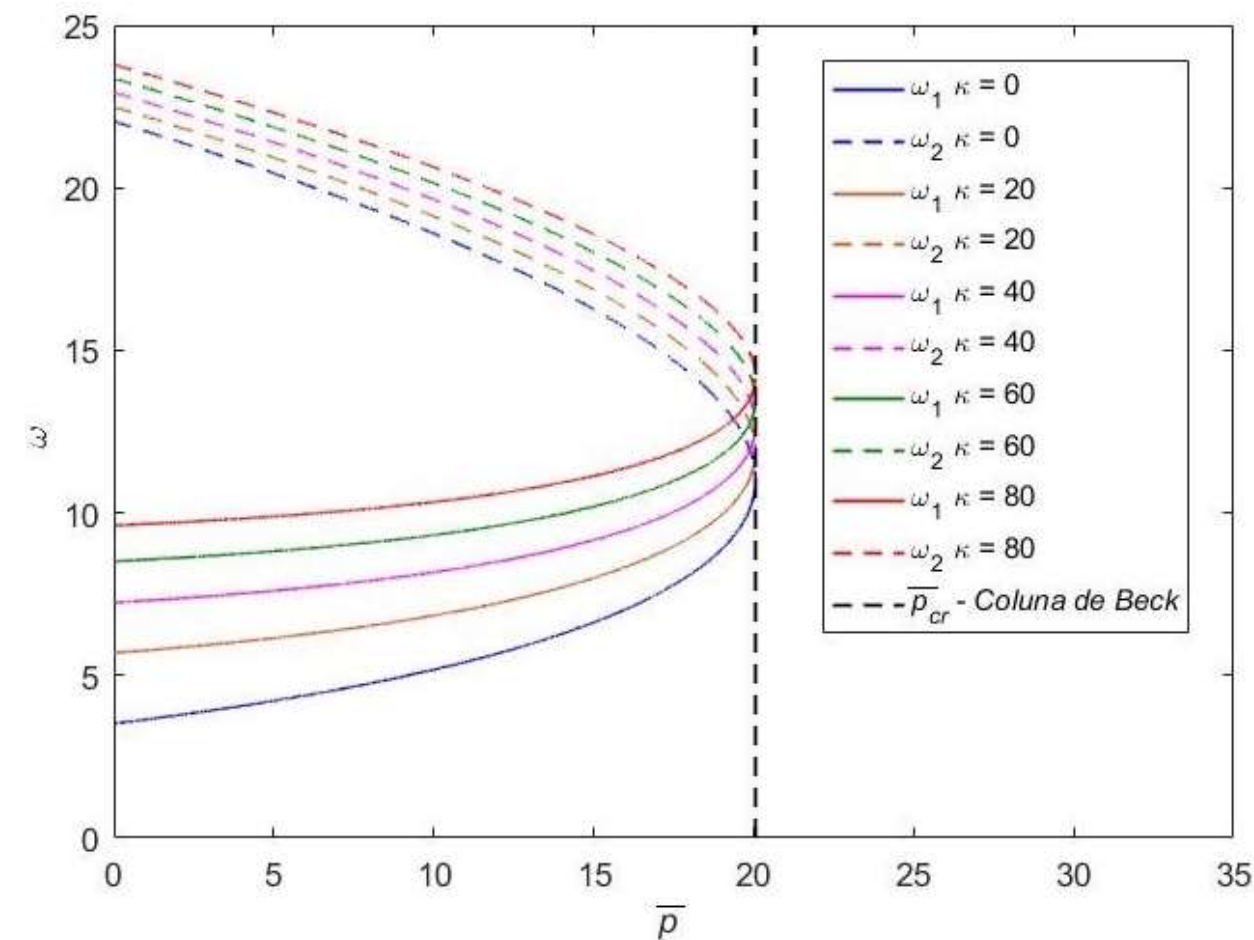

Figura 4.5 - Variação das duas primeiras frequências ao incremento de carga para diferentes valores do parâmetro de base elástica (Caso I).

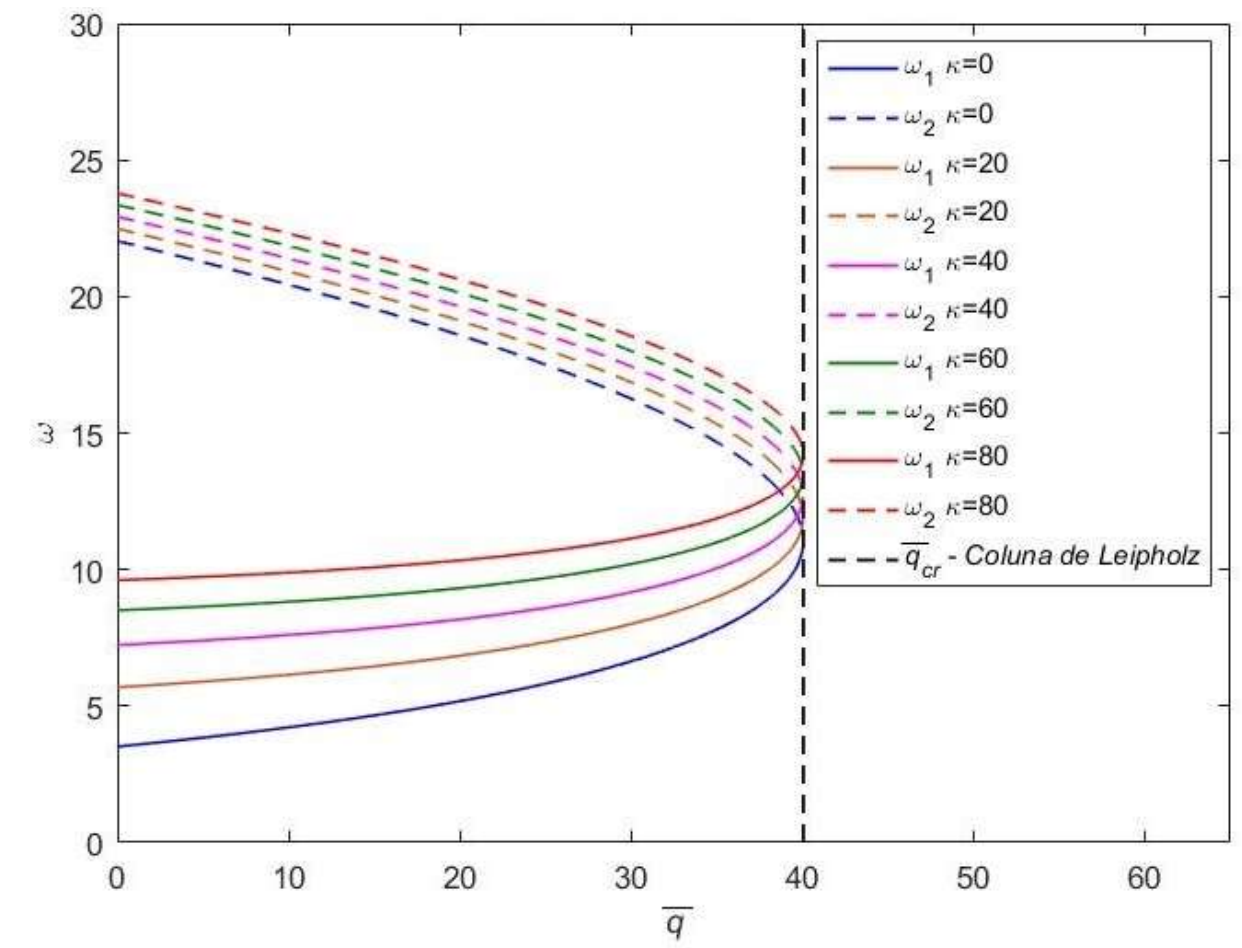

Figura 4.6 - Variação das duas primeiras frequências ao incremento de carga para diferentes valores do parâmetro de base elástica (Caso II). 
O comportamento das colunas de ambos os casos é bastante similar: o acréscimo do parâmetro de base elástica não altera o valor crítico de carga nem o tipo de condição crítica. Ou seja, a perda de estabilidade continua sendo dinâmica e o parâmetro crítico do modelo o mesmo, relacionado ao respectivo sistema na forma clássica, sem base elástica. A principal mudança observada é então o aumento das frequências de coalescência de acordo com o acréscimo do parâmetro $\kappa$.

No gráfico da Figura 4.7 estão representadas de forma discreta as frequências de coalescências das combinações analisadas nos gráficos das Figuras 4.5 e 4.6 e uma função polinomial contínua que melhor descreve a variação das frequências no domínio do parâmetro de base elástica analisado. Destaca-se que em ambos os casos o comportamento das frequências e seus valores é o mesmo, podendo assim ser expresso pela mesma função, um polinômio quadrático que apresenta um bom ajuste aos valores discretos. Como pode ser observado, a variação é muito próxima da linear.

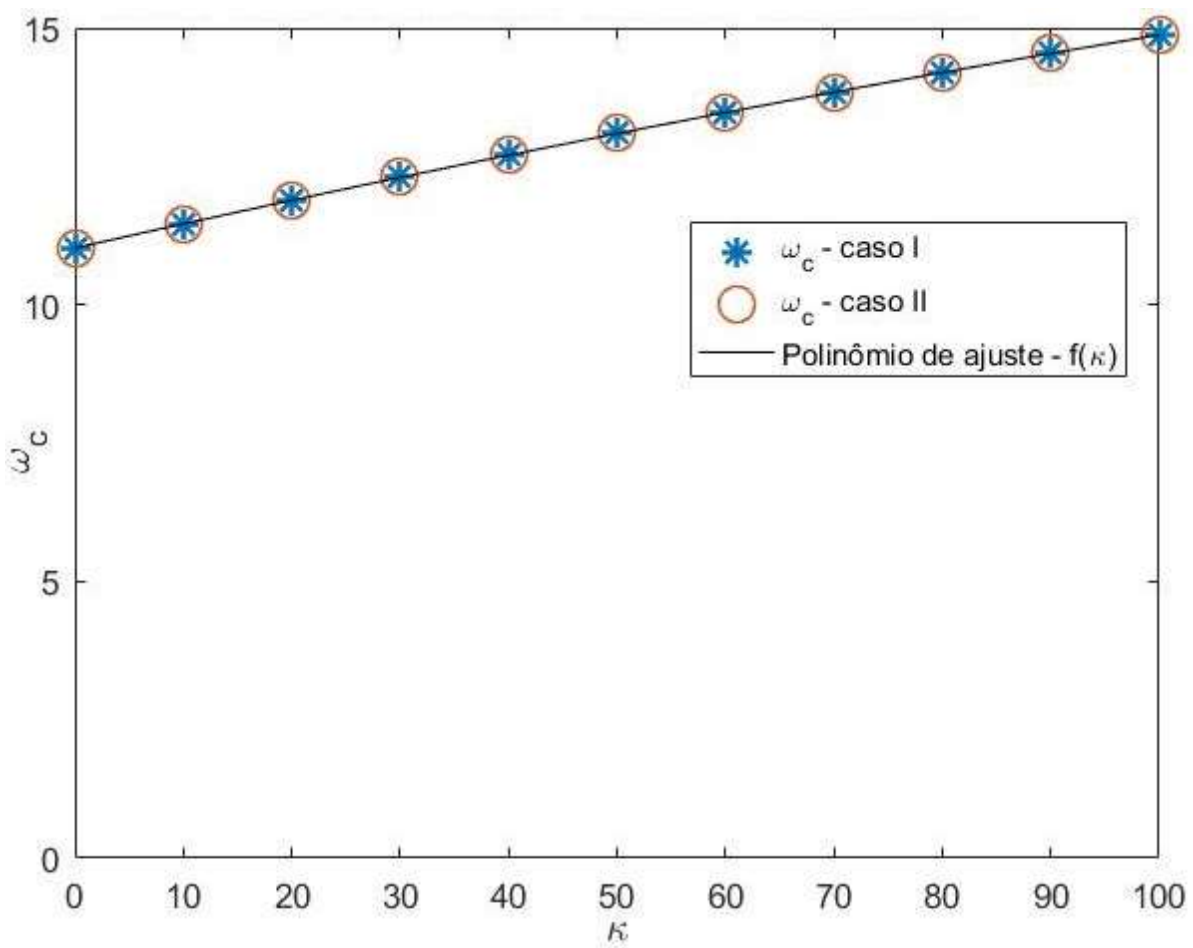

Figura 4.7 - Comportamento das frequências de coalescências dos casos I e II ao incremento de rigidez da base elástica.

Como a perda de estabilidade é caracterizada pela coalescência das frequências, ao sofrerem um aumento proporcional ao acréscimo de $\kappa$, a carga crítica não se altera. A presença de base elástica em sistemas com essa condição crítica não gera um efeito estabilizador, sendo a estabilidade do sistema indiferente à constante de rigidez da base elástica. O resultado descrito é então 
consistente com o obtido por Hermann \& Smith [8] ao analisar a influência em um sistema correspondente ao caso I.

Essa relação de indiferença do parâmetro crítico à presença de base elástica é, entretanto, considerada paradoxal pois, para sistemas conservativos, cuja perda de estabilidade se dá por divergência, a presença de base elástica resulta em um efeito pronunciadamente estabilizador. Essa característica presente no modelo da coluna de Beck é vista como forte argumento para a não representatividade deste modelo [7].

Repetimos aqui o argumento apresentado anteriormente. $\mathrm{O}$ aparente paradoxo decorre de um erro de interpretação do fenômeno, ao se utilizar de um conceito estático de carga de flambagem em um problema regido pela troca de energias entre dois modos de vibração. $\mathrm{Na}$ carga crítica, haverá vibrações em "flutter" apresentando frequências crescentes, cujas amplitudes se reduzem com o aumento da rigidez da base elástica, em virtude da limitação da energia externa introduzida no sistema. Portanto, não há contradição nem paradoxo no resultado preconizado por Hermann e Smith, aqui confirmado.

\subsubsection{Análise da Influência dos Apoios Elásticos}

O estudo de influência dos apoios elásticos foi feito através da análise do comportamento dos casos I e II para restrições elásticas de deslocamento transversal e de rotação, primeiro avaliadas separadamente e depois combinadas.

\subsubsection{Análise da influência dos Apoios Elásticos Separados}

O estudo de influência dos apoios elásticos é feito através do incremento da constante de mola dos apoios elásticos. A análise se inicia com uma constante de mola igual a zero, relacionada à condição de contorno da coluna engastadalivre, depois para a condição parcialmente restrita, tanto para o deslocamento transversal como para a rotação (Figuras 4.8 (a) e 4.9 (a)). A tendência de comportamento dos sistemas nas condições dos apoios restritos, quando a constante de mola tende a infinito (Figuras 4.8 (b) e 4.9 (b)), também é incorporada a análise. 


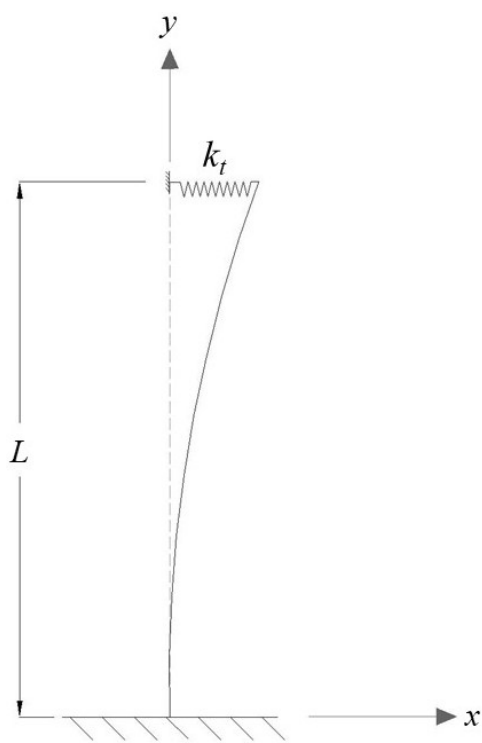

(a)

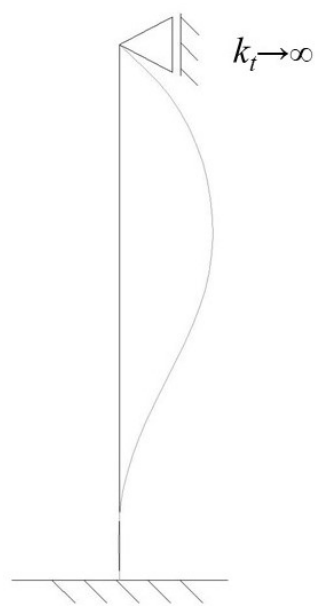

(b)

Figura 4.8 - Apoio elástico - mola translacional: (a) Coluna engastada e com deslocamento transversal parcialmente restrito; (b) Coluna engastada-apoiada.

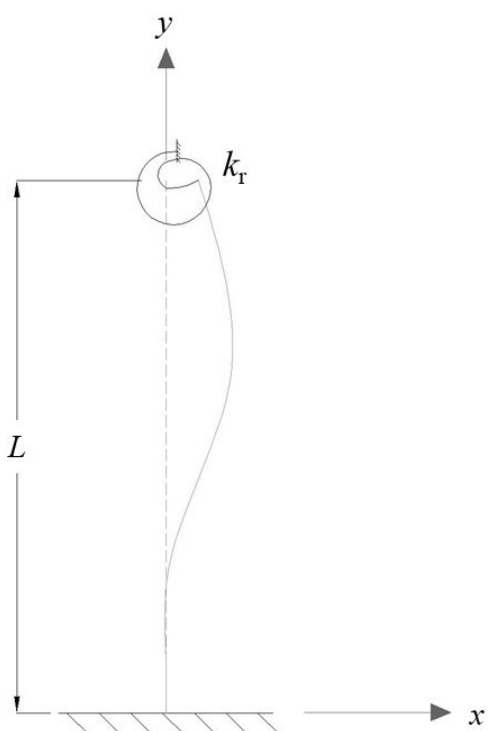

(a)

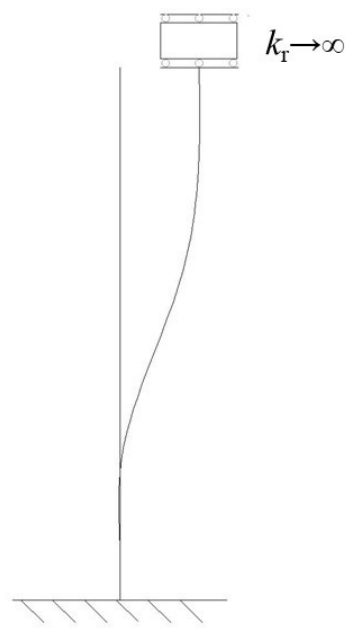

(b)

Figura 4.9 - Apoia elástico - mola rotacional: (a) Coluna engastada e com rotação parcialmente restrita; (b) Coluna engastada e com restrição à rotação.

As curvas representadas nas Figuras 4.10 e 4.11 correspondem à variação da carga crítica do caso I ao incremento de rigidez dos apoios elásticos $k_{t}$ e $k_{r}$, respectivamente. Ambos gráficos apresentam um comportamento similar: para valores inferiores de rigidez a condição crítica é dinâmica, "flutter", e a partir de 
um determinado ponto a condição é alterada de "flutter" para divergência. Os pontos de transição são

$$
\begin{aligned}
& k_{t}^{*}(I)=34,8 ; \\
& k_{r} *(I)=4,60,
\end{aligned}
$$

sendo o valor $k_{t}^{*}(I)$ e comportamento da coluna do caso I, engastadaelasticamente apoiada, consistente com os resultados reportados por Sundararajan [39] e Suanno [40].

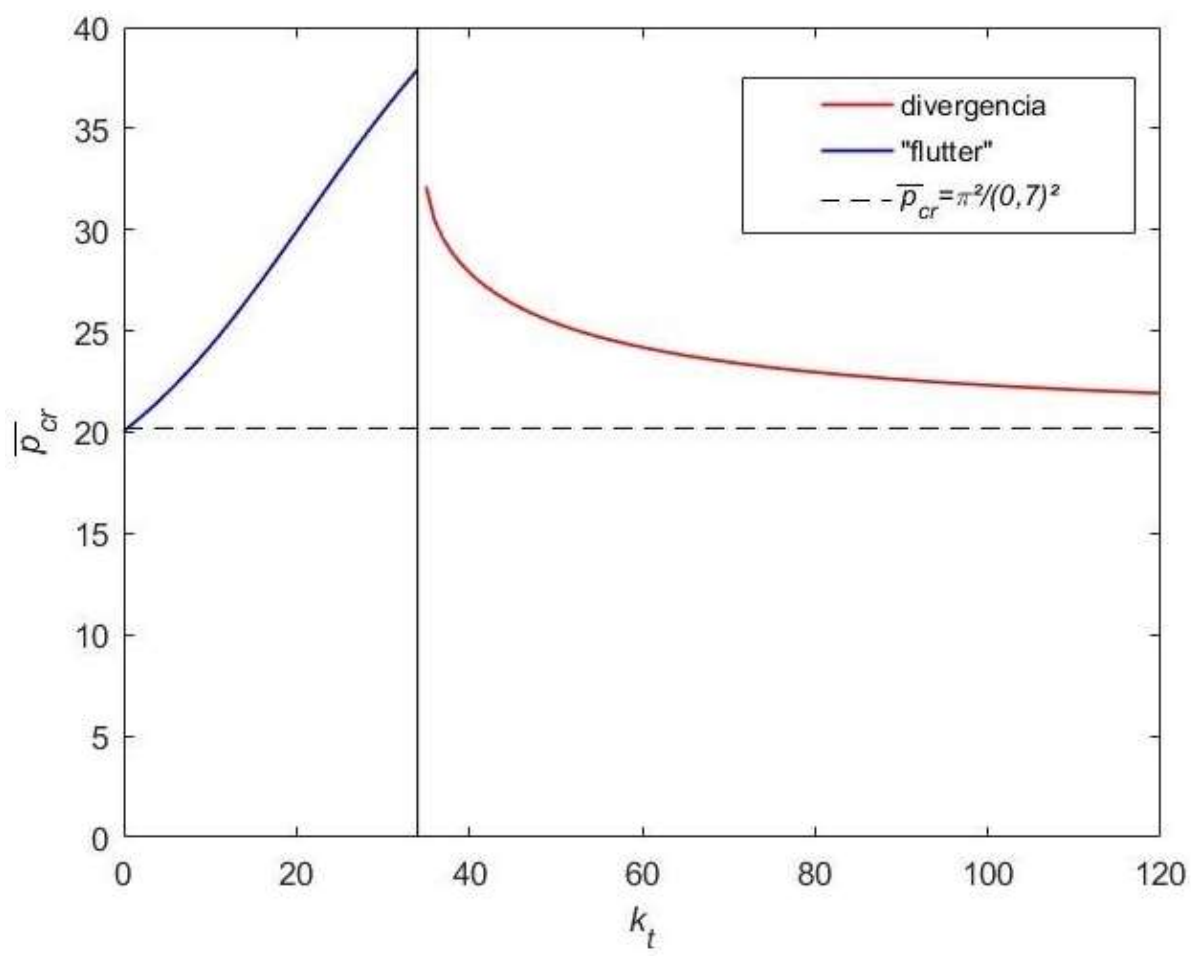

Figura 4.10 - Carga crítica vs. rigidez translacional da mola $\left(k_{t}\right)$ - Caso I. 


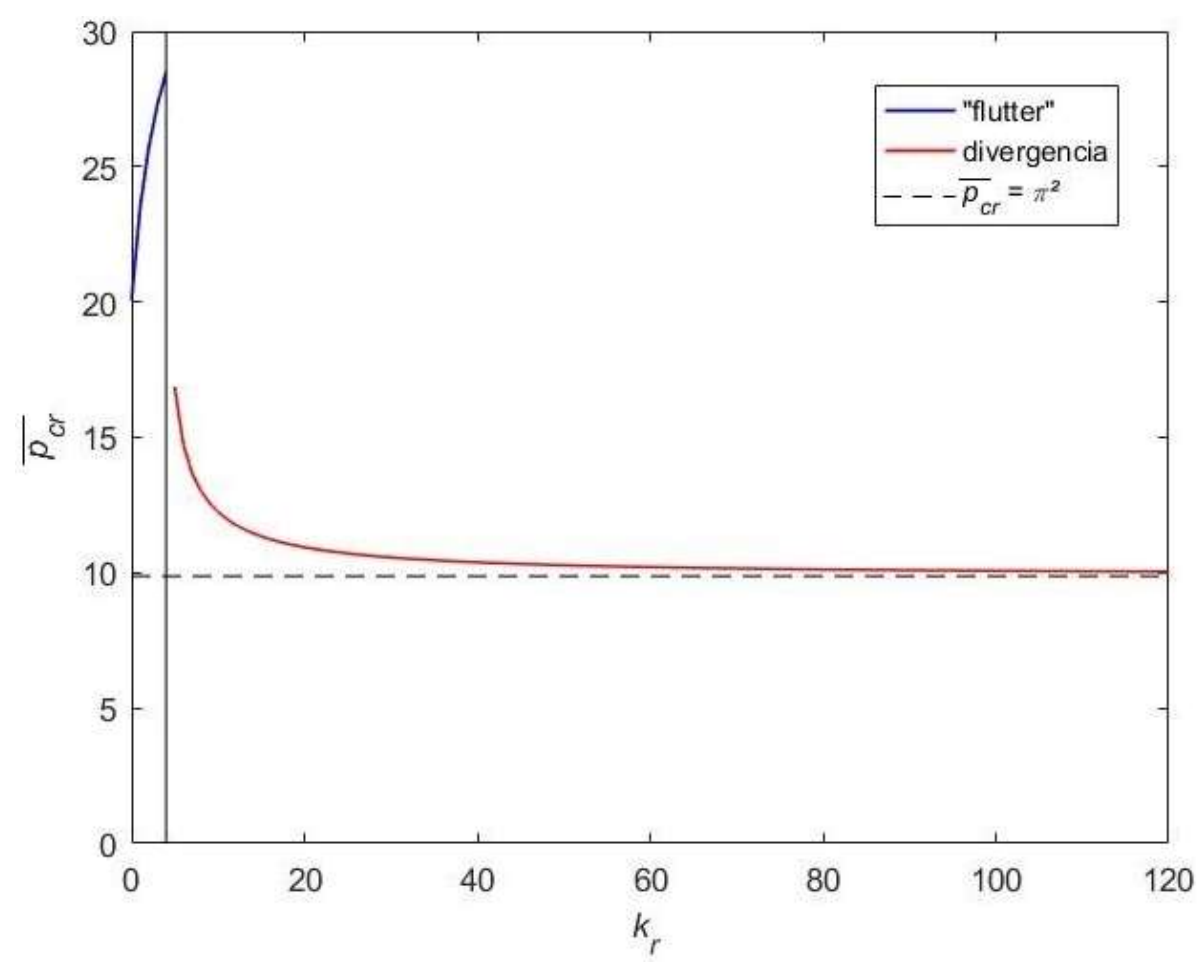

Figura 4.11 - Carga crítica vs. rigidez rotacional da mola $\left(k_{r}\right)$ - Caso I.

Inicialmente há um efeito estabilizador ao incremento de rigidez dos apoios, com o parâmetro de carga crítico aumentando com o incremento de rigidez. Porém, após o ponto de transição há uma queda brusca do parâmetro crítico e uma mudança no comportamento. Há um efeito desestabilizador no trecho de divergência e o parâmetro crítico converge para

$$
\begin{gathered}
\bar{p}_{c r}{ }^{(1)}=\frac{\pi^{2}}{0,7^{2}} ; \\
\bar{p}_{c r}{ }^{(2)}=\pi^{2} .
\end{gathered}
$$

Estes parâmetros correspondem aos casos clássicos de flambagem estática de colunas engastada-apoiada e engastada com rotação impedida sob ação de cargas de direção constante, respectivamente [18].

Na Figura 4.12 está representada a variação do parâmetro crítico de carga ao incremento de rigidez de mola translacional $\left(k_{t}\right)$ para o caso II. A influência deste apoio elástico no caso II é similar a que foi apresentada anteriormente para o caso I. Assim como no caso I, há a mudança de comportamento e condição crítica em uma determinada constante de mola do apoio elástico, dita como ponto de transição, dado por

$$
k_{t}^{*}(I I)=97,5 \text {. }
$$


Após o ponto de transição a condição crítica é estática, sendo também perceptível efeito desestabilizador ao incremento de $k_{t}$ neste trecho e a tendência de convergência do parâmetro de carga

$$
\bar{q}_{c r}{ }^{(1)}=57,0 .
$$

Esta tendência foi, entretanto, mais suave que no caso I uma vez que foi necessário um intervalo de valores de constante de mola $k_{t}$ consideravelmente maior para explicitar o comportamento. Além disso, diferentemente dos valores observados para os parâmetros críticos estáticos do caso I (equação (4.6) e equação (4.7)), no caso II não é atingido o parâmetro de carga crítico do sistema conservativo correspondente (coluna sob peso próprio) $[53,54]$

$$
\bar{q}_{c r}^{(1)}(\text { conservativo })=52,5 \text {. }
$$

O comportamento da coluna no caso II para a condição de apoio engastada-elasticamente apoiada está de acordo com o resultado reportado por Venuraju \& Ramu [41]. O valor do parâmetro de carga de tendência (equação (4.9)) e o valor do ponto de transição (equação (4.8)) foram consistentes com os apresentados por Venuraju \& Ramu, apenas apresentando no segundo uma variação de $1 \%$.

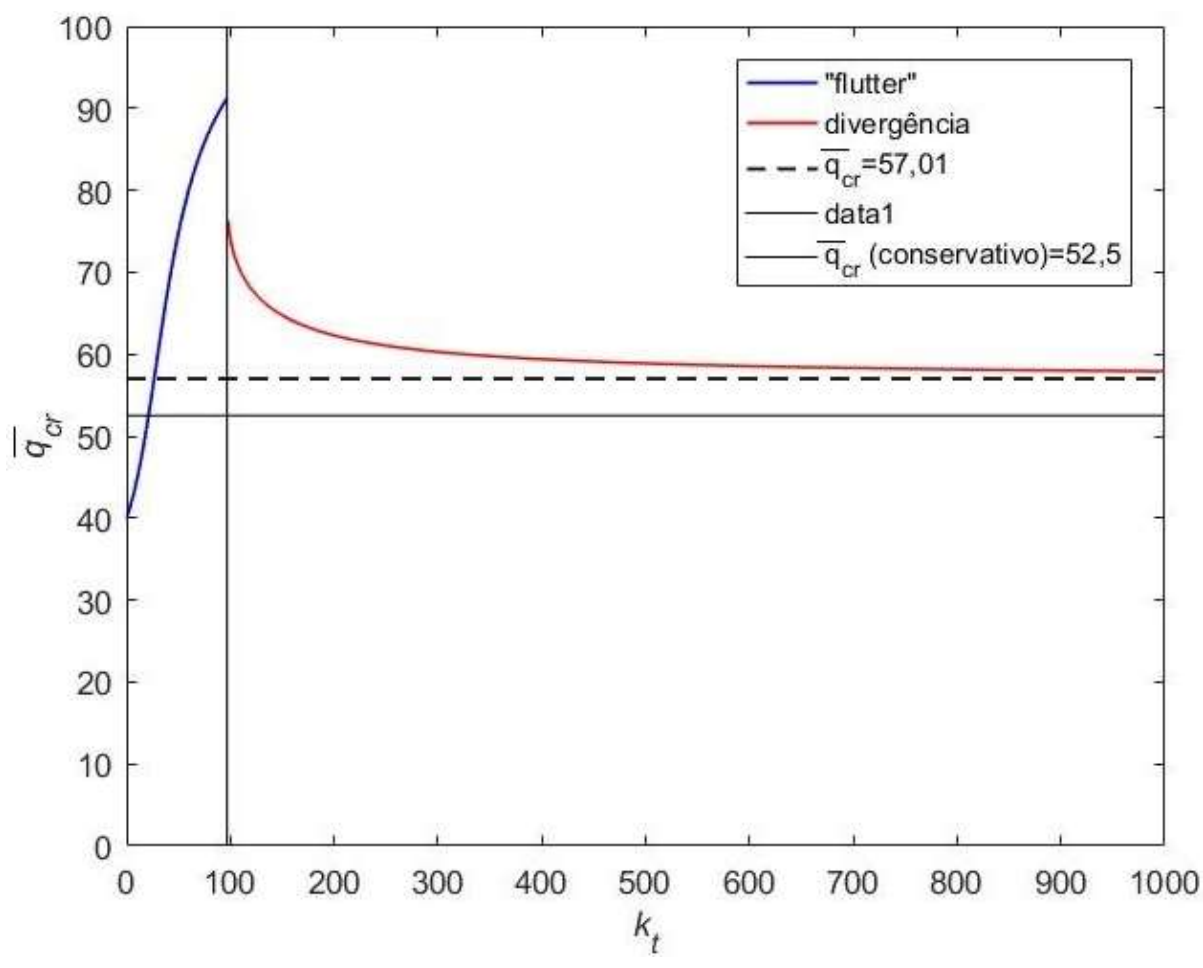

Figura 4.12 - Carga crítica vs. rigidez translacional da mola $\left(k_{t}\right)$ - Caso II.

Cabe destacar que os pontos de transição, valores de constante de mola que marcam a fronteira entre as condições críticas de "flutter" e divergência, correspondem ao valor ótimo de rigidez dos apoios. A maior carga crítica 
observada nos casos das Figuras 4.10, 4.11 e 4.12 associadas a estas constantes de rigidez (equação (4.11)).

$$
\begin{aligned}
& \bar{p}_{c r}\left(k_{t}=k_{t} *(I)\right)=38,3 ; \\
& \bar{p}_{c r}\left(k_{r}=k_{r} *(I)\right)=29,1 ; \\
& \bar{q}_{c r}\left(k_{t}=k_{t} *(I I)\right)=91,3 .
\end{aligned}
$$

A influência do apoio elástico com a mola rotacional $\left(k_{r}\right)$ no caso II, apresentada na Figura 4.13, é bastante distinta das apresentadas anteriormente (Figuras 4.10, 4.11 e 4.12). Não é observada a mudança na condição crítica, permanecendo a perda de estabilidade por "flutter" para qualquer valor de $k_{r}$, desde a extremidade livre $\left(k_{r}=0\right)$ até a extremidade restrita $\left(k_{r} \rightarrow \infty\right)$. Há um efeito estabilizador com a convergência do parâmetro crítico de carga em

$$
\bar{q}_{c r}{ }^{(2)}=65,3 .
$$

Observa-se também que o valor de tendência do parâmetro crítico nesse caso não está associado ao parâmetro crítico estático do sistema na condição de rotação restrita. O parâmetro crítico (equação (4.12)) corresponde a aproximadamente $340 \%$ do parâmetro estático para a coluna com respectiva condição de contorno e carregamento conservativo (coluna sob peso próprio) $[53,54]$

$$
\bar{q}_{c r}{ }^{(2)}(\text { conservativo })=18,9 .
$$

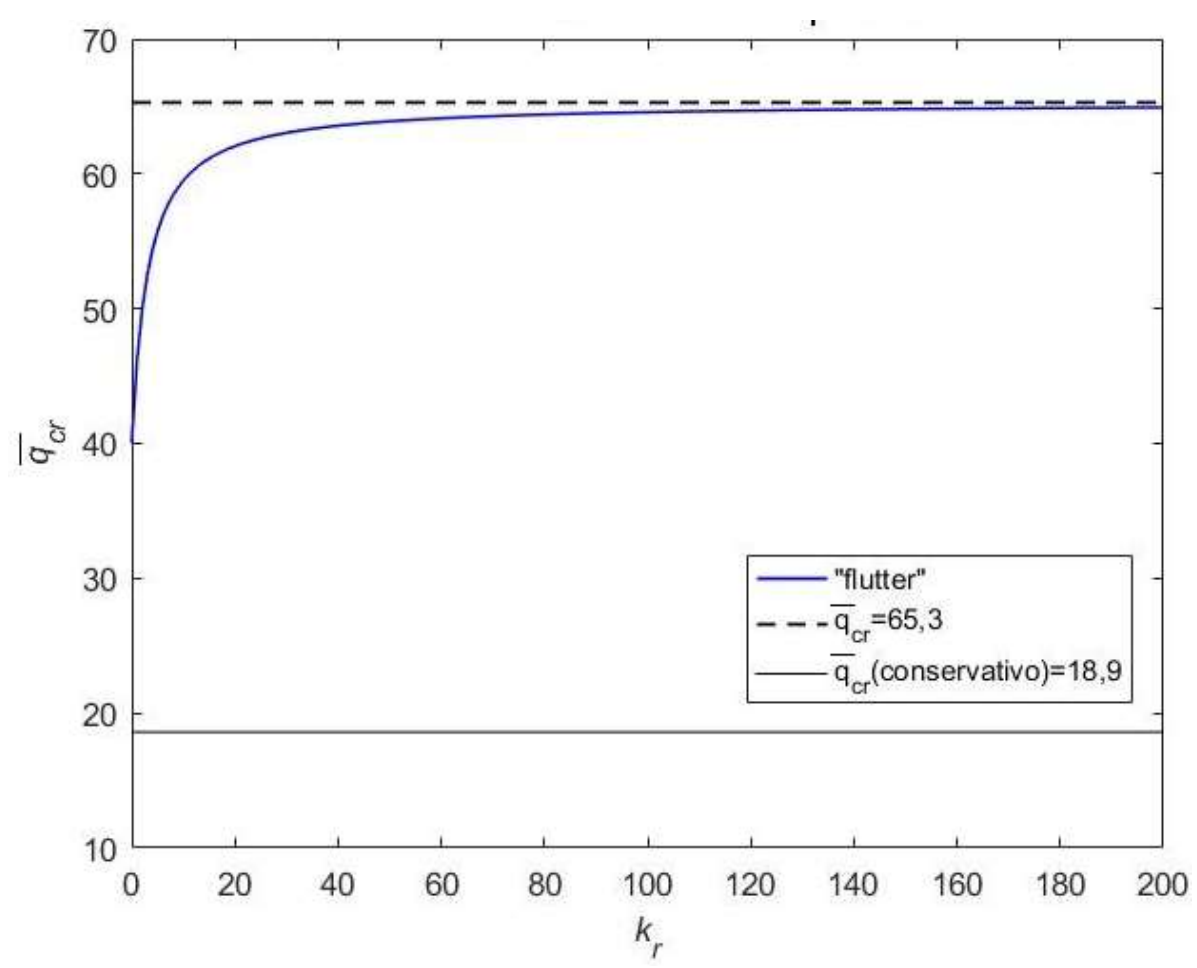

Figura 4.13 - Carga crítica vs. rigidez rotacional da mola $\left(k_{r}\right)$ - Caso II. 
Os comportamentos dos sistemas observados nos casos I e II para o incremento de rigidez dos apoios elásticos podem ser justificados pelo efeito deste incremento de rigidez na parcela restauradora do carregamento seguidor. As Figuras 4.14 (b) e 4.15 (b) apresentam em detalhe as componentes restauradoras, na direção $y$, para os dois carregamentos estudados.

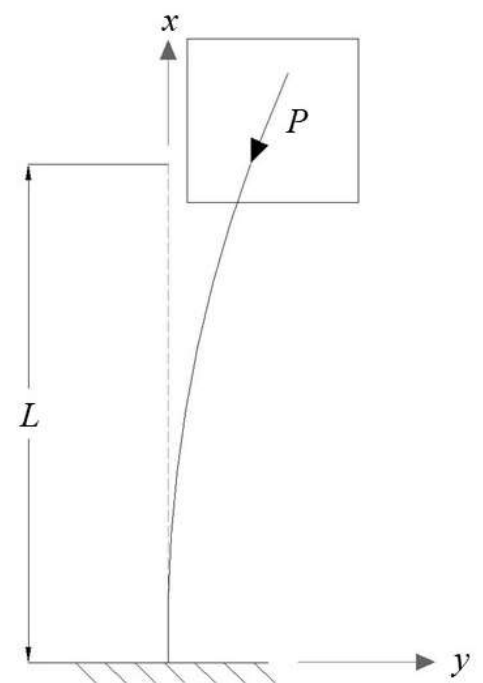

(a)

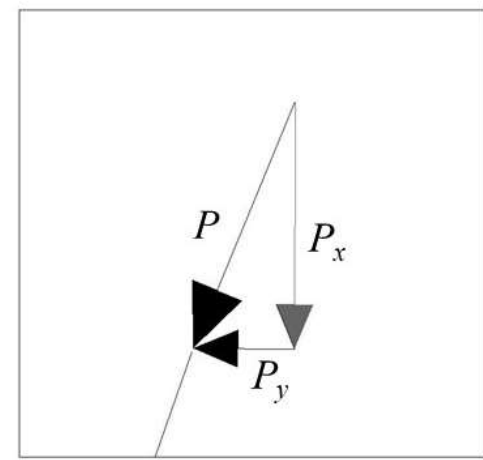

(b)

Figura 4.14 - Representação da componente restauradora - coluna de Beck: (a) Coluna deformada; (b) Detalhe das parcelas da carga $P$ quando deformada.

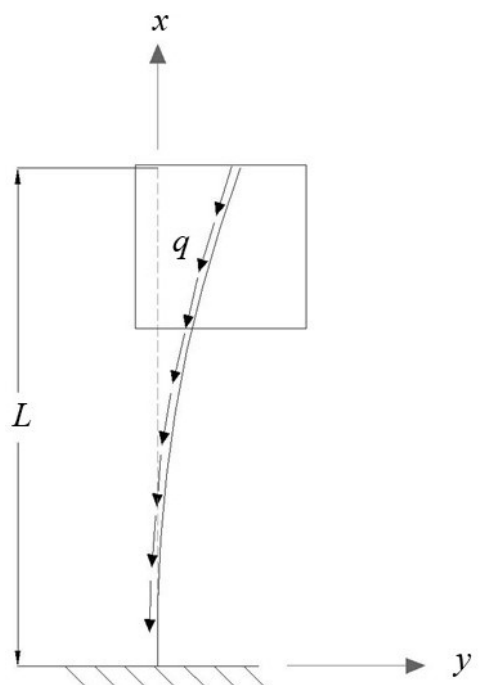

(a)

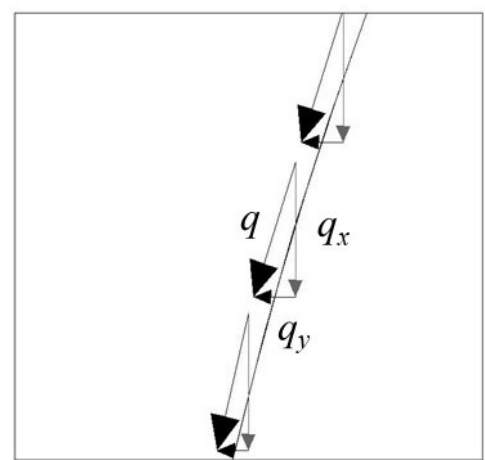

(b)

Figura 4.15 - Representação da componente restauradora - coluna de Leipholz: (a) Coluna deformada; (b) Detalhe das parcelas do carregamento $q$ quando deformada. 
Assim, a mudança de tipo de condição crítica no caso I e caso II está associada à diminuição do efeito da parcela restauradora na estabilidade do sistema. Durante a análise incremental de rigidez dos apoios, a componente restauradora vai tendo seu efeito diminuído, principalmente nos exemplos do caso I uma vez que o carregamento é concentrado em $x=L$.

A distribuição do carregamento ao longo do comprimento da coluna no caso II faz com que a forma da deformada do elemento seja importante para avaliar a influência do incremento de rigidez dos apoios. A Figura 4.16 apresenta o carregamento do tipo circulatório ou seguidor distribuído na coluna nas duas condições extremas, impedimento ao deslocamento transversal (Figura 4.16 (a)) e à rotação na extremidade (Figura 4.16 (b)).

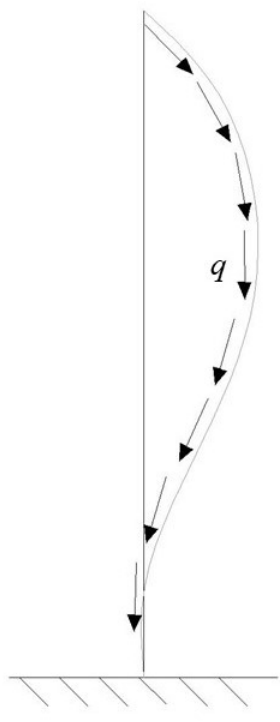

(a)

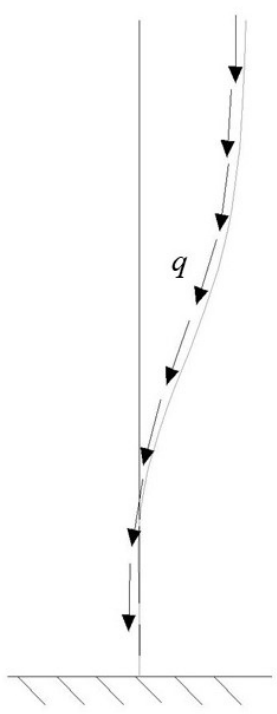

(b)

Figura 4.16 - Distribuição do carregamento $q$ na coluna deformada para diferentes condições no apoio superior: (a) translação impedida, rotação livre; (b) translação livre, rotação impedida.

Vale ressaltar a diferença da distribuição da parcela restauradora do carregamento para a restrição de deslocamento transversal e rotacional. A restrição ao deslocamento transversal no apoio faz com que as parcelas horizontais tendam a se anularem (Figura 4.16 (a)). Dessa forma a relevância dessa parcela da carga na análise de estabilidade diminui, permitindo que o sistema tenha o parâmetro crítico convergindo para um parâmetro próximo ao de uma coluna com peso próprio. Entretanto, permanece algum efeito estabilizador, mesmo que diminuído, e o parâmetro crítico estático desse sistema não coincide totalmente ao de coluna de seção constante sob peso próprio (sistema conservativo correspondente). 
Na Figura 4.16 (b), entretanto, não há o equilíbrio entre as parcelas horizontais dessa forma mesmo na condição limite, rotação impedida, a parcela restauradora continua a ter papel relevante na estabilidade da coluna. O sistema então não apresenta uma perda de estabilidade estática e a tendência do parâmetro crítico ao analisar valores crescentes de $k_{r}$ será de um valor superior ao estático clássico.

Para uma melhor compreensão do estudo de influência do apoio elástico a Figura 4.17 apresenta a variação das duas primeiras frequências de vibração com o parâmetro de carga $\bar{p}$ para diversos valores de $k_{r}$. Este gráfico é representativo para a restrição elástica translacional do caso I e II devido ao comportamento similar observado nos gráficos das Figuras 4.10, 4.11 e 4.12.

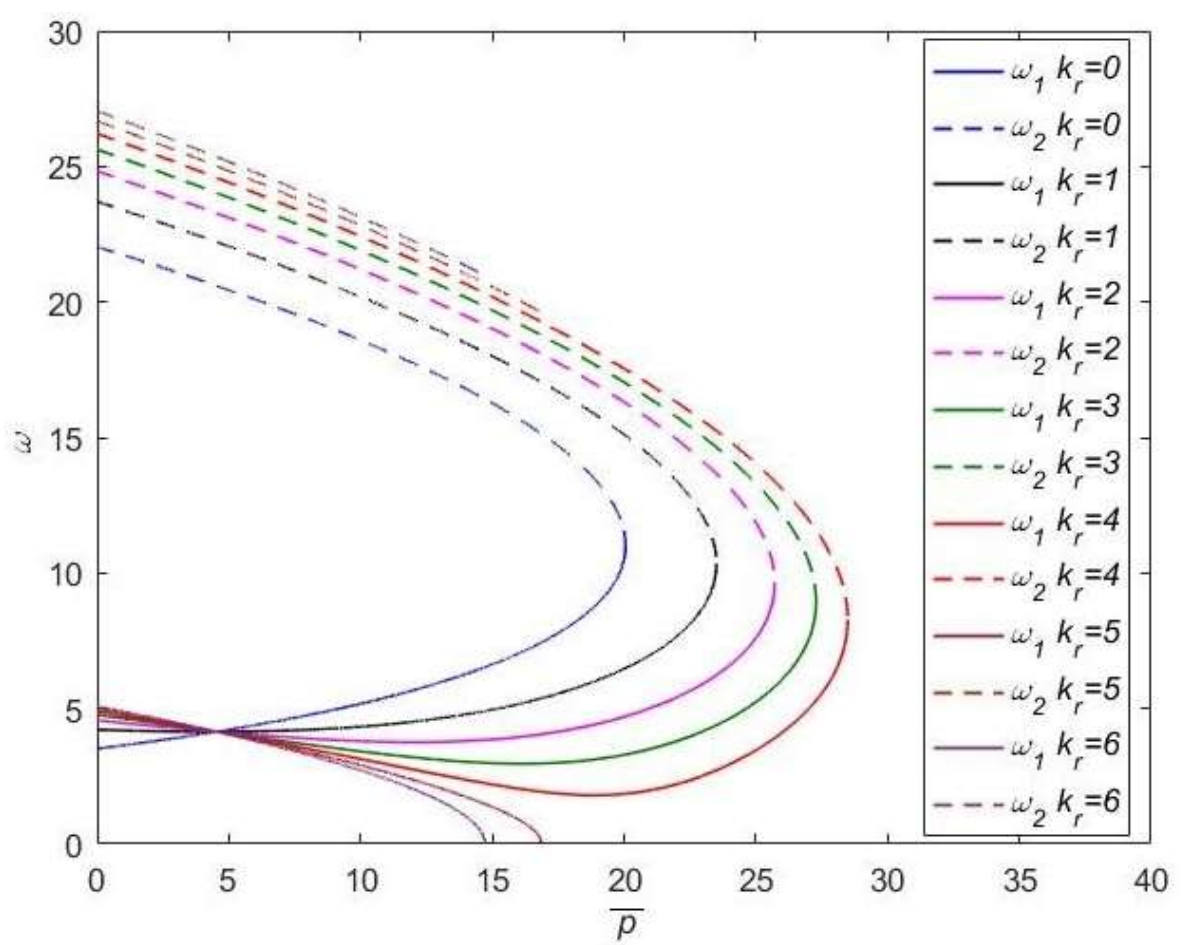

Figura 4.17 - Primeira e segunda frequência de vibração vs. parâmetro de carga, para diferentes parâmetros de rigidez rotacional $\left(k_{r}\right)$ - Caso I.

O gráfico representado na Figura 4.17 permite avaliar como corre a perda de estabilidade e os correspondentes valores de parâmetro crítico, seja por coalescência das frequências ou por anulação da primeira frequência, no caso I. Nota-se que a curva da primeira frequência sofre grandes alterações à medida que a constante de rigidez $k_{r}$ é modificada. $\mathrm{O}$ incremento de rigidez do apoio elástico altera o sinal da inclinação da curva de $\omega_{1}$, de positivo para negativo. Assim, após o ponto de transição (equação (4.5)) a inclinação da curva é mais negativa e o parâmetro de carga crítica é definido pela interceptação da curva com o eixo das abcissas, caracterizando divergência. 
Já a influência do apoio elástico rotacional no caso II é bastante diferente, como se vê na representação da variação das duas primeiras frequências ao incremento de carga com diferentes valores de $k_{r}$, na Figura 4.18. Os valores escolhidos para a rigidez do apoio elástico rotacional foram definidos de forma a melhor representar o comportamento observado na Figura 4.13. Para pequenos valores de $k_{r}$ é perceptível um efeito estabilizador, que vai diminuindo à medida que o valor do parâmetro aumenta. O parâmetro crítico de carga apresenta então uma tendência de convergir ao valor apresentado na equação (4.12) assim apresentando uma certa indiferença ao incremento do parâmetro de apoio elástico rotacional. Além do parâmetro de carga crítico, a frequência de coalescência do sistema também tende a um único valor à medida que a rigidez do apoio elástico rotacional aumenta.

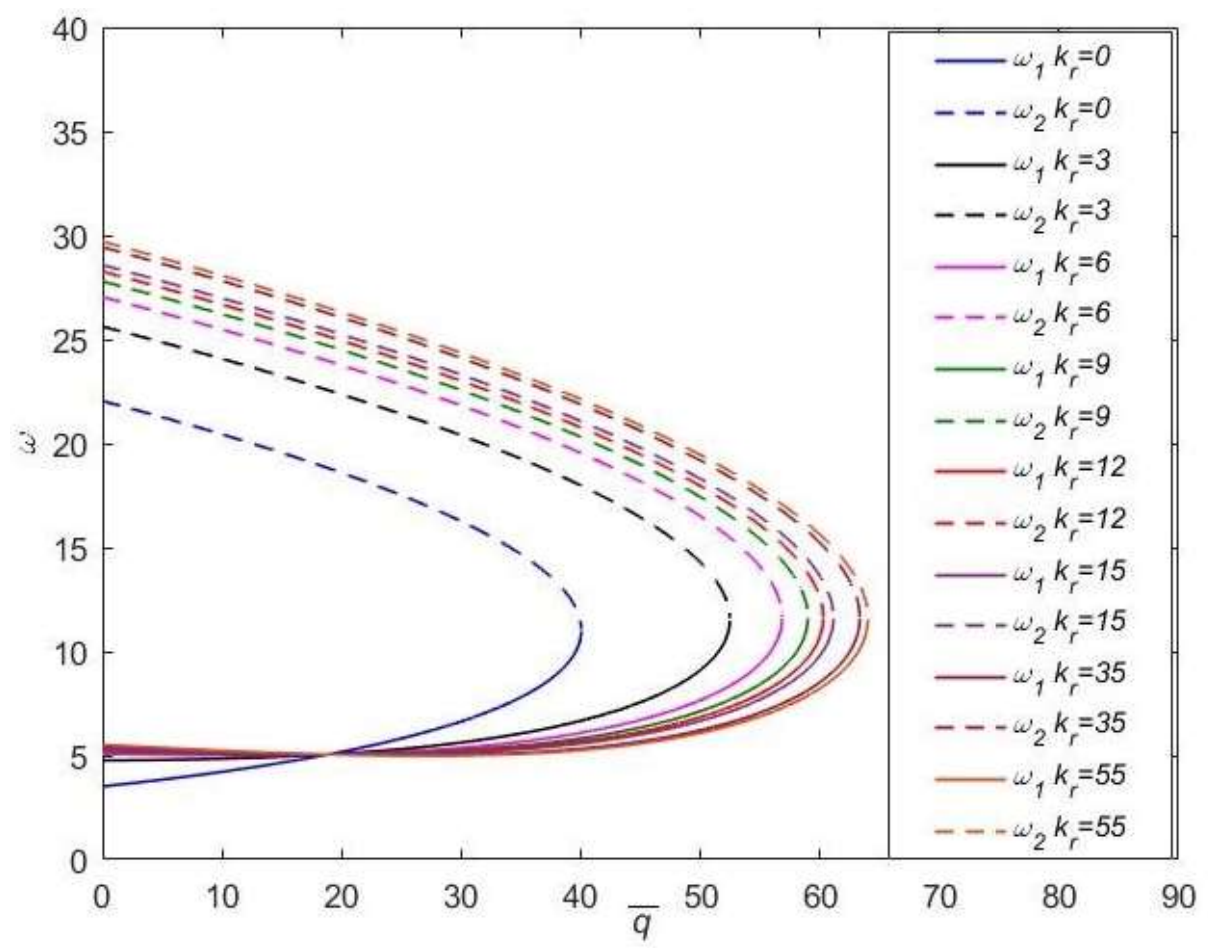

Figura 4.18 - Primeira e segunda frequência de vibração vs. parâmetro de carga, para diferentes parâmetros rigidez rotacional $\left(k_{r}\right)$ - Caso II.

Para concluir a análise de influência dos apoios elásticos nos casos I e II, avalia-se na Figura 4.19 a variação das frequências de coalescência com o incremento do parâmetro de rigidez do apoio elástico, no trecho de "flutter". As linhas pretas verticais marcam o limite entre a condição crítica dinâmica e estátca associado aos pontos de transição dos apoios elásticos.

A curva que mais difere das demais descreve a variação das frequências para a análise de influência do apoio rotacional no caso II ( $k_{r}-$ casoII). Devido à perda de estabilidade não ser alterada com o aumento da restrição rotacional do 
apoio, não há um ponto de transição e a frequência de coalescência sofre um leve aumento e depois tende a

$$
\omega^{I I}\left(k_{r} \rightarrow \infty\right)=11,6
$$

para uma análise incremental da constante $k_{r}$.

As demais curvas apresentam pontos de transição e uma mudança na condição crítica, representado pela reta na vertical, após esse valor de parâmetros de apoio elástico a instabilidade ocorre por divergência. Observa-se que o trecho que antecede o ponto de transição tem inclinação negativa e sofre uma mudança abrupta pois, quando a condição crítica muda a frequência que marca a condição crítica passa a ser nula. Os valores de frequência associados aos pontos de transição correspondem a

$$
\begin{aligned}
& \omega_{c}^{I}\left(k_{t}=k_{t}^{*}(I)\right)=7,52 \\
& \omega_{c}^{I}\left(k_{r}=k_{r} *(I)\right)=7,90 \\
& \omega_{c}^{I I}\left(k_{t}=k_{t}^{*}(I I)\right)=9,98
\end{aligned}
$$

Apesar das semelhanças entre as curvas $k_{t}$ - caso I, $k_{r}$ - caso I e $k_{t}$ - caso II descritas no parágrafo anterior, o aspecto da curva enquanto a instabilidade por "flutter" ocorre é notavelmente distinto. A relação entre a frequência de coalescência e o acréscimo de rigidez dos apoios elásticos se distingue quanto à forma, apresentando boas aproximações por funções respectivamente: linear, polinomial de segunda ordem e polinomial de quarta ordem. Há também a presença de um trecho com inclinação positiva para pequenos valores de rigidez dos apoios elásticos para as curvas $k_{t}$ - caso I e $k_{t}$ - caso II, sendo o intervalo da última consideravelmente maior. A curva $k_{r}$ - caso I apresenta, entretanto, apenas um trecho com inclinação negativa. 


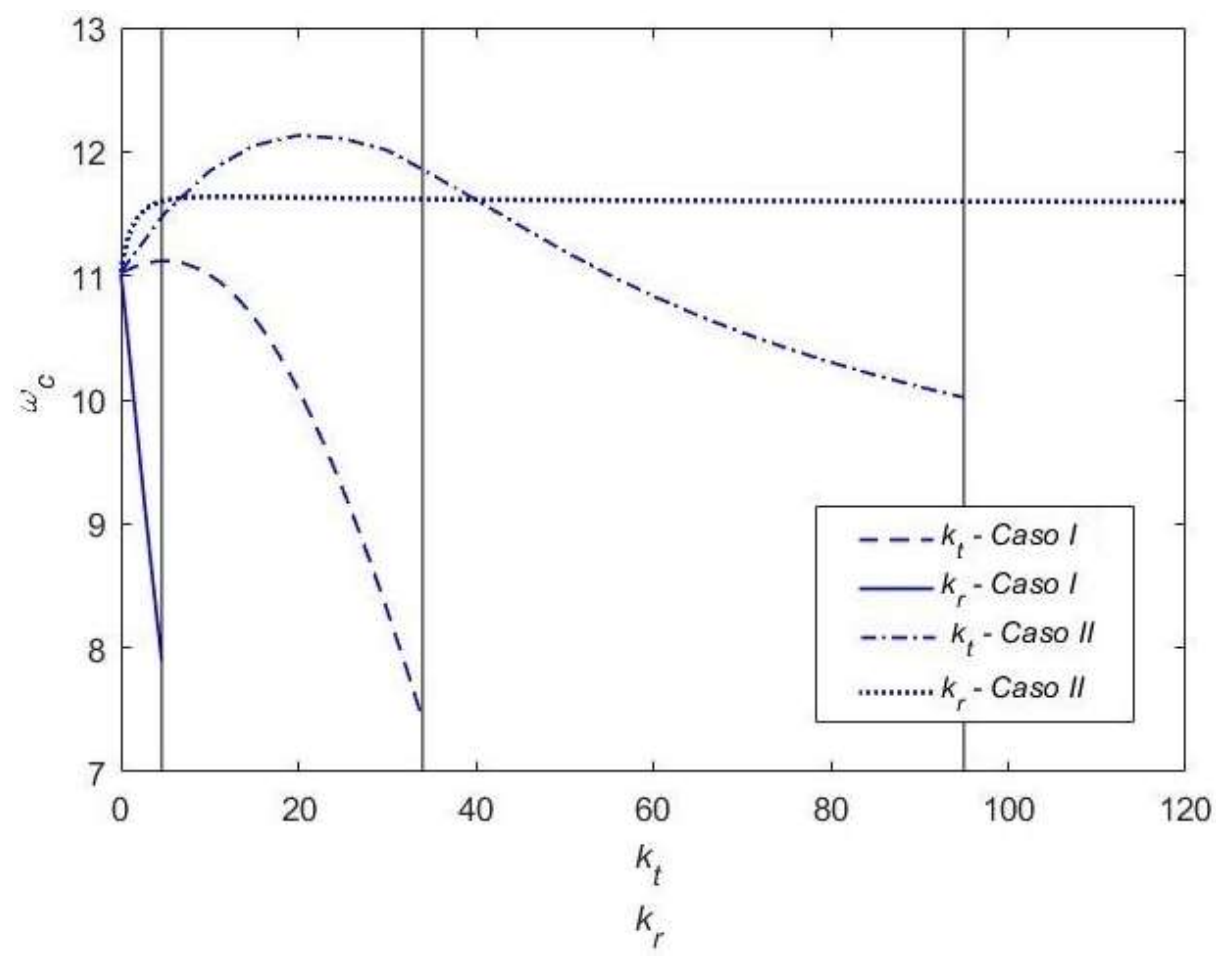

Figura 4.19 - Variação das frequências de coalescência com o incremento do parâmetro dos apoios elásticos $\left(k_{t} e k_{r}\right)$.

\subsubsection{Análise da Influência dos Apoios Elásticos Combinados}

A combinação dos apoios elásticos translacional e rotacional na estabilidade do modelo de coluna nos dois casos, I e II, consiste em um engaste parcial na extremidade $x=L$ da coluna (Figura 4.20). Este efeito foi avaliado através de combinações de parâmetros de apoios elásticos escolhidos de forma a possibilitar uma compreensão da interação entre os dois levando em consideração os comportamentos e valores dos pontos de transição ao serem analisados isoladamente. 


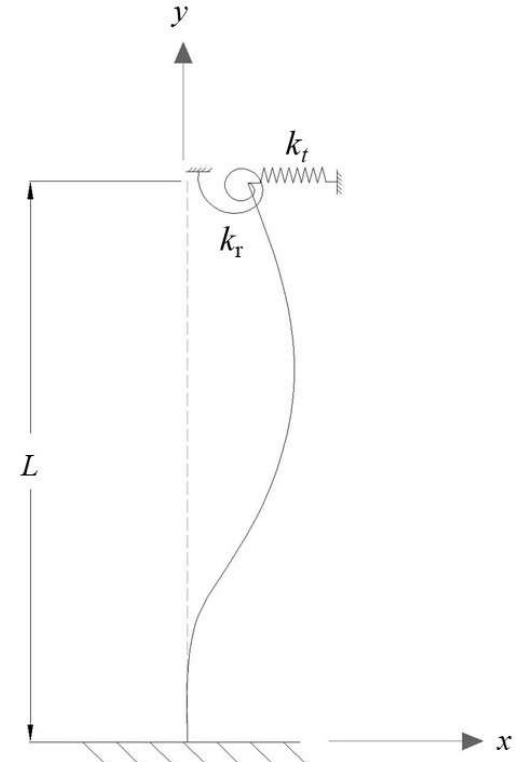

Figura 4.20 - Coluna engastada e com deslocamento transversal e rotação parcialmente restritos

Cada valor de parâmetro do apoio elástico $k_{t}$, ilustrada na Tabela 4.3, foi combinado com os diferentes valores de $k_{r}$. A análise conjunta das restrições elásticas $\left(k_{t}\right.$ e $\left.k_{r}\right)$ na estabilidade das colunas do caso I e II foi feita através da observação da variação das primeiras frequências ao incremento do parâmetro de carga para cada uma das combinações e os gráficos foram separados então pelos valores do parâmetro $k_{t}$. Em cada um deles foram expostas as quatro combinações com $k_{r}$ sendo possível comparar o tipo de condição crítica e parâmetro crítico de cada uma.

Tabela 4.3 - Valores de parâmetro elástico dos apoios a serem combinados nas análises dos casos I e II

\begin{tabular}{c|c|c|c}
\hline \multicolumn{2}{c|}{ Caso I } & \multicolumn{2}{c}{ Caso II } \\
\hline$k_{t}=10$ & $k_{r}=0$ & $k_{t}=70$ & $k_{r}=0$ \\
\hline$k_{t}=20$ & $k_{r}=5$ & $k_{t}=100$ & $k_{r}=15$ \\
\hline$k_{t}=36$ & $k_{r}=10$ & $k_{t}=150$ & $k_{r}=30$ \\
\hline$k_{t}=40$ & $k_{r}=15$ & $k_{t}=180$ & $k_{r}=90$ \\
\hline
\end{tabular}

As Figuras 4.21 a 4.24 apresentam a variação das duas primeiras frequências ao incremento de carga para as combinações de apoios elásticos do caso I (Tabela 4.3). Nos gráficos é possível perceber que a análise combinada dos apoios elásticos se diferencia bastante da feita no item 4.2.3.1 para os parâmetros separados. Os pontos de transição observados ao analisar separadamente as 
restrições elásticas, que marcam o limite entre "flutter" e divergência, não é respeitado na análise combinada. Para diversas combinações cujas restrições elásticas rotacional e translacional foram superiores aos respectivos limites, $k_{t} *(I)=34,8$ e $k_{r} *(I)=4,60$ (ver item 4.2.3.1), foi observada perda de estabilidade por "flutter". Isto indica que o comportamento do sistema depende da relação entre os valores dos parâmetros dos apoios elásticos e não somente de seus valores individuais.

Mesmo sendo observada instabilidade por "flutter" para valores de $k_{r}$ superiores à $k_{r}{ }^{*}(I)$, as Figuras 4.21 e 4.22 apresentaram um comportamento de certa forma esperado de acordo com as análises dos parâmetros individuais. Nessas combinações, em que $k_{t}$ é inferior a $k_{t}^{*}(I)$, o aumento do parâmetro de apoio elástico rotacional $\left(k_{r}\right)$ fez com que a condição crítica alterasse para estática.

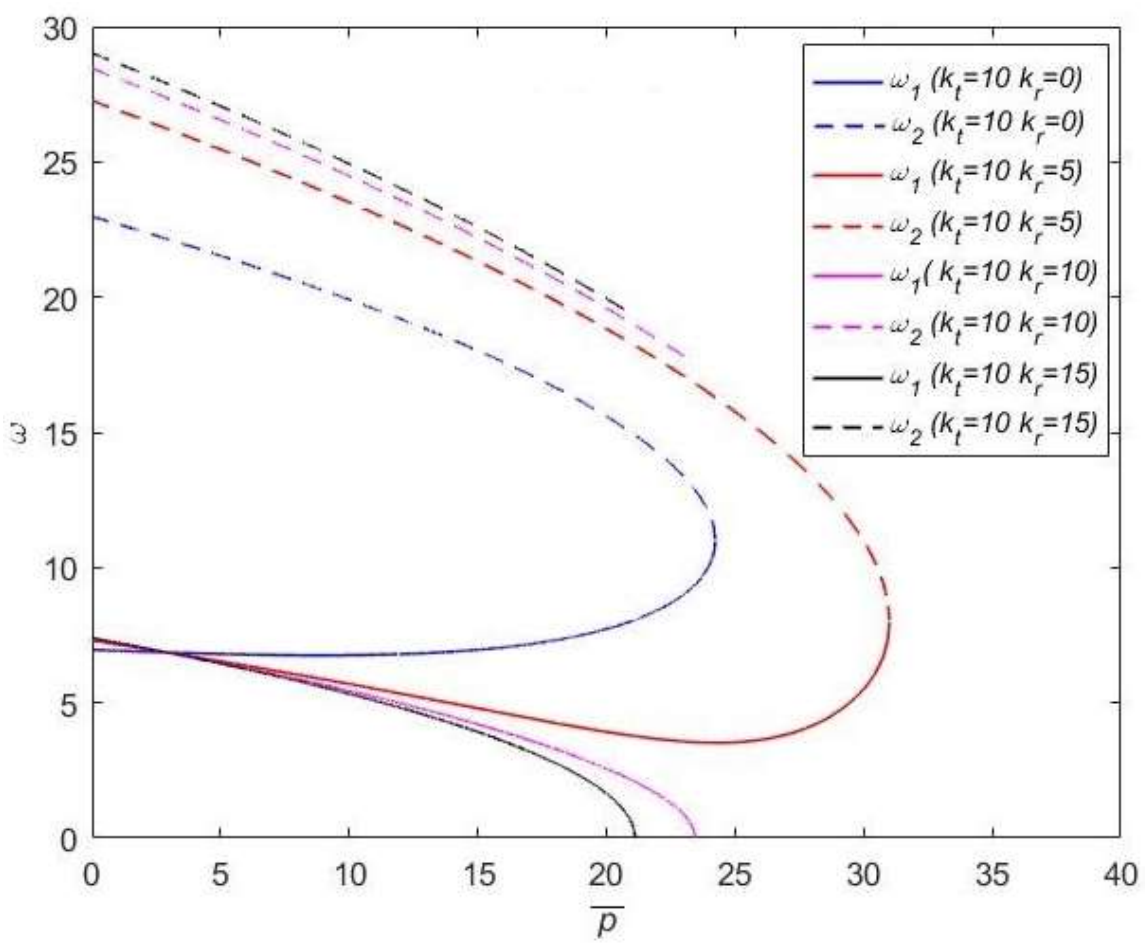

Figura 4.21 - Variação das duas primeiras frequências ao incremento de carga para a combinação de $k_{t}=10$ e $k_{r}=[0 ; 5 ; 10 ; 15]$ (Caso I). 


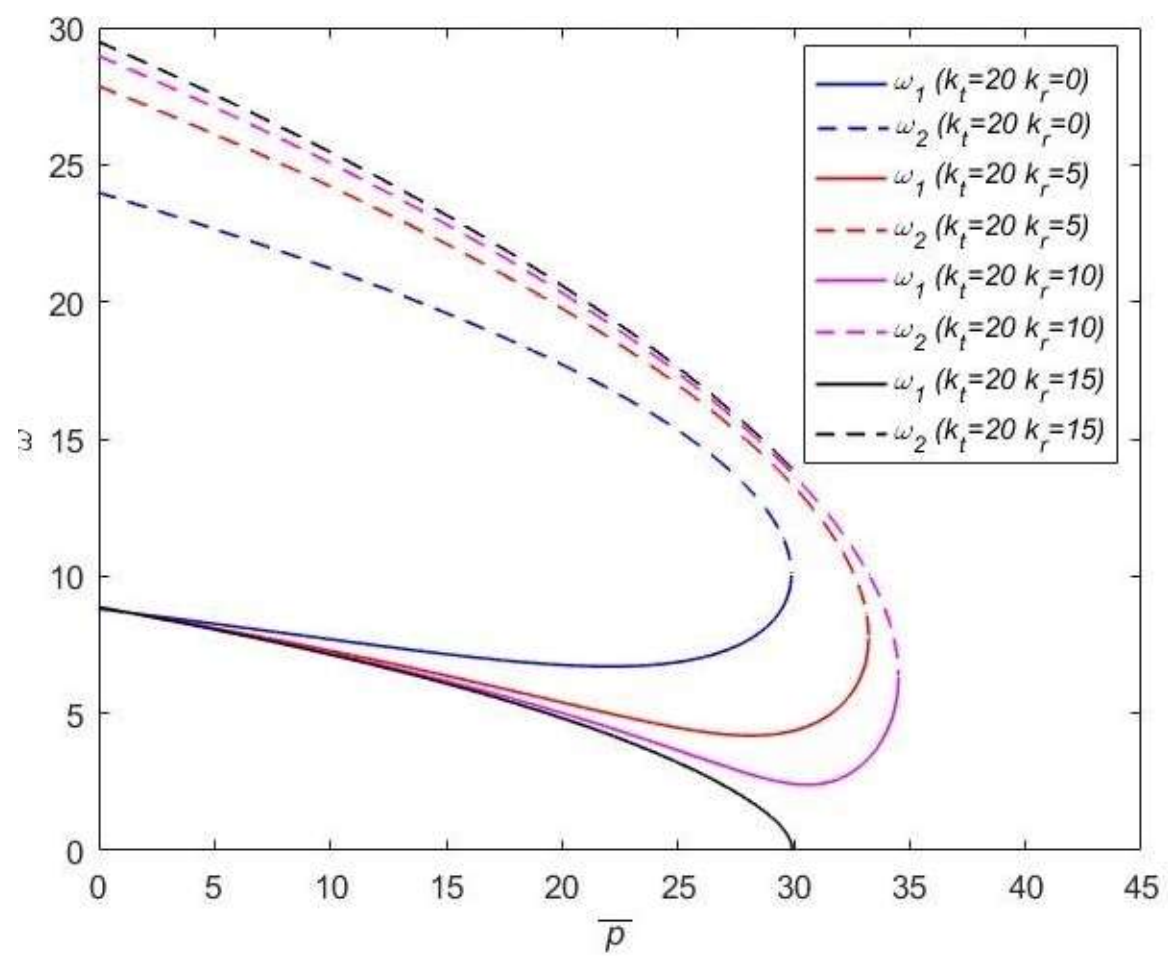

Figura 4.22 - Variação das duas primeiras frequências ao incremento de carga para a combinação de $k_{t}=20$ e $k_{r}=[0 ; 5 ; 10 ; 15]$ (Caso I).

As combinações analisadas para $k_{t}=36$ (Figura 4.23), superior à $k_{t} *(I)$, apresentaram, entretanto, um comportamento um tanto inesperado. Na primeira combinação analisada para $k_{r}=0 \mathrm{o}$ sistema perde estabilidade por divergência e com o aumento do parâmetro $k_{r}$ o sistema altera a condição crítica para dinâmica. A curva da primeira frequência para os valores de $k_{r} \geq 5$ se aproxima do eixo das abcissas, inicialmente indicando que a condição crítica seria estática ao anular a $\omega_{1}$, porém em um certo ponto há uma mudança brusca da tangente da curva e as frequências se igualam. O aumento de rigidez do apoio teve um efeito estabilizador quando a condição crítica foi alterada para dinâmica e, enquanto a condição foi esta, o aumento do parâmetro $k_{r}$ gerou pouca alteração no parâmetro crítico. 


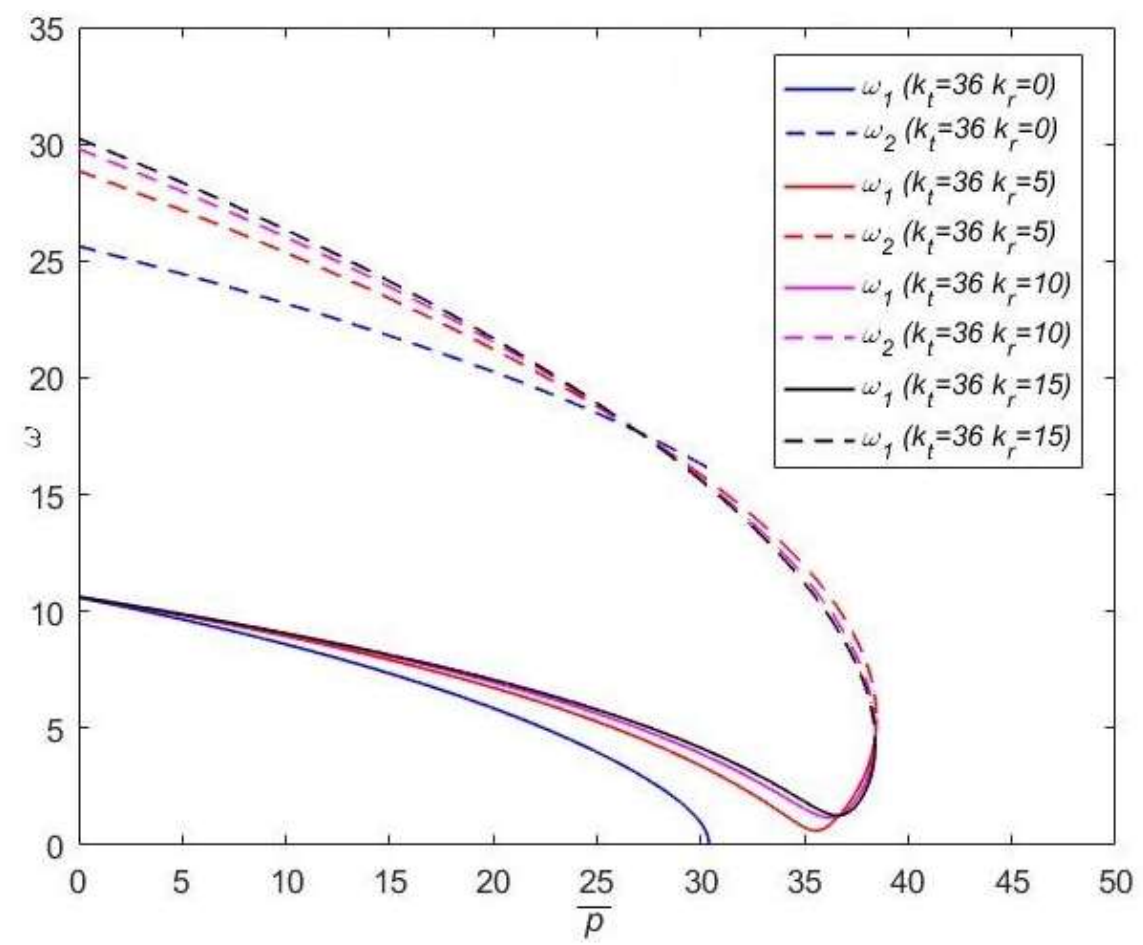

Figura 4.23 - Variação das duas primeiras frequências ao incremento de carga para a combinação de $k_{t}=36$ e $k_{r}=[0 ; 5 ; 10 ; 15]$ (Caso I).

O gráfico representado na Figura 4.24 para as combinações com $k_{t}=40$ apresenta um comportamento esperado e usual de sistemas conservativos. Pois o aumento de $k_{r}$, aumento da restrição do apoio, tem efeito estabilizador, sendo só observada nessas combinações a divergência. 


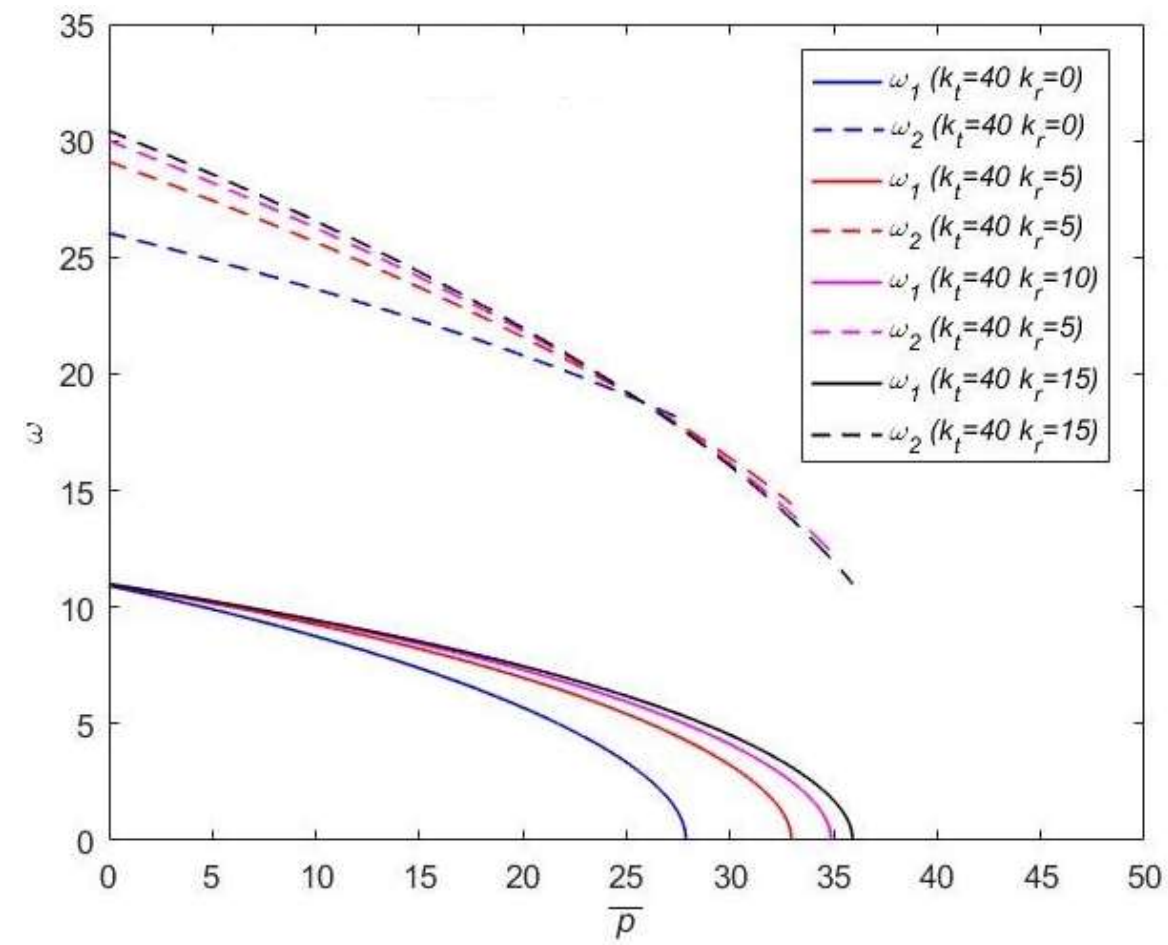

Figura 4.24 - Variação das duas primeiras frequências ao incremento de carga para a combinação de $k_{t}=40$ e $k_{r}=[0 ; 5 ; 10 ; 15]$ (Caso I).

As Figuras 4.25 a 4.28 apresentam a variação das duas primeiras frequências ao incremento de carga para as combinações de apoios elásticos do caso II (Tabela 4.3). Vale ressaltar a diferença entre os casos I e II observada na análise de influência do apoio elástico rotacional separado apresentada item 4.2.3.1. O incremento de $k_{r}$ no caso II não altera a condição crítica apresentando apenas "flutter" e o parâmetro crítico tende a apresentar pouca sensibilidade ao incremento de restrição rotacional. 


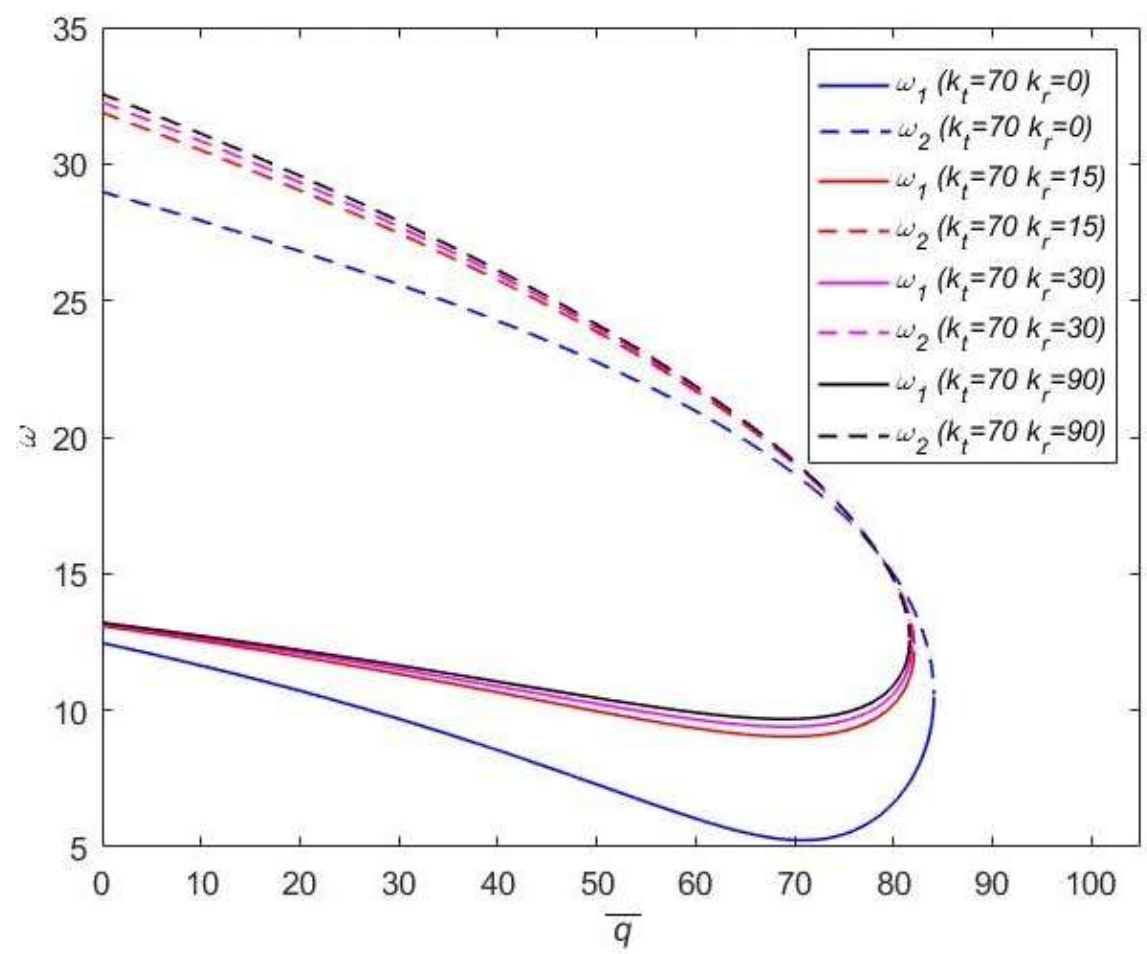

Figura 4.25 - Variação das duas primeiras frequências ao incremento de carga para a combinação de $k_{t}=70$ e $k_{r}=[0 ; 15 ; 30 ; 90]$ (Caso II).

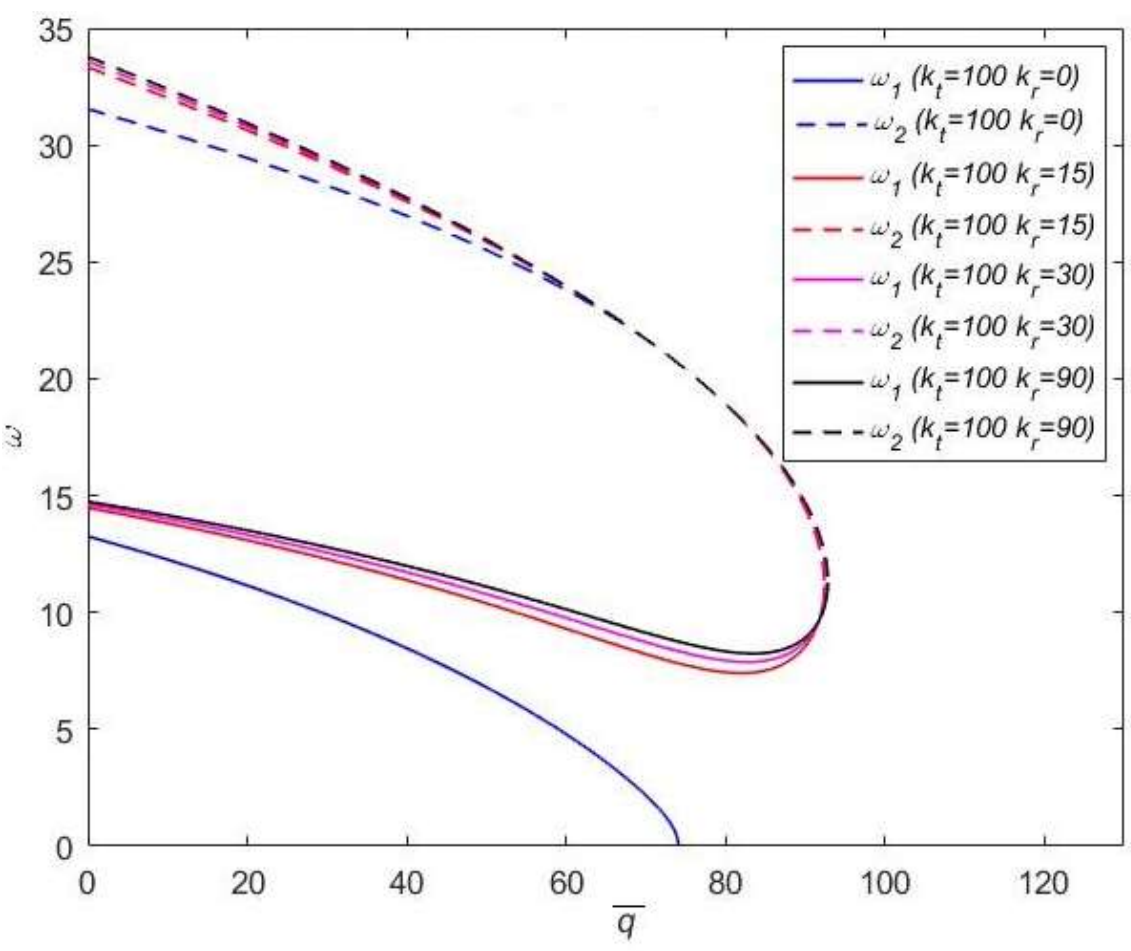

Figura 4.26 - Variação das duas primeiras frequências ao incremento de carga para a combinação de $k_{t}=100$ e $k_{r}=[0 ; 15 ; 30 ; 90]$ (Caso II). 


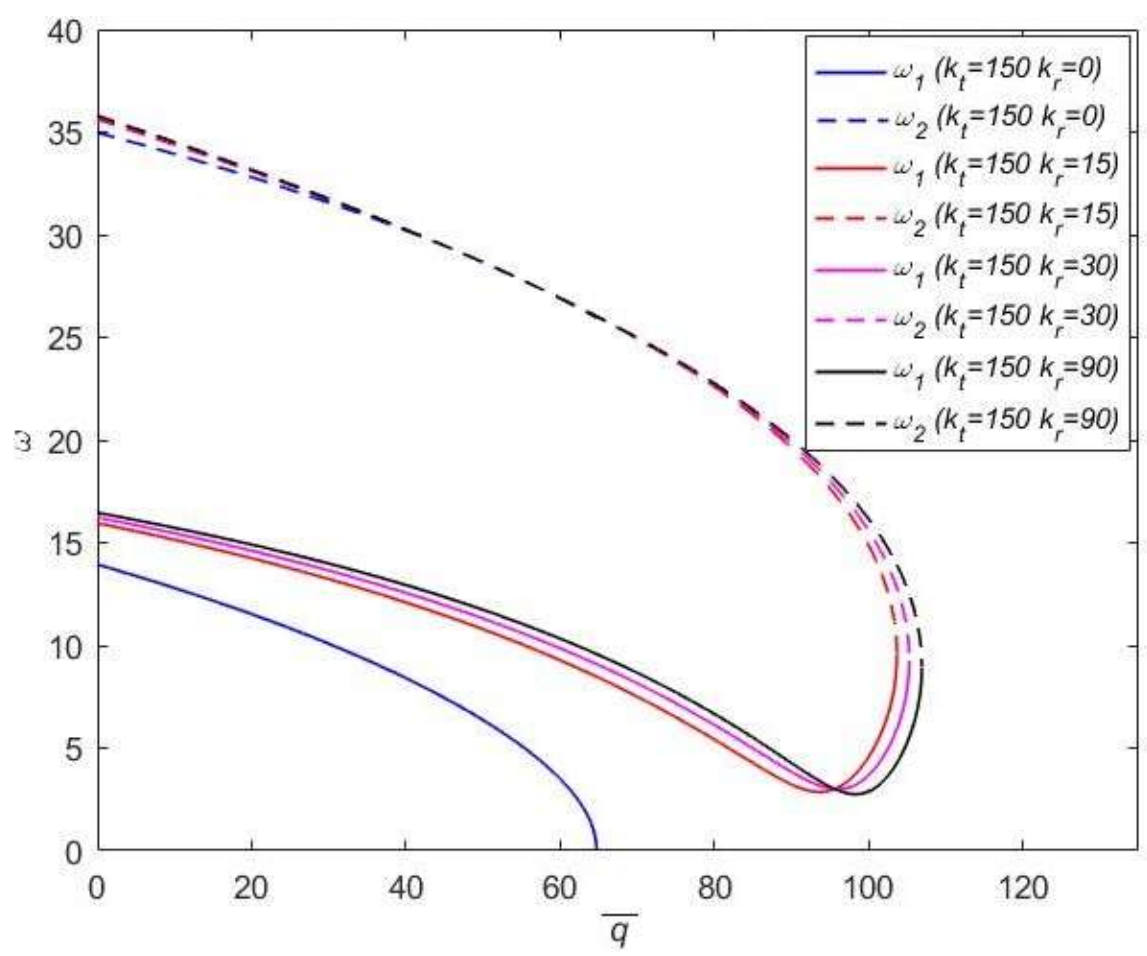

Figura 4.27 - Variação das duas primeiras frequências ao incremento de carga para a combinação de $k_{t}=150$ e $k_{r}=[0 ; 15 ; 30 ; 90]$ (Caso II).

Os efeitos observados nas combinações realizadas neste caso são de certa forma similares ao observado na combinação da Figura 4.23 do caso I, com exceção à ultima combinação para $k_{t}=180$ (Figura 4.28). O aumento na restrição rotacional afasta a curva da primeira frequência $\left(\omega_{1}\right)$ do eixo das abcissas, fazendo com que o sistema tenda ao "flutter".

As combinações com $k_{r} \geq 15$ não tiveram significativas alterações no parâmetro crítico, apresentando uma certa indiferença ao incremento de $k_{r}$. Se destacam as combinações para $k_{t}=70$, inferior a $k t^{*}(I I)=97,5$ (ver item 4.2.3.1), não apenas pela não alteração da condição crítica como pela pequena diminuição do parâmetro crítico observada para $k_{r}>0$ (Figura 4.25).

O mesmo comportamento usual de sistema conservativos observado nas combinações com $k_{t}=40$ do caso I (Figura 4.24) foi observado na figura para as combinações com $k_{t}=180$ do caso II (Figura 4.28). O aumento dos valores de $k_{r}$ analisados geraram um efeito estabilizador, sendo observada apenas divergência. 


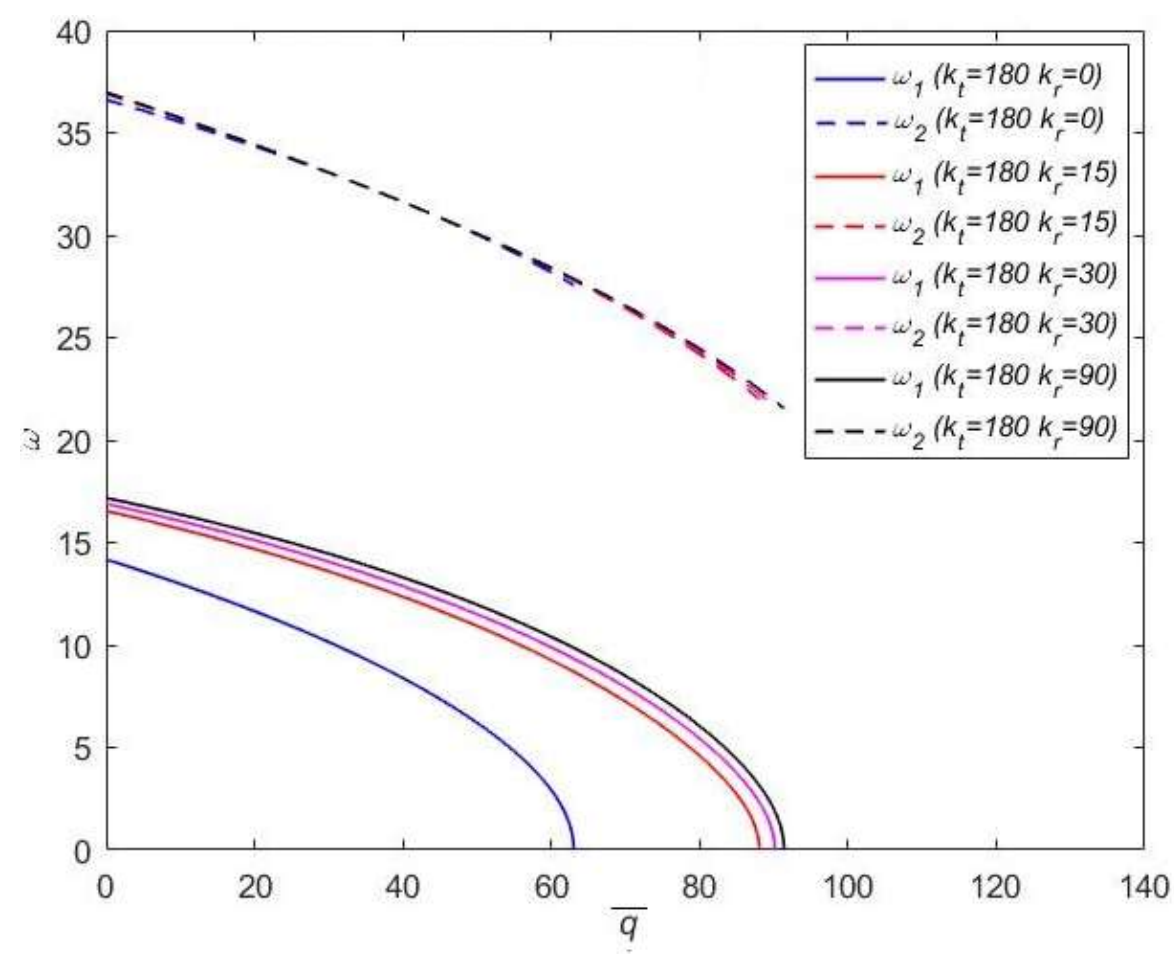

Figura 4.28 - Variação das duas primeiras frequências ao incremento de carga para a combinação de $k_{t}=180$ e $k_{r}=[0 ; 15 ; 30 ; 90]$ (Caso II).

\subsubsection{Análise Conjunta da Influência da Base Elástica e dos Apoios Elásticos}

A análise conjunta da influência da base elástica de Winkler e dos apoios resume todos os conceitos abordados nas análises de influência destes parâmetros isolados, feita nos itens 4.2.2 e 4.2.3.1. A análise conjunta de influência foi feita de forma a avaliar as semelhanças e diferenças entre as respostas de análise de influência dos apoios elásticos para constantes de base elástica $\kappa=0, \kappa=50 \mathrm{e}$ $\kappa=100$.

O comportamento dos sistemas na análise conjunta é de certo modo similar ao descrito no item 4.2.3.1, em que foi analisada apenas a influência dos apoios elásticos isolados. Os sistemas continuam apresentando as mesmas características para o incremento de rigidez dos apoios. Por exemplo, as Figuras 4.29 a 4.31 apresentam, nas análises com presença base elástica $(\kappa=50$ e $\kappa=100)$ o mesmo comportamento observado sem $(\kappa=0)$. Há mudança de tipo de condição crítica e convergência do parâmetro de carga crítica ao valor obtido na análise estática para as condições de contorno engastada-apoiada e engastada com restrição rotacional. 


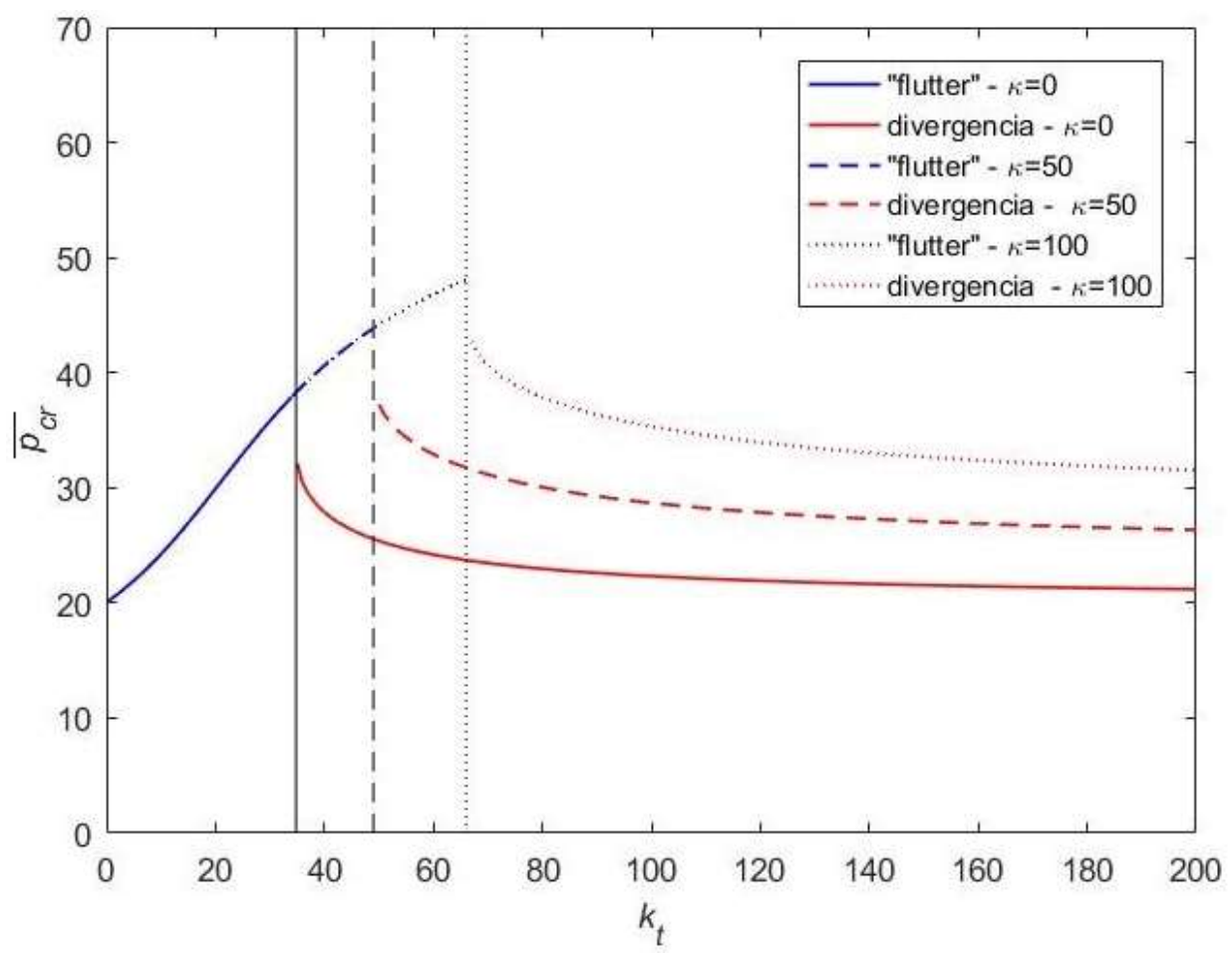

Figura 4.29 - Carga crítica vs. rigidez translacional transversal da mola $\left(k_{t}\right)$ para

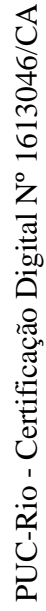
$\kappa=0, \kappa=50$ e $\kappa=100-$ Caso $I$.

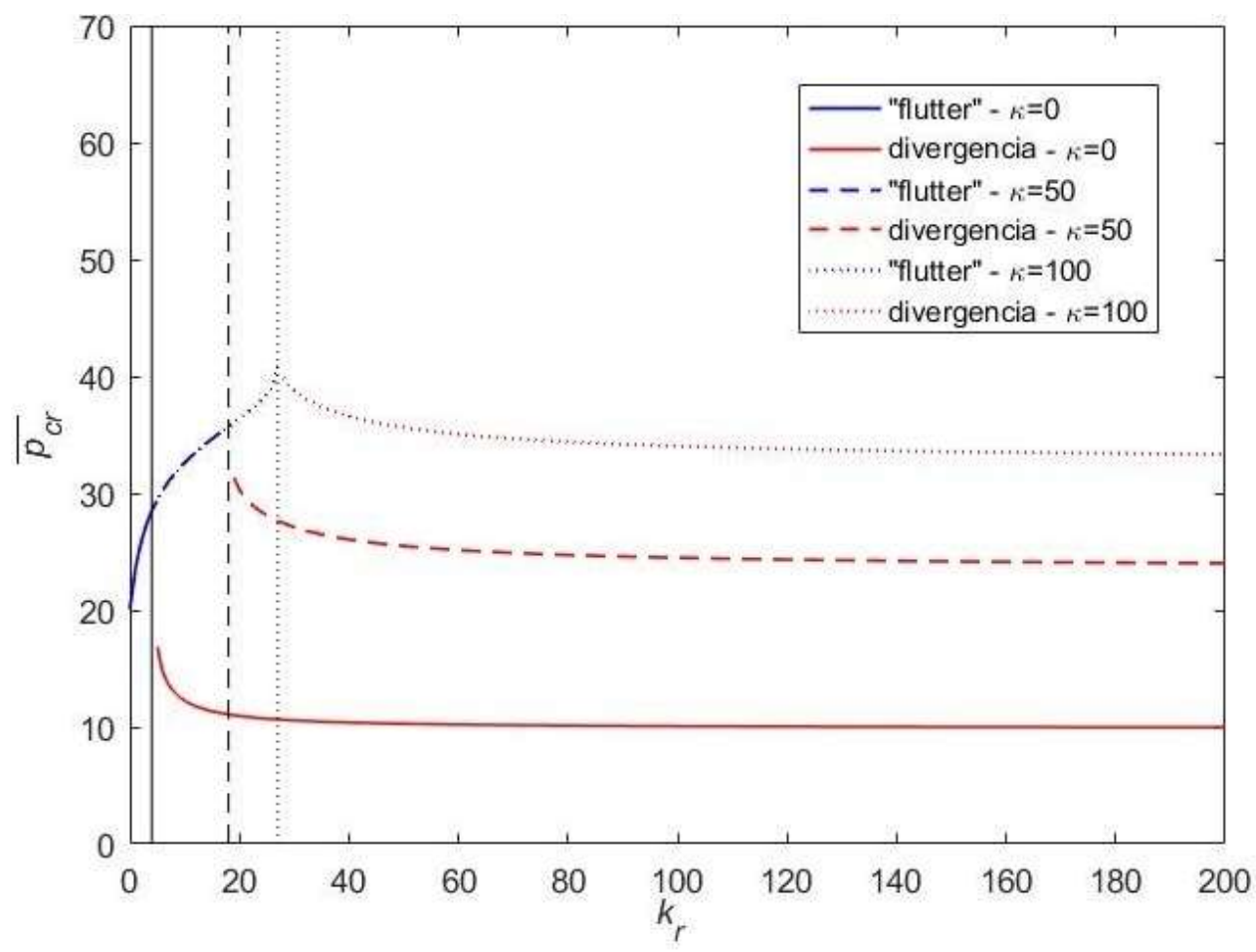

Figura 4.30 - Carga crítica vs. rigidez rotacional da mola $\left(k_{r}\right)$ para $\kappa=0, \kappa=50 \mathrm{e}$ $\kappa=100-$ Caso I. 


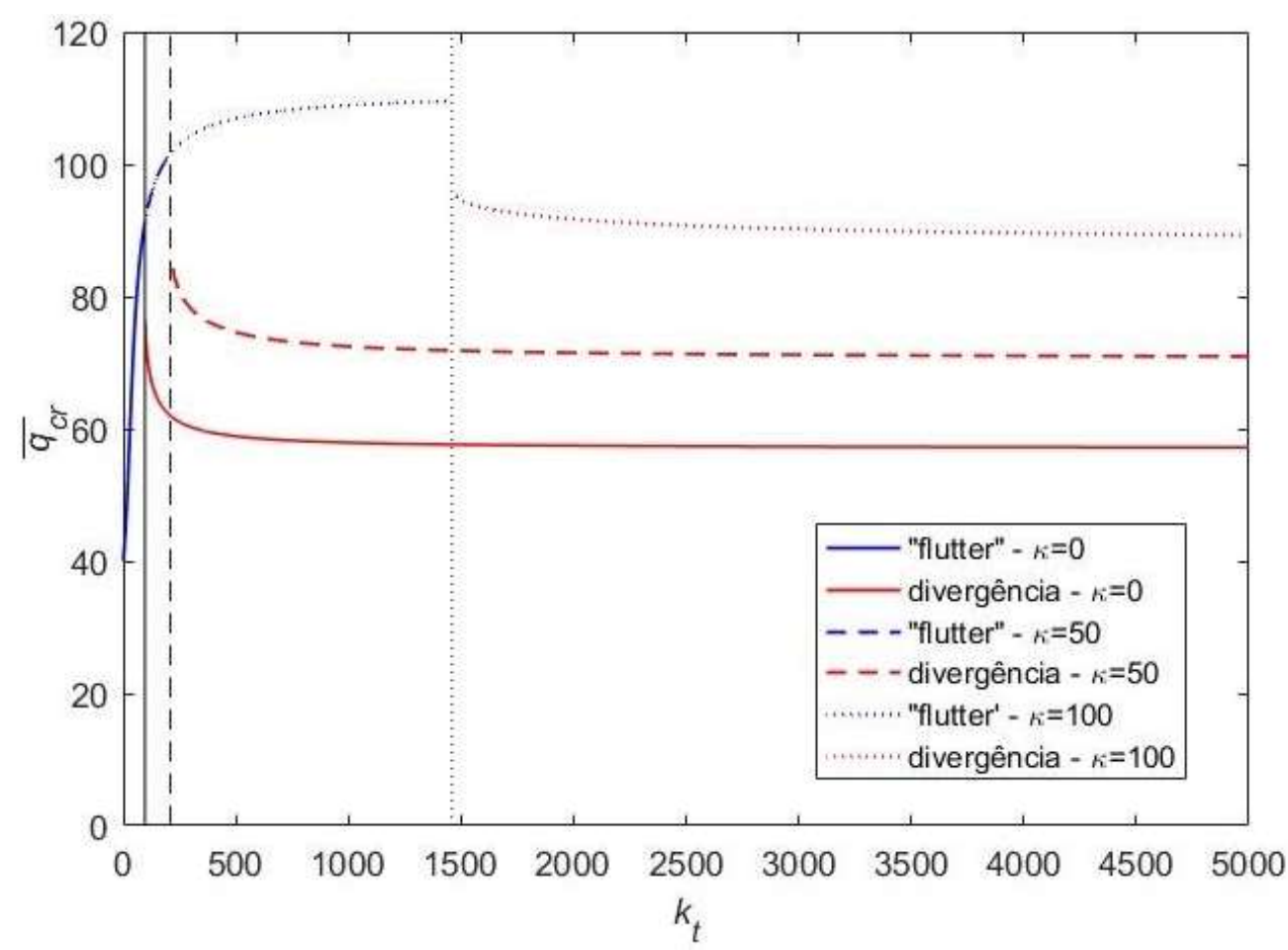

Figura 4.31 - Carga crítica vs. rigidez translacional da mola $\left(k_{t}\right)$ para $\kappa=0, \kappa=50 \mathrm{e}$ $\kappa=100-$ Caso II.

Observa-se, entretanto, que o aumento da constante de base elástica no estudo de influência do apoio translacional do caso II (Figura 4.31) gera uma tendência de um parâmetro crítico em "flutter". Sendo também necessário um intervalo consideravelmente maior de $k_{t}$ para evidenciar a mudança de condição crítica. Assim, para definir melhor esse comportamento a Figura 4.32 apresenta a variação do parâmetro crítico para maiores intensidades de base elástica. Para valores de $\kappa>100$ as tendências já observadas no gráfico para $\kappa=50$ e $\kappa=100$ permanecem, até que para uma constante de base elástica $(\kappa)$ superior a 111 a divergência não é mais observada (Figura 4.33). O sistema para qualquer restrição elástica translacional apresenta "flutter" com a tendência de parâmetro crítico correspondente a

$$
\bar{q}_{c r}\left(k_{t} \rightarrow \infty ; \kappa>111\right)=110,9 .
$$




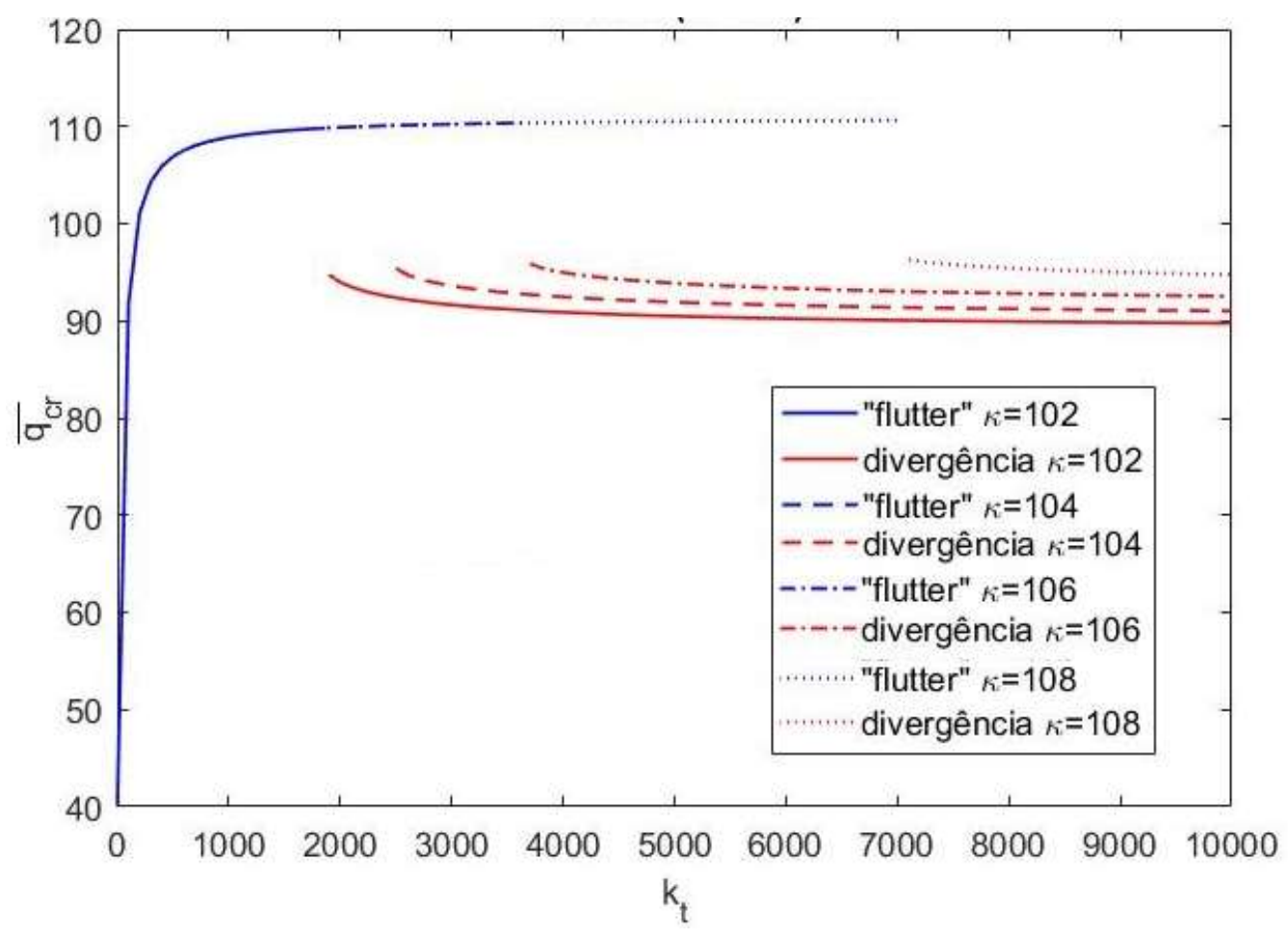

Figura 4.32 - Carga crítica vs. rigidez translacional da mola $\left(k_{t}\right)$ para $\kappa=102$, $\kappa=104, \kappa=106$ e $\kappa=108-$ Caso II.

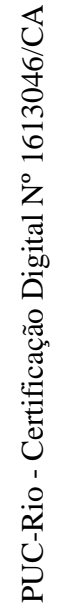

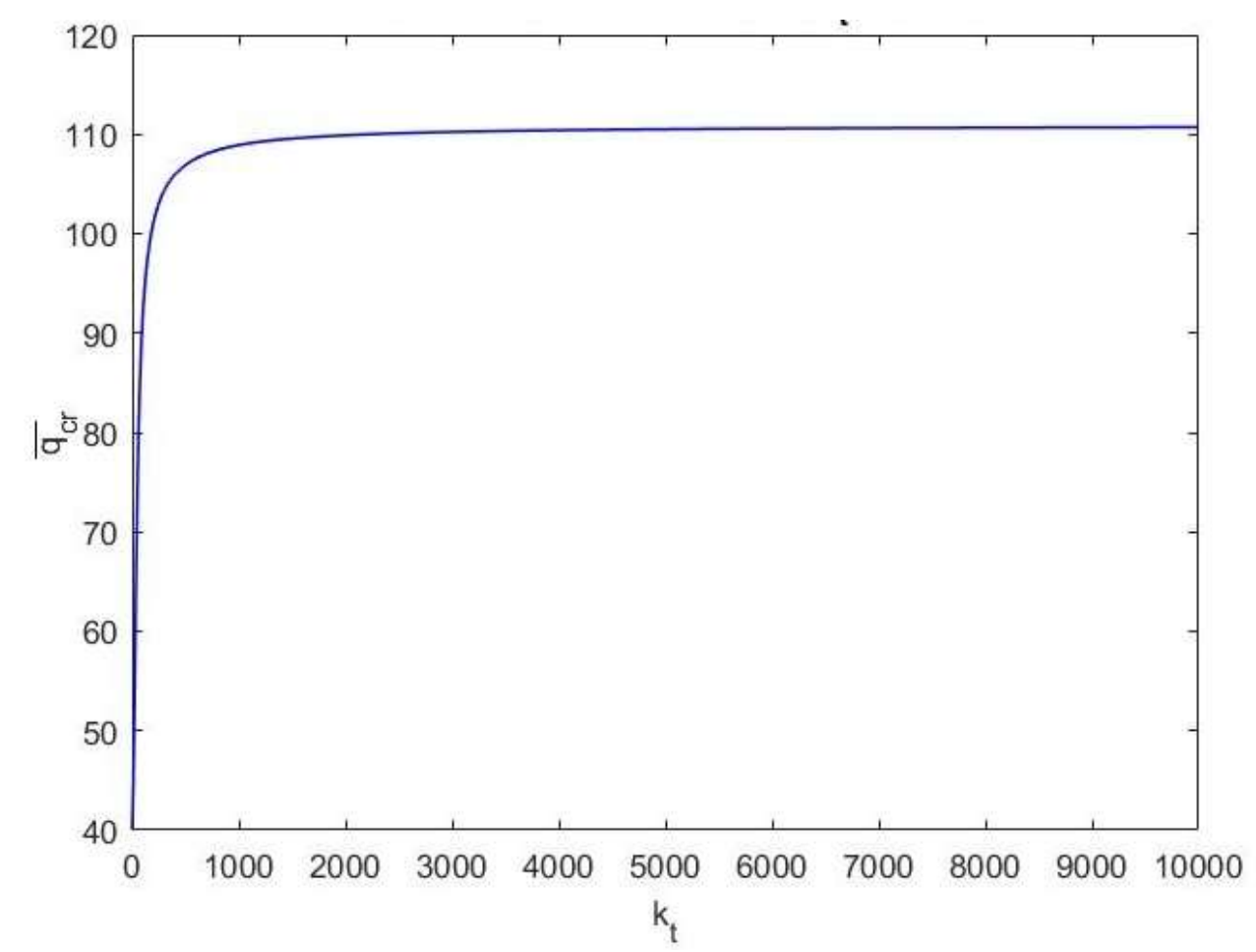

Figura 4.33 - Carga crítica vs. rigidez translacional da mola $\left(k_{t}\right)$ para $\kappa=111-$ Caso II. 
A Figura 4.34 apresenta o comportamento das duas primeiras frequências ao incremento de carga na condição engastada-apoiada $\left(k_{t} \rightarrow \infty\right)$ da coluna do caso II para diferentes parâmetros de base elástica próximos ao limite $\kappa=111$. A variação do comportamento das duas primeiras frequências ao incremento de carga com as diferentes constantes de base elástica permite uma melhor compreensão do fenômeno observado na Figura 4.33, para $\kappa=111$. Enquanto o sistema perde estabilidade por divergência, a curva da primeira frequência $\left(\omega_{1}\right)$ intercepta o eixo das abcissas a valores de carga cada vez maiores, demonstrando o efeito estabilizador. Já para o parâmetro de base elástica $\kappa=111$, em que instabilidade se dá por "flutter", a curva $\omega_{1}$ se aproxima do eixo das abcissas e em seguida altera bruscamente sua inclinação de forma a coincidir com a curva $\omega_{2}$. Este comportamento é similar ao observado na análise de influência dos apoios elásticos combinados feita no item 4.2.3.2.

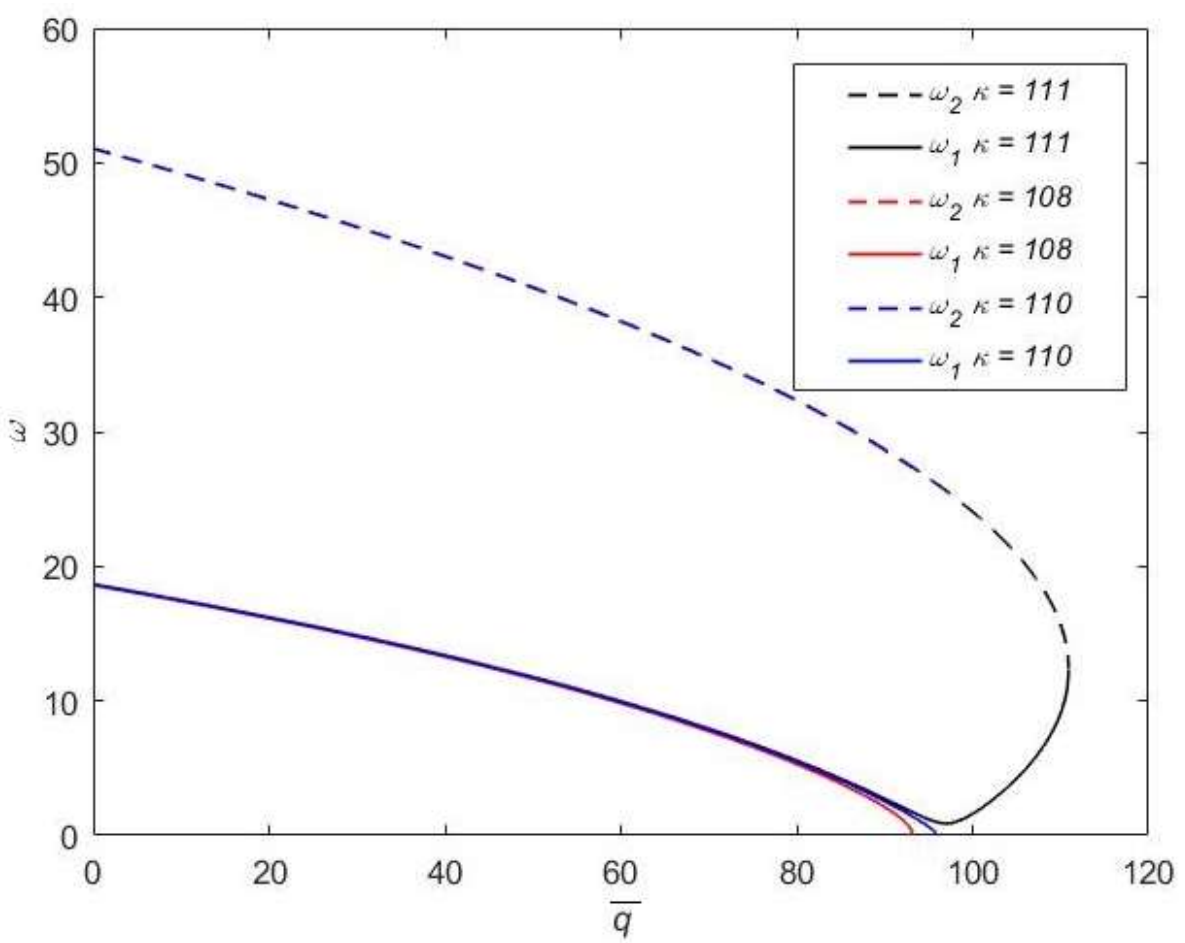

Figura 4.34 - Primeira e segunda frequência de vibração vs. parâmetro de carga na condição engastada-apoiada da coluna do caso II para $\kappa=108, \kappa=110$ e $\kappa=111$.

A relevância da base elástica na análise conjunta está associada ao aumento das frequências do sistema. Este aumento resulta, para os casos em que há mudança no tipo de condição crítica, em um aumento do trecho descrito por "flutter" e em consequência maiores valores de constante de mola nos pontos de transição (Tabela 4.4). Assim, a curva que relaciona o parâmetro crítico à constante de apoio elástico em "flutter" é a mesma para as diferentes constantes de base elástica analisadas, apenas sofrendo uma extensão com o aumento da constante $\kappa$. 
Tabela 4.4 - Comparação entre os valores de rigidez dos pontos de transição para $\kappa=0, \kappa=50$ e $\kappa=100$.

\begin{tabular}{c|ccc}
\hline$\kappa$ & $k_{t}^{*}(I)$ & $k_{r}^{*}(I)$ & $k_{t}^{*}(I I)$ \\
\hline 0 & 34,8 & 4,60 & 97,6 \\
\hline 50 & 49,0 & 18,4 & 211 \\
\hline 100 & 66,6 & 26,9 & $14,710^{2}$ \\
\hline
\end{tabular}

Além disso, o usual efeito estabilizador em sistemas conservativos é observado no trecho em que a perda de estabilidade se dá por divergência. Há a tendência de convergência do parâmetro crítico após os pontos de transição, e este aumenta com a presença de base elástica (Tabela 4.5).

Tabela 4.5 - Comparação entre os valores de parâmetro crítico de convergência $\left(k_{t} \rightarrow \infty\right.$ ou $\left.k_{r} \rightarrow \infty\right)$ para $\kappa=0, \kappa=50$ e $\kappa=100$.

\begin{tabular}{c|ccc}
\hline$\kappa$ & $\bar{p}_{c r}^{(1)}$ & $\bar{p}_{c r}^{(2)}$ & $\bar{q}_{c r}^{(1)}$ \\
\hline 0 & $\pi^{2} / 0,7$ & $\pi^{2}$ & 57,0 \\
\hline 50 & 24,3 & 23,6 & 70,6 \\
\hline 100 & 28,3 & 32,7 & 88,0 \\
\hline
\end{tabular}

Vale destacar que para esses sistemas elasticamente apoiados com mudança no tipo de condição crítica, como nos casos descritos acima, a presença de base elástica tem um grande efeito estabilizador para um dado intervalo de parâmetro de mola do apoio. Este intervalo está associado a mudança de condição crítica na presença de base elástica, alterando de divergência $(\kappa=0)$ para "flutter" $(\kappa>0)$. A Tabela 4.6 exemplifica este efeito para o caso I ao analisar conjuntamente a influência da base elástica e do apoio elástico translacional (Figura 4.29) 
Tabela 4.6 - Efeito estabilizador na presença de base elástica para o caso I com influência do apoio elástico translacional $\left(k_{t}\right)$.

\begin{tabular}{c|ccc}
\hline \multirow{2}{*}{$\kappa$} & $\bar{p}_{c r}$ & $\bar{p}_{c r}$ & $\bar{p}_{c r}$ \\
$\left(k_{t}=30\right)$ & $\left(k_{t}=40\right)$ & $\left(k_{t}=60\right)$ \\
\hline 0 & $\begin{array}{c}35,8 \\
\text { ("flutter") }\end{array}$ & $\begin{array}{c}27,9 \\
\text { (divergência) }\end{array}$ & $\begin{array}{c}24,2 \\
\text { (divergência) }\end{array}$ \\
\hline 50 & $\begin{array}{c}35,8 \\
\text { ("flutter") }\end{array}$ & $\begin{array}{c}40,6 \\
\text { ("flutter") }\end{array}$ & $\begin{array}{c}32,9 \\
\text { (divergência) }\end{array}$ \\
\hline 100 & $\begin{array}{c}35,8 \\
\text { ("flutter") }\end{array}$ & $\begin{array}{c}40,6 \\
\text { ("flutter") }\end{array}$ & $\begin{array}{c}46,8 \\
\text { ("flutter") }\end{array}$ \\
\hline
\end{tabular}

Já ao variar o parâmetro de base elástica na análise de influência da restrição rotacional no caso II, por apresentar apenas "flutter" não houve diferença na resposta, sendo então o sistema indiferente ao aumento de $\kappa$. A Figura 4.35 apresenta curvas sobrepostas para $\kappa=0$ e $\kappa=100$. Esse resultado está de acordo com o esperado uma vez que a base elástica, como observada no item 4.2.2, não altera o parâmetro crítico para sistemas com perda de estabilidade descrito pela coalescência das frequências.

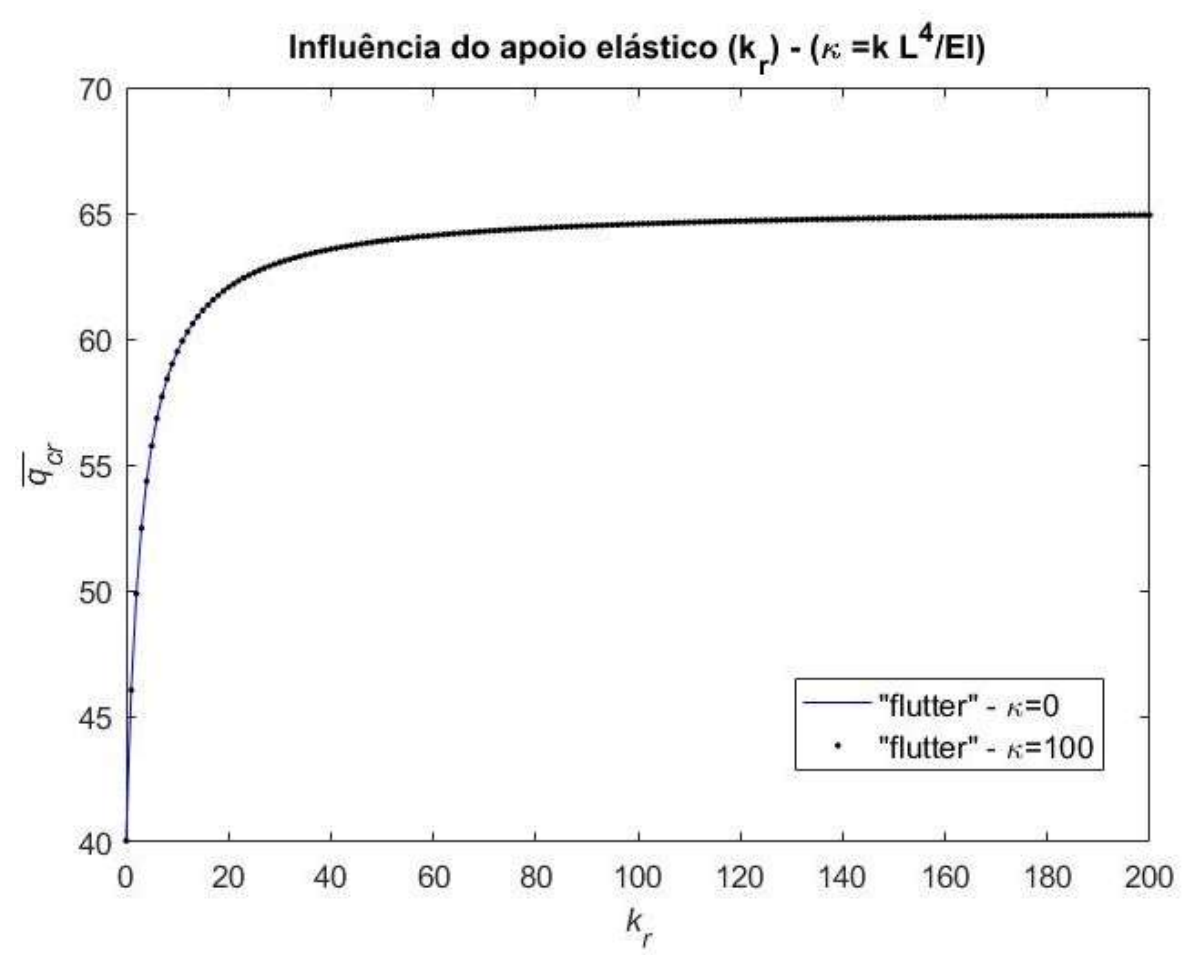

Figura 4.35 - Carga crítica vs. rigidez translacional da mola $\left(k_{r}\right)$ para $\kappa=0, \kappa=100-$ Caso II. 
A variação das frequências de coalescência ao incremento do parâmetro de rigidez dos apoios elásticos para as diferentes constantes de base elástica investigadas conclui essa análise conjunta (Figuras 4.36 a 4.39). As retas, seguindo o padrão utilizado nos demais gráficos, marcam a mudança de condição crítica associadas aos respectivos pontos de transição dos apoios elásticos de cada caso.

As Figuras 4.36 e 4.37 estão relacionadas as colunas do caso I, representando respectivamente a influência do apoio translacional $\left(k_{t}\right)$ e rotacional $\left(k_{r}\right)$. As curvas apresentadas nesses gráficos têm seu aspecto de certa forma similar, alterando principalmente o comprimento da curva relacionado ao aumento dos pontos de transição com incremento da constante de base elástica.

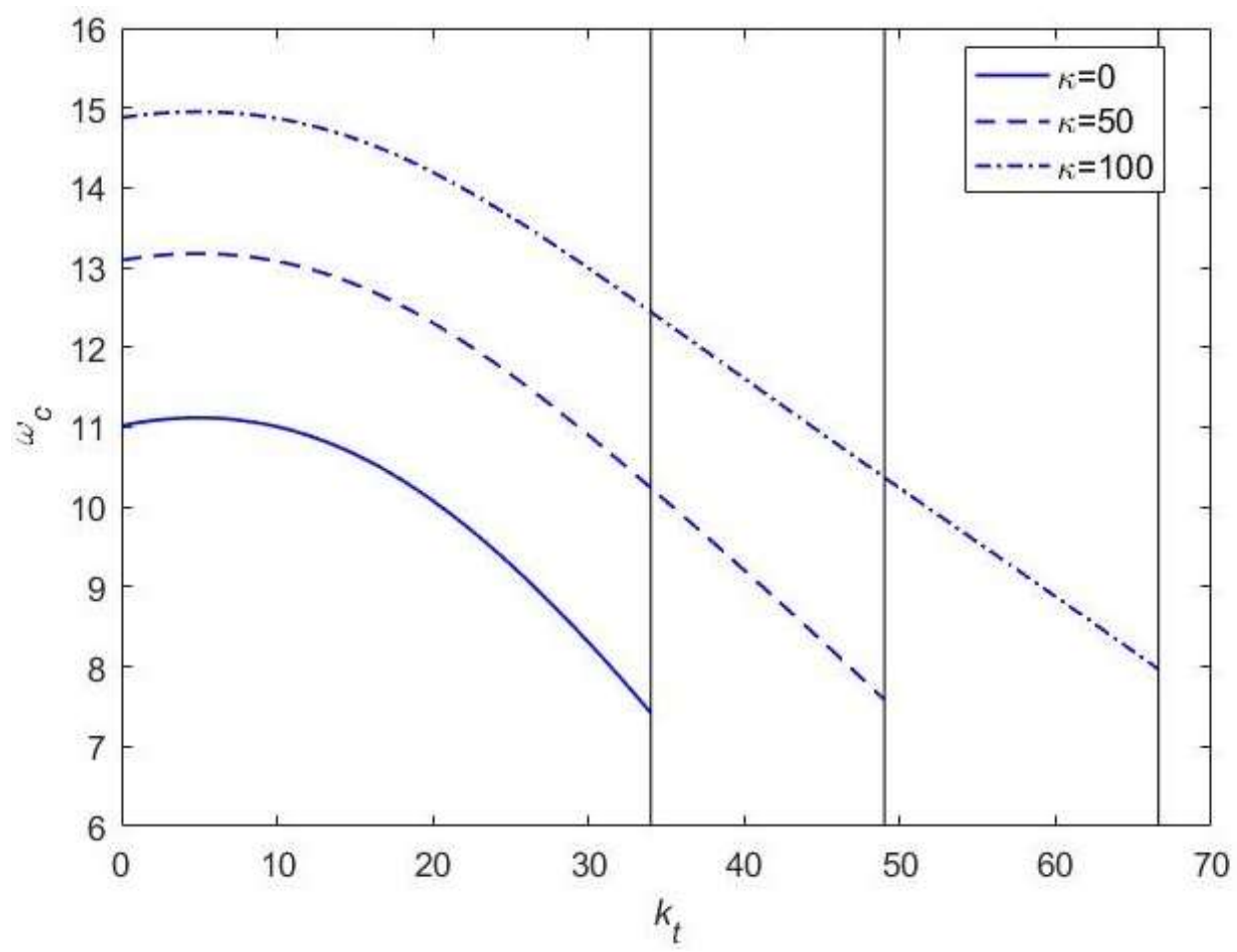

Figura 4.36 - Variação das frequências de coalescência ao incremento do parâmetro do apoio elástico translacional $\left(k_{t}\right)$ para $\kappa=0, \kappa=50$ e $\kappa=100-$ Caso I. 


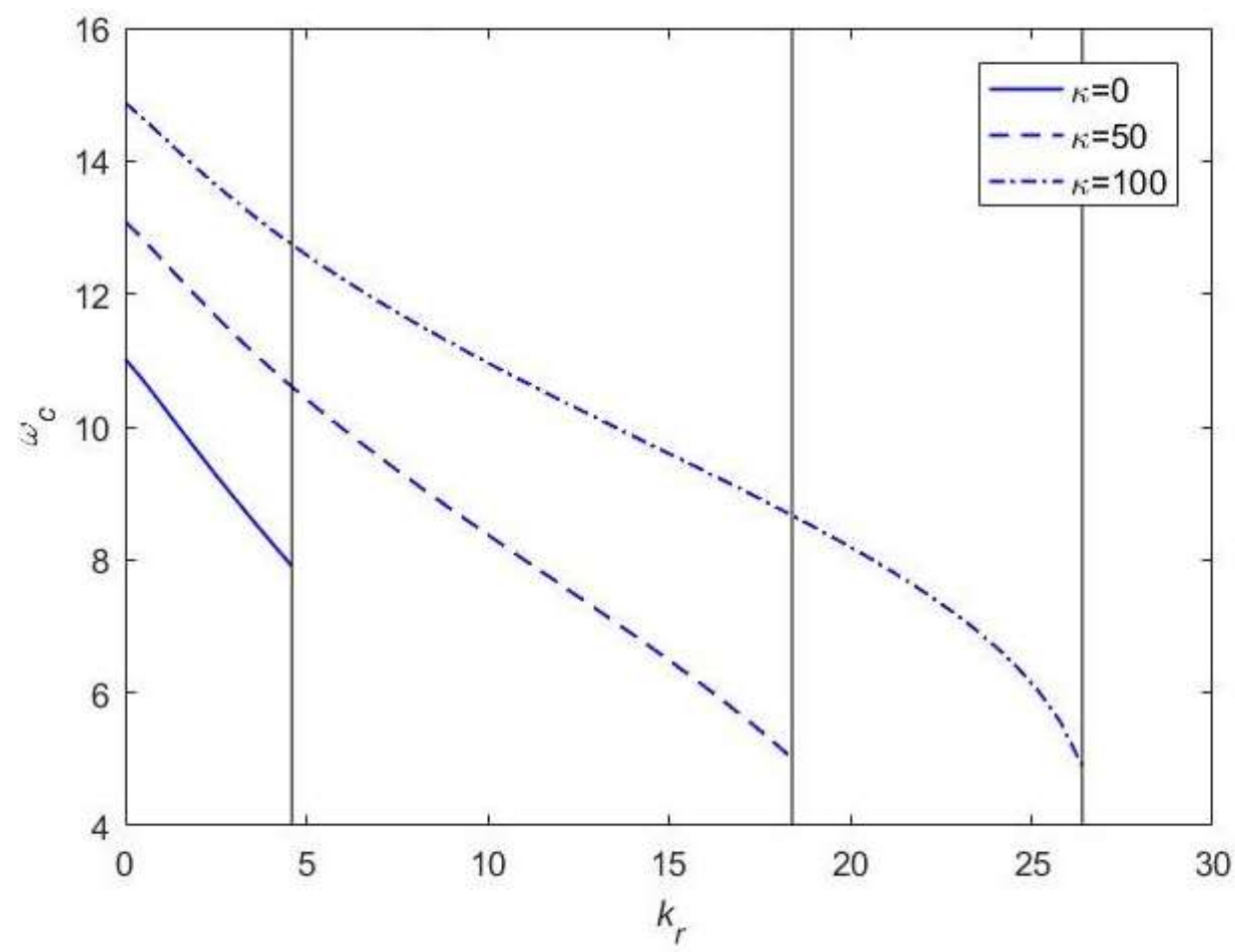

Figura 4.37 - Variação das frequências de coalescência ao incremento do parâmetro de apoio elástico rotacional $\left(k_{r}\right)$ para $\kappa=0, \kappa=50$ e $\kappa=100-$ Caso I.

Ao comparar o efeito da base elástica na variação das frequências de coalescência do caso I ao incremento de $k_{t}$ e $k_{r}$ (Figuras 4.36 e 4.37), observa-se que a frequência associada ao ponto de transição varia de forma distinta com a base elástica. No gráfico da Figura 4.36 a presença de base elástica pouco altera as frequências associadas ao ponto de transição, já no gráfico da Figura 4.37 há um decrescimento considerável dessas frequências (Tabela 4.7).

Tabela 4.7 - Comparação da variação das frequências de coalescência associadas ao ponto de transição para $\kappa=0, \kappa=50$ e $\kappa=100$ - Caso I

\begin{tabular}{c|cc}
\hline$\kappa$ & $\omega_{c}{ }^{I}\left(k_{t}^{*}(I)\right)$ & $\omega_{c}^{I}\left(k_{r}^{*}(I)\right)$ \\
\hline 0 & 7,52 & 7,90 \\
\hline 50 & 7,58 & 5,01 \\
\hline 100 & 7,97 & 3,69 \\
\hline
\end{tabular}

A variação da frequência de coalescência para o incremento do parâmetro de apoio elástico translacional do caso II foi o que apresentou maior diferença devido a presença de base elástica (Figura 4.38). O incremento de constante de base elástica além de aumentar as frequências, altera também o formato das curvas uma vez que para $\kappa>100$ já é possível perceber uma tendência na frequência de coalescência. 
Como já observado na Figura 4.33 ao analisar em conjunto a influência da base elástica com a restrição elástica translacional, a influência de $k_{t}$ na estabilidade do sistema muda para $\kappa>111$. Assim, é observada uma tendência na frequência de coalescência em não variar com o incremento do parâmetro dos apoios elásticos para $\kappa=100$ (Figura 4.38). O mesmo comportamento é observado para a coluna do caso II com sob influência do apoio elástico rotacional para qualquer valor de $\kappa$ (Figura 4.39).

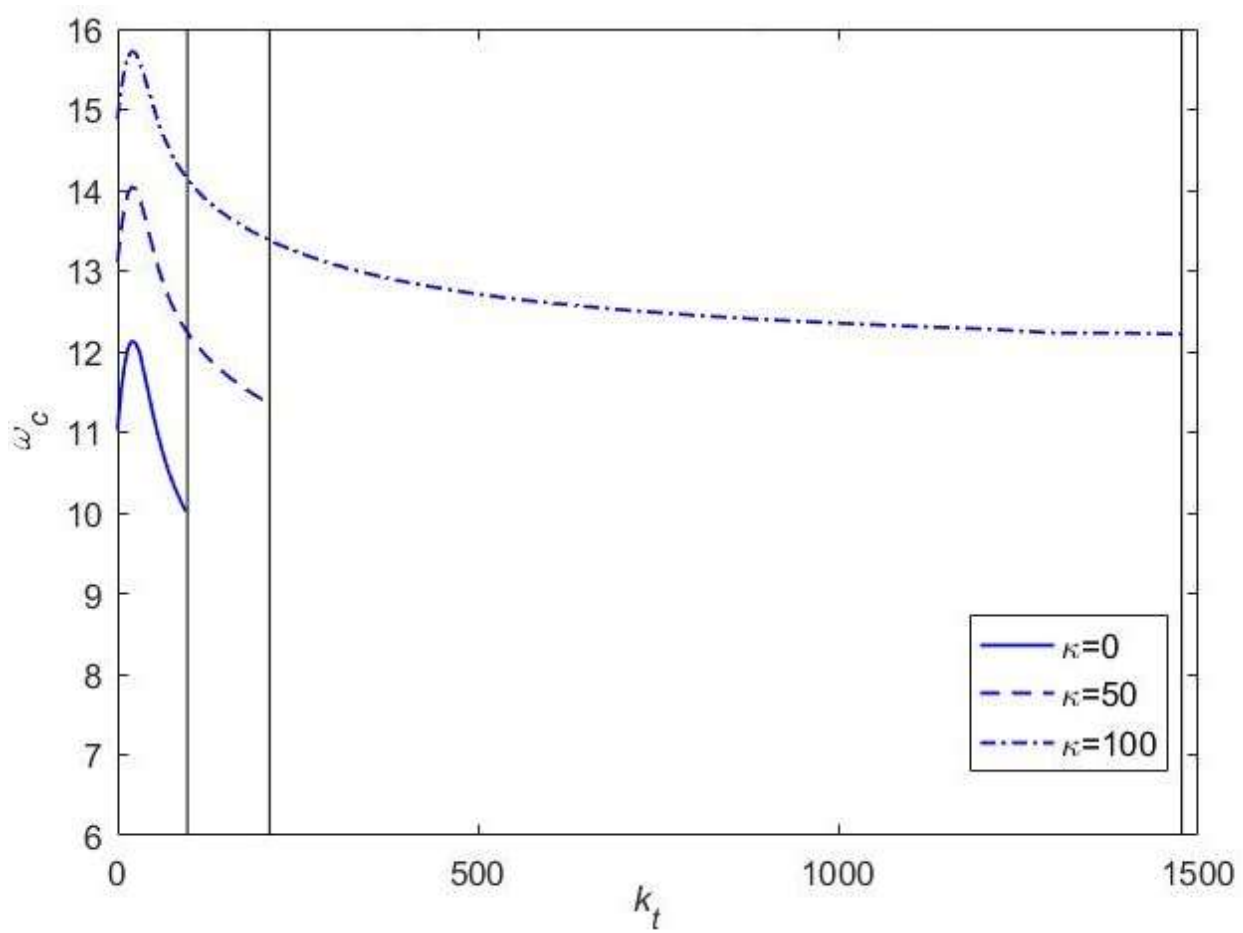

Figura 4.38 - Variação das frequências de coalescência ao incremento do parâmetro do apoio elástico translacional $\left(k_{t}\right)$ para $\kappa=0, \kappa=50$ e $\kappa=100-$ Caso II. 


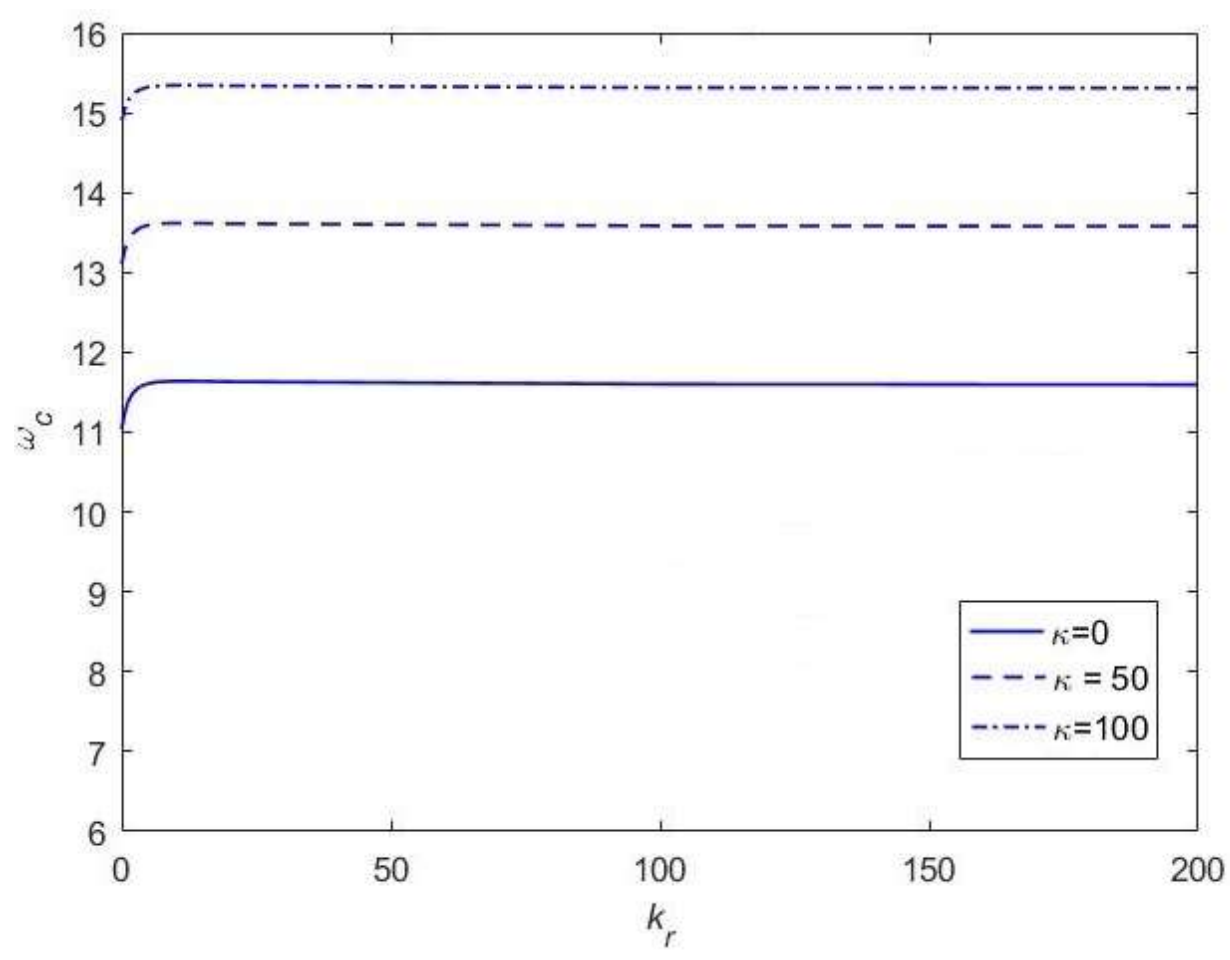

Figura 4.39 - Variação das frequências de coalescência ao incremento do parâmetro de apoio elástico rotacional $\left(k_{r}\right)$ para $\kappa=0, \kappa=50$ e $\kappa=100-$ Caso II.

\subsection{Comparação Entre os Modelos Clássicos de Colunas e o Modelo com Análise da Influência dos Apoios Elásticos}

A análise de estabilidade de tubulações engastada-livre apresenta além da força circulatória concentrada na extremidade livre da coluna, mesma analisada no modelo de coluna do caso I, o efeito da força Coriolis. A equação de movimento deste sistema é então descrita por

$$
E I \frac{\partial^{4} w}{\partial x^{4}}+\left(m_{f}+m_{t}\right) \frac{\partial^{2} w}{\partial t^{2}}+k w+m_{f} U^{2} \frac{\partial^{2} w}{\partial x^{2}}+2 m_{f} U \frac{\partial^{2} w}{\partial x \partial t}=0
$$

onde $m_{f}$ corresponde à massa de fluido distribuída ao longo da tubulação, $m_{s}$ à massa da tubulação também distribuída e $U$ à velocidade do fluido. Nesse problema o parâmetro de controle para o estudo de estabilidade corresponde à velocidade $U$ do fluido na tubulação. A equação também pode ser escrita na forma adimensional, por

$$
w^{\prime \prime \prime \prime}+\ddot{w}+\kappa w+u^{2} w^{\prime \prime}+2 u \sqrt{\beta} \dot{w}^{\prime}=0
$$


onde:

$$
u=U L \sqrt{\frac{m_{f}}{E I}} ; \beta=\frac{m_{f}}{m_{f}+m_{s}} ; \kappa=\frac{k L^{4}}{E I} ; \xi=\frac{x}{L} ; \tau=\frac{t}{L^{2}} \sqrt{\frac{E I}{m_{f}+m_{s}}} .
$$

dessa forma $w$ é função de $\xi$ e $\tau$.

A relevância da força de Coriolis no sistema está associada à relação entre a massa do fluido e a massa do sistema, sendo observada na equação de movimento adimensional (equação (4.20)). A equivalência entre o modelo de tubulação com movimento de fluido e o modelo de coluna do caso I ocorre então para a situação limite em que $\beta=0$ sendo o parâmetro de carga $\bar{p}$ equivalente a $u^{2}$.

Os resultados apresentados neste item sobre a análise de estabilidade do modelo de tubulações para as análises de influência da força de Coriolis, base elástica de Winkler e apoios elásticos foram reportados por Lottati [9], Sugiyama et.al [42] e Noah \& Hopkins [43]. Nos três trabalhos são analisados elementos de viga com as mesmas considerações admitidas neste trabalho, com exceção do modelo constitutivo utilizado por Sugyama et.al e Noah \& Hopkins que incorpora ao material do tubo um comportamento viscoelástico. O perfil de velocidade do fluido foi considerado em todos constante, sendo desprezado o atrito com a parede da tubulação.

Assim, a partir desses estudos faz-se uma comparação com os resultados obtidos do modelo de coluna para o caso I, por se tratar mais compatível com o modelo de tubulação.

\section{i. Influência da força de Coriolis.}

A força de Coriolis altera o comportamento do sistema de tubulação e o fator amplificador de seu efeito está associado à relação entre a massa linear do fluido e a massa linear total do sistema $(\beta)$. A Figura 4.40 apresenta a variação da velocidade crítica do fluido com perfil uniforme $\left(u_{c r}\right)$ do modelo de tubulação engastada-livre $\operatorname{com} \beta$ [9]. A influência deste parâmetro na estabilidade do sistema altera de acordo com seu valor, para $0<\beta \leq 10^{-4}$ é observado um efeito desestabilizador (Figura 4.40a) já para $10^{-4}<\beta \leq 1$ há uma mudança de comportamento, passando a ter um efeito estabilizador (Figura 4.40b).

Vale ressaltar que o efeito estabilizador observado para valores de $10^{-4}>\beta>1$ faz com que a simplificação do modelo de coluna do caso I (coluna de Beck) esteja a favor da segurança. 


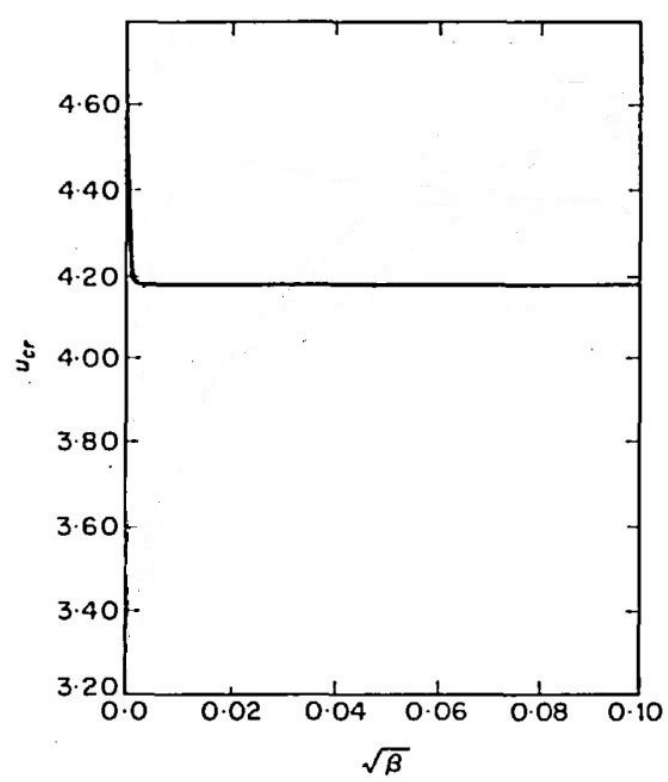

(a)

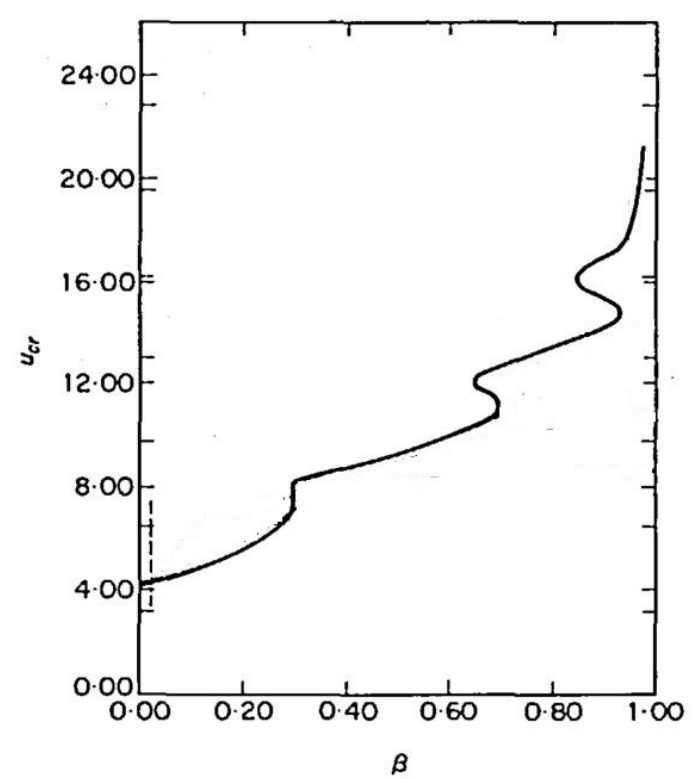

(b)

Figura 4.40 - Relação entre a velocidade crítica $\left(u_{c r}\right)$ e o parâmetro $\beta$ (adaptado [9]): (a) Efeito desestabilizador $0<\beta \leq 10^{-4}$; (b) Efeito estabilizador $10^{-4}<\beta \leq 1$.

ii. Influência da base elástica de Winkler.

A influência da base elástica, como já comentado, é a principal fonte de críticas ao modelo simplificado de coluna. A Figura 4.41 o comparativo entre o comportamento do sistema com e sem presença de base elástica de Winkler (respectivamente $\kappa=100, \kappa=0$ ) descrito por Lottati [9] no modelo de tubulação engastada-livre. 


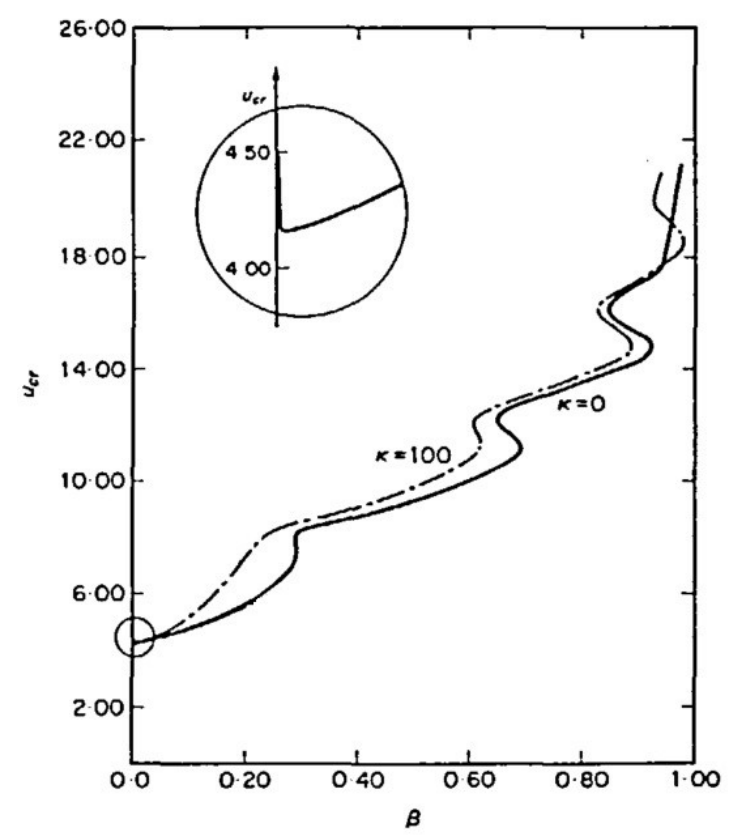

Figura 4.41 - Influência da base elástica de Winkler $\left(\kappa=k L^{4} / E I\right)$ no modelo de tubulação engastada-livre (adaptada [9]).

O efeito estabilizador presente no modelo de tubulação varia de acordo $\operatorname{com} \beta$, porém está presente em todo o intervalo. Bastante diferente então do efeito observado no modelo de coluna do caso I (item 4.2.2) em que a presença de base elástica não altera o parâmetro crítico de carga.

A diferença entre o efeito da base elástica nos dois modelos se dá principalmente pelo tipo de forma de instabilidade dos sistemas. A condição crítica no caso da coluna se dá por coalescência de duas frequências ("coupledmode flutter"), então o aumento das frequências é proporcional ao aumento da rigidez da base elástica e não altera o parâmetro crítico.

Já para o caso do modelo de tubulação com movimento de fluido a condição crítica é determinada apenas pela instabilidade em uma das frequências ("single-mode flutter"), representada por um complexo conjugado. Logo, como nos sistemas que sofrem divergência, condição crítica determinada quando uma das frequências se anula, o aumento das frequências pela presença da base elástica gera um efeito estabilizador.

iii. Influência dos apoios elásticos.

A influência dos apoios elásticos na extremidade livre nos dois modelos, tubulação com movimento de fluido e coluna com força seguidora concentrada, tem comportamento bastante similar. Os dois modelos apresentam mesmo resultados de parâmetro crítico e condição crítica quando as extremidades estão restritas ao deslocamento ou a rotação, pois a força de Coriolis perde efeito ao se restringirem os deslocamentos na extremidade. Ambos os modelos, sujeitos à 
força seguidora, ao restringir o deslocamento na extremidade são caracterizados como conservativos e a perda de estabilidade se dá por divergência e parâmetro crítico é idêntico ao sistema conservativo com carga de direção constante.

Foi observado experimentalmente e teoricamente para o modelo de tubulação por Sugiyama et.al [42] e Noah \& Hopkins [43]: a mudança de condição crítica com aumento da rigidez do apoio elástico na extremidade; a diminuição do parâmetro crítico ao alterar a condição de "flutter" para divergência e mudança do efeito estabilizador em flutter para desestabilizador em divergência para o incremento de rigidez do apoio. Sugiyama et.al analisou teoricamente e experimentalmente a influência do apoio elástico translacional e Noah \& Hopkins teoricamente a influência separada e conjunta dos apoios elásticos translacional e rotacional.

O comportamento do sistema sujeito a uma análise incremental do apoio elástico, separadamente, e os valores dos pontos de transição teóricos reportados por Sugiyama et.al [42] e Noah \& Hopkins [43] estão de acordo com os obtidos no modelo simplificado de coluna do caso I (item 4.2.3.1). Para valores de constante de apoio elástico menores que o ponto de transição a perda de estabilidade é dinâmica e o incremento da constante tem efeito estabilizador. Há uma queda brusca do parâmetro crítico no ponto de transição, em que há a mudança de condição crítica e para valores de constante superiores a perda de estabilidade se dá por divergência. Nesse segundo trecho o efeito do incremento da constante de mola é desestabilizador e o parâmetro crítico tende ao parâmetro do modelo clássico conservativo correspondente a condição de contorno.

A compatibilidade observada dos valores de ponto de transição mesmo ao se comparar um modelo de maior complexidade, efeito do fluido e modelo constitutivo Kelvin-Voight [42, 43], pode ser justificada pelo fato dos termos associados a estes efeitos estarem relacionados ao comportamento dinâmico do sistema. Como este ponto marca a mudança entre a condição crítica dinâmica e estática, ao analisar o comportamento da estrutura de forma estática os termos dependentes do tempo perdem efeito, observado também para a força de Coriolis no caso da tubulação bi-apoiada e bi-engastada por Païdoussis [32].

Ao analisar experimentalmente Sugiyama et.al [42] observou, entretanto, uma variação do ponto de transição com os três valores $\beta$ analisados (Tabela 4.8) e mesmo material com comportamento viscoelástico. A equação de movimento utilizada em seu estudo foi

$$
w^{\prime \prime \prime \prime}+\gamma \dot{w}^{\prime \prime \prime}+\ddot{w}+u^{2} w^{\prime \prime}+2 u \sqrt{\beta} \dot{w}^{\prime}+k w \delta\left(\xi-\xi_{1}\right)=0
$$

onde os termos adicionais correspondem ao modelo constitutivo utilizado e a condição de contorno aplicada pelo uso da função de Dirac $\delta(\xi)$. Os parâmetros associados a estes termos são:

$$
\gamma=\frac{1}{L^{2}} \frac{E^{*}}{E}\left[\frac{E I}{m_{f}+m_{s}}\right] ; k_{t}=\frac{K L^{3}}{E I} ; \xi_{1}=1 .
$$


em que $\mathrm{E}^{*}$ é o coeficiente de amortecimento do material e $\mathrm{K}$ é a constante de mola do apoio elástico translacional.

A diferença entre experimentos e o valor teórico se mostrou superior na relação de massas $(\beta)$ com maior valor [42]. Vale ressaltar que foi observado que o aumento da velocidade crítica devido ao aumento de $\beta$ resulta em uma maior da redução da velocidade crítica no ponto de transição (Figura 4.42).

Tabela 4.8 - Valores de ponto de transição para a constante de apoio elástico transversal $\left(k_{t}^{*}\right)$ observado no ensaio reportado por Sugiyama et.al [42] para diferentes valores de $\beta$

\begin{tabular}{c|c}
\hline$\beta$ & $k_{t}{ }^{*}$ \\
\hline 0,249 & 35,9 \\
\hline 0,505 & 34,6 \\
\hline 0,780 & 23,4 \\
\hline
\end{tabular}

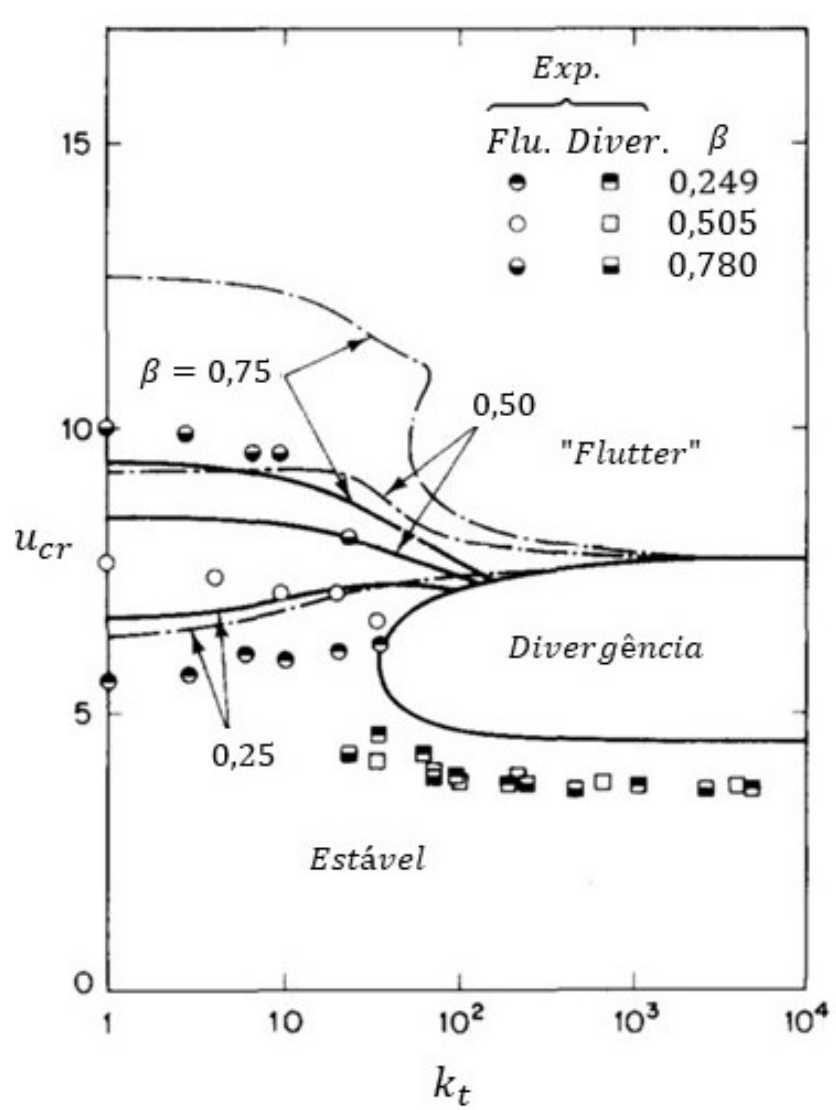

Figura 4.42 - Influência do apoio elástico translacional $\left(k t=K L^{3} / E I\right)$ no modelo de tubulação engastada-elasticamente apoiada com duas curvas teóricas (sólida para $\gamma=0,02$ e tracejada para $\gamma=0,001$ ) (adaptada [42]). 
A análise de influência dos apoios elásticos conjunta realizada por Noah \& Hopkins [43] mostrou a dependência do comportamento do sistema não somente nos valores de constante dos apoios elásticos mas da relação entre eles. Tendo como valores limites $\left(k_{t} *(I)=34,8\right.$ e $\left.k_{r} *(I)=4,60\right)$, os mesmos observados no item 4.2.3.1, foram analisadas as seguintes combinações: $k_{t}=20 k_{r}=10 ; k_{t}=40 k_{r}$ $=10$ e $k_{t}=100 k_{r}=10$. Em todas as combinações $k_{r}>k_{r} *(I)$, sendo apenas na segunda e terceira $k_{t}>k_{t} *(I)$. Na primeira combinação foi observada ainda a condição crítica dinâmica, já nas demais foi observado divergência. Este mesmo comportamento foi visto nas duas primeiras combinações no item 4.2.3.2 para o modelo de coluna do caso I. 


\section{Considerações Finais}

\subsection{Conclusões}

Foi desenvolvido neste trabalho um programa computacional para avaliar o comportamento crítico de colunas submetidas à carregamentos circulatórios. A metodologia implementada foi desenvolvida através do método aproximado de Rayleigh-Ritz, enriquecendo-se o campo de deslocamento de um elemento de viga Euler-Bernoulli descrito por funções polinomiais, com funções adicionais trigonométricas, e incluindo o efeito não conservativo das forças circulatórias com uso de matrizes de carga não simétricas.

A validação da metodologia implementada no programa foi feita através de valores de referência da literatura para os dois tipos de carregamento analisados no modelo de coluna, carga seguidora concentrada na extremidade livre (caso I) e carregamento seguidor distribuído ao longo do elemento (caso II). O programa gerou resultados com boa correlação com as referências de forma eficiente e rápida.

Analisaram-se as influências da base elástica de Winkler e apoio elástico rotacional e translacional para ambos os casos. Foi avaliado o comportamento do sistema variando-se independentemente os parâmetros de base elástica e dos apoios elásticos, seguido de uma análise combinada dos efeitos dos dois tipos de apoios elásticos e da base elástica com o apoio elástico.

No caso da influência da base elástica, foi observado para ambos os casos uma indiferença ao acréscimo da constante de base elástica permanecendo constante o valor do parâmetro de carga crítico. A única alteração observada neste processo incremental foi o aumento das frequências de coalescência, e para os dois casos foi gerada a mesma relação entre o aumento das frequências de coalescência e o aumento da constante de base elástica. Uma vez que este problema é regido pela troca de energia entre os dois modos de vibração, haverá "flutter" na carga crítica por efeito da energia externa introduzida no sistema. Dessa forma, os efeitos obtidos no sistema com o aumento da constante de base elástica, ou seja, a redução das amplitudes e aumento das frequências no "flutter" induzidos pelo mesmo parâmetro de carga, não são contraditórios. O resultado obtido por Hermann \& Smith [8] é então aqui confirmado.

Já a análise de influência dos apoios elásticos gerou respostas um tanto distintas entre os dois casos estudados. No caso I, a influência dos dois tipos de apoio elástico (translacional e rotacional) foi bastante similar. O incremento da constante de apoio elástico tem efeito estabilizador enquanto o sistema perde estabilidade dinamicamente, havendo então um ponto de transição que marca a mudança de condição crítica para estática. $\mathrm{Na}$ condição crítica estática o 
incremento da constante, entretanto, tem efeito desestabilizador e o parâmetro crítico tende ao parâmetro clássico do sistema conservativo com carga de direção constante.

Já no caso II a influência dos dois tipos de apoio elástico gerou resultados distintos, podendo isto ser justificado pela distribuição do carregamento ao longo do elemento atuante sobre as diferentes deformadas associadas às restrições de translação e rotação. A influência do apoio elástico translacional é similar à observada no caso I, porém na análise de influência do apoio elástico rotacional não foi constatada a mudança na condição crítica. O incremento da constante de apoio elástico rotacional no caso II teve para pequenos valores um grande efeito estabilizador. Em seguida foi observada uma indiferença ao seu incremento, uma vez que o parâmetro de carga crítica apresentou uma tendência, ainda na condição dinâmica, para um valor aproximadamente $340 \%$ superior ao parâmetro de carga crítico de uma coluna sujeita a peso próprio.

As análises dos apoios elásticos combinados, em ambos os casos, geraram resultados inesperados uma vez que os comportamentos e valores observados nas análises dos mesmos sistemas submetidos separadamente aos apoios elásticos rotacional e translacional não foram limitantes. Observou-se nas análises combinadas condição crítica dinâmica em sistemas para valores de constante de apoio elástico superiores aos pontos de transição. Esses resultados indicam que a resposta do sistema depende não apenas dos valores das constantes individuais (translacional e rotacional) mas da relação entre elas.

A análise conjunta da base elástica com os apoios elásticos resumiu de certa forma os resultados constatados nas análises dos parâmetros feita separadamente. A base elástica não gerou efeito estabilizador no sistema em condição crítica dinâmica aumentando apenas as frequências, que para um aumento da constante de apoio elástico gerou maiores valores dos pontos de transição. No caso II, para apoio elástico translacional, como a condição crítica permanece dinâmica, a presença de base elástica não alterou a influência do apoio na estabilidade do sistema.

Ressalta-se, entretanto, o comportamento distinto observado no caso II ao avaliar a influência conjunta do apoio elástico translacional em presença de base elástica. Neste foi observado um grande aumento no ponto de transição para os valores de constante de base elástica analisados e uma certa tendência de estabilização do parâmetro crítico de carga na condição dinâmica. Ao se avaliarem em detalhe valores superiores de constantes de base elástica, observouse uma tendência do sistema em permanecer na condição crítica dinâmica tendo então uma resposta ao incremento de constante de apoio elástico translacional similar à observada com o apoio rotacional também no caso II.

Comparando os resultados das análises de influência do modelo clássico de coluna do caso I com o modelo de tubulação com movimento de fluido pode-se concluir que o modelo simplificado de coluna gera alguns resultados bastante coerentes com o modelo mais complexo de tubulação, como a influência dos apoios elásticos. A influência da base elástica, porém, se distingue bastante devido 
à diferença na forma de perda de estabilidade na condição dinâmica dos dois modelos. Destaca-se que o modelo de coluna com carregamento seguidor concentrado apresenta uma considerável simplificação ao negligenciar o fluido no modelo, descartando o efeito da força de Coriolis. A simplificação do modelo de coluna gera um método consideravelmente menos complexo de determinação do parâmetro crítico pois ao desconsiderar a força dependente da velocidade o problema de autovalor deixa de ser quadrático, possibilitando a análise das frequências no domínio real.

\subsection{Sugestões para trabalhos futuros}

Os seguintes tópicos são sugeridos para a continuidade deste trabalho:

i. Considerar outras forças não conservativas como dependentes da velocidade e do tempo no programa através da mesma metodologia já implementada.

ii. Estudar a representação das forças de atrito para incorporar um carregamento não conservativo presente em todos os sistemas reais.

iii. Considerar não linearidade geométrica e física nos modelos propostos para um estudo de instabilidade mais completo.

iv. Avaliar a influência de base elástica do tipo Pasternack e não uniforme nos modelos de coluna.

v. Avaliar o efeito da inércia rotacional, principalmente no modelo de coluna de Leipholz e de tubulação com movimento de fluido. 


\section{Referências bibliográficas}

[1] V. V. Bolotin, Nonconservative Problems of Theory of Elastic Stability. 1963.

[2] H. Ziegler, Principles of Structural Stability, Second. Basel: Birkhäuser Basel, 1977.

[3] M. Beck, "Die Knicklast des Einseitig Eingespannten Tan- gential Gedrückten Stabes," Zeitschrift für AngewandteMathematik und Physik, vol. 3, pp. 225-228, 1952.

[4] H. Leipholz, "Die Knicklast des einseitig eingespannten Stabes mit gleichmässig verteilter, tangentialer Längsbelastung," Zeitschrift für AngewandteMathematik und Physik, vol. 13, pp. 581-589, 1962.

[5] M. A. Langthjem and Y. Sugiyama, "Dynamic stability of columns subjected to follower loads: a survey," Journal of Sound and Vibration, vol. 238, no. 5, pp. 809-851, 2000.

[6] W. T. Koiter, "UNREALISTIC FOLLOWER FORCES," Journal of Sound and Vibration, vol. 194, no. 4, p. 636, Jul. 1996.

[7] I. Elishakoff, "Controversy associated with the so-called 'follower forces': critical overview," Applied Mechanics Reviews, vol. 58, no. 2, p. 117, 2005 .

[8] T. E. Smith and G. Hermann, "Stability of a Beam on an Elastic Foundation Subjected to a Follower Force," Journal of Applied Mechanics, vol. 39, pp. 628-629, 1972.

[9] I. Lottati and A. Kornecki, "The effect of an elastic foundation and of dissipative forces on the stability of fluid-conveying pipes," Journal of Sound and Vibration, vol. 109, no. 2, pp. 327-338, 1986.

[10] Y. SUGIYAMA, M. A. LANGTHJEM, and B.-J. RYU, "REALISTIC FOLLOWER FORCES," Journal of Sound and Vibration, vol. 225, no. 4, pp. 779-782, Aug. 1999.

[11] B. Y. Sugiyama, K. Katayama, and S. Kinop, "Flutter of cantilevered column under rocket thrust," Journal of Aerospace Engineering, vol. 8, no. 1, pp. 9-15, 1995.

[12] Y. Sugiyama, J. Matsuike, B. Ryu, K. Katayama, S. Kinoi, and N. Enomoto, "Effect of Concentrated Mass on Stability of Cantilevers Under Rocket Thrust," AIAA Journal, vol. 33, no. 3, pp. 499-503, 1995.

[13] Y. Sugiyama, K. Katayama, and K. Kiriyama, "Experimental verification of dynamic stability of vertical cantilevered columns subjected to a subtangential force," Journal of Sound and Vibration, vol. 236, no. 2, pp. 193- 
207, 2000.

[14] D. Bigoni and G. Noselli, "Experimental evidence of flutter and divergence instabilities induced by dry friction," Journal of the Mechanics and Physics of Solids, vol. 59, no. 10, pp. 2208-2226, 2011.

[15] M. P. Païdoussis, Fluid-Structure Interactions, Second edi., vol. 1. Québec: Elsevier Ltd., 2014.

[16] J. E. Mottershead and S. N. Chan, "Flutter instability of circular discs with frictional follower loads," ASME Journal of Vibration and Acoustics, vol. 117, no. January 1995, pp. 161-163, 1995.

[17] H. Leipholz, Stability Theory. Wiesbaden: Vieweg+Teubner Verlag, 1987.

[18] Z. P. Bazant, L. Cedolin, and J. W. Hutchinson, Stability of Structures: Elastic, Inelastic, Fracture, and Damage Theories, no. 2. 1993.

[19] R. S. Barsoum, "Finite element method applied to the problem of stability of a non-conservative system," International Journal of Numerical Methods in Engineering, vol. 3, no. January 1970, pp. 63-87, 1971.

[20] D. B. McIver, "Hamilton's principle for systems of changing mass," Journal of Engineering Mathematics, vol. 7, no. 3, pp. 249-261, 1973.

[21] M. Kheiri and M. P. Païdoussis, "On the use of generalized Hamilton's principle for the derivation of the equation of motion of a pipe conveying fluid," Journal of Fluids and Structures, 2014.

[22] T. B. Benjamin, "Dynamics of a System of Articulated Pipes Conveying Fluid. I. Theory," Proceedings of the Royal Society A: Mathematical, Physical and Engineering Sciences, vol. 261, no. 1307, pp. 457-486, 1961.

[23] R. W. Gregory and M. P. Paidoussis, "Unstable Oscillation of Tubular Cantilevers Conveying Fluid. I. Theory," Proceedings of the Royal Society A: Mathematical, Physical and Engineering Sciences, vol. 293, no. 1435, pp. 512-527, Aug. 1966.

[24] U. Lee, C. H. Pak, and S. C. Hong, "The dynamics of a piping system with internal unsteady flow," Journal of Sound and Vibration, vol. 180, no. 2. pp. 297-311, 1995.

[25] L. R. Curling and M. P. Païdoussis, "Analyses for random flow-induced vibration of cylindrical structures subjected to turbulent axial flow," Journal of Sound and Vibration, vol. 264, no. 4, pp. 795-833, 2003.

[26] A. M. Hellum, R. Mukherjee, and A. J. Hull, "Dynamics of pipes conveying fluid with non-uniform turbulent and laminar velocity profiles," Journal of Fluids and Structures, vol. 26, no. 5, pp. 804-813, 2010.

[27] G. T. S. Done and A. Simpson, "Dynamic instability of certain conservative and non-conservative systems," Journal of Mechanical Engineering Science, vol. 19, no. 6, pp. 251-263, Dec. 1977.

[28] P. J. Holmes, "Pipes Supported at Both Ends Cannot Flutter," Journal of Applied Mechanics, vol. 45, no. 3, pp. 619-622, 1978. 
[29] V. V Bolotin, "Dynamic instabilities in mechanics of structures," Applied Mechanics Review, vol. 52, pp. R1-R9, 1999.

[30] F.-J. Bourrières, "Sur un phénomène d'oscillation auto-entretenue en mécanique des fluides réels," Publications Scientifiques et Techniques duMinistère de l'Air, vol. 147, 1939.

[31] R. W. Gregory and M. P. Paidoussis, "Unstable Oscillation of Tubular Cantilevers Conveying Fluid . II . Experiments," Proceedings of the Royal Society A: Mathematical, Physical and Engineering Sciences, vol. 293, no. 1435, pp. 528-542, 1966.

[32] T. B. Benjamin, "Dynamics of a system of articulated pipes conveying fluid II . Experiments," Proceedings of the Royal Society A: Mathematical, Physical and Engineering Sciences, vol. 261, no. 1307, pp. 487-499, 1961.

[33] A. S. Greenwlad and J. Dungundji, "Static and dynamic instabilities of a propellant line," MIT Aeroelastic and Structures Research Lab, AFOSR Sci, pp. 67-1395, 1967.

[34] M. Becker, W. Hauger, and W. Winzen, "Exact stability analysis of uniform cantilevered pipes conveying fluid or gas," Archives of Mechanics (Warsaw), vol. 30, pp. 757-768, 1978.

[35] I. Elishakoff and X. Wang, "Generalization of smith-herrmann problem with the aid of computerized symbolic algebra," Journal of Sound and Vibration, vol. 117, no. 3, pp. 537-542, Sep. 1987.

[36] J. Kim, K. Lee, and J. Lee, "Beam stability on an elastic foundation subjected to distributed follower force," Journal of Mechanical Science and Technology, vol. 22, pp. 2386-2392, 2008.

[37] P. DJONDJOROV, V. VASSILEV, and V. DZHUPANOV, "Dynamic Stability of Fluid Conveying Cantilevered Pipes on Elastic Foundations," Journal of Sound and Vibration, vol. 247, no. 3, pp. 537-546, 2001.

[38] A. Marzani, F. Tornabene, and V. Erasmo, "Nonconservative stability problems via generalized differential quadrature method," Journal of Sound and Vibration, vol. 315, pp. 176-196, 2008.

[39] C. Sundararajan, "Influence of an elastic end support on the vibration and stability of Beck's column," International Journal of Mechanical Sciences, vol. 18, no. 5, pp. 239-241, May 1976.

[40] R. L. M. Suanno, “Análise da estabilidade de estruturas sob a ação de cargas não-conservativas," Pontifícia Universidade Católica do Rio de Janeiro, 1988.

[41] S. A. Venuraju, M. T. ;Ramu, "Influence of an additional discrete elastic support on the stability of a Leipholz column," Computers and Structures, vol. 36 , no. 4, pp. 769-775, 1990.

[42] Y. Sugiyama, Y. Tanaka, T. Kishi, and H. Kawagoe, "Effect of a spring support on the stability of pipes conveying fluid," Journal of Sound and Vibration, vol. 100, no. 2, pp. 257-270, 1985. 
[43] S. T. Noah and G. R. Hopkins, "Dynamic stability of elastically supported pipes conveying pulsating fluid," Journal of Sound and Vibration, vol. 71, no. 1, pp. 103-116, 1980.

[44] S. Timoshenko and J. Gere, Theory of elastic stability, Second edi. New York: McGraw-Hill International Book Company, 1963.

[45] O. F. Z. Inch, "Influência da viscoelasticidade e cisalhamento na estabilidade dinâmica de vigas e tubos," Pontifícia Universidade Católica do Rio de Janeiro - PUC-RIO, 2014.

[46] R. L. M. Suanno and R. Rosas e Silva, "Influence of mass distribution, shear deformation, and rotatory inertia on flutter loads," The American Society Of Mechanical Enginners, vol. 42, no. 11, pp. 249-252, 1989.

[47] R. Cook, D. Malkus, M. Plesha, and R. Witt, Concepts and Applications of Finite Element Analysis, Forth edit. Winsconsin: John Wiley \& Sons, 2002.

[48] H. D. Hibbitt, "Some follower forces and load stiffness," International Journal of Numerical Methods in Engineering, vol. 14, no. 6, pp. 937-941, 1979.

[49] J. H. Argyris and S. Symeonidis, "Nonlinear Finite Element Analysis of Elastic Systems Under Non-conservative Loading - Natural Formulation Part I. Quasistatic Problems," Computer Methods in Applied Mechanics and Engineering, vol. 26, pp. 75-123, 1981.

[50] "Get Started with MATLAB." [Online]. Available: https://www.mathworks.com/help/matlab/getting-started-with-matlab.html. [Accessed: 19-Feb-2018].

[51] V. I. Feodosyev, Selected Problems and Questions in Strenght of Materials. Mir Publisher, 1977.

[52] S. A. Fazelzadeh and M. A. Kazemi-Lari, "Stability analysis of partially loaded Leipholz column carrying a lumped mass and resting on elastic foundation," Journal of Sound and Vibration, vol. 332, no. 3, pp. 595-607, 2013.

[53] R. D. Blevins, Formulas for Natural Frequency and Mode Shape. New York: Kreiger Publ. Comp., 1979.

[54] Y. Sugiyama and H. Kawagoe, "Vibration and stability of elastic columns under the combined action of uniformly distributed vertical and tangential forces," Journal of Sound and Vibration, vol. 38, no. 3, pp. 341-355, 1975. 